\author{
UNIVERSIDADE DE SÃO PAULO - USP \\ FACULDADE DE ECONOMIA, ADMINISTRAÇÃO E CONTABILIDADE \\ DEPARTAMENTO DE ECONOMIA \\ PROGRAMA DE PÓS-GRADUAÇÃO EM ECONOMIA
}

\title{
Distribuição, estrutura produtiva e demanda agregada no Brasil: uma análise de inspiração Kaleckiana
}

Clara Zanon Brenck

Orientadora: Laura Barbosa de Carvalho

São Paulo, Brasil

2019 
Prof. Dr. Vahan Agopyan

Reitor da Universidade de São Paulo

Prof. Dr. Fábio Frezatti

Diretor da Faculdade de Economia, Administração e Contabilidade

Prof. Dr. Jose Carlos de Souza Santos

Chefe do Departamento de Economia

Prof. Dr. Ariaster Baumgratz Chimeli

Coordenador do Programa de Pós-Graduação em Economia 


\title{
Distribuição, estrutura produtiva e demanda agregada no Brasil: uma análise de inspiração Kaleckiana
}

Dissertação apresentada ao Departamento de Economia da Faculdade de Economia, Administração e Contabilidade da Universidade de São Paulo como requisito parcial para a obtenção do título de Mestre em Ciências.

Orientadora: Laura Barbosa de Carvalho

\author{
Versão Final \\ (versão original disponível na Faculdade de Economia, Administração e Contabilidade)
}

São Paulo, Brasil 
Ficha catalográfica

Elaborada pela Seção de Processamento Técnico do SBD/FEA com os dados inseridos pelo(a) autor(a)

\section{Brenck, Clara}

Distribuição, estrutura produtiva e demanda agregada no Brasil: uma análise de inspiração Kaleckiana / Clara Brenck. - São Paulo, 2019. $130 \mathrm{p}$.

Dissertação (Mestrado) - Universidade de São Paulo, 2019. Orientador: Laura Barbosa de Carvalho.

1. Distribuição. 2. Desigualdade salarial. 3. Estrutura produtiva. 4. Demanda agregada. 5. Modelo Kaleckiano. I. Universidade de São Paulo. Faculdade de Economia, Administração e Contabilidade. II. Título. 
Clara Zanon Brenck

\section{Distribuição, estrutura produtiva e demanda agregada no Brasil: uma análise de inspiração Kaleckiana}

Dissertação apresentada ao Departamento de Economia da Faculdade de Economia, Administração e Contabilidade da Universidade de São Paulo como requisito parcial para a obtenção do título de Mestre em Ciências.

Laura Barbosa de Carvalho

Orientadora

Fernando Monteiro Rugitsky

Nelson Henrique Barbosa Filho

Pedro Mendes Loureiro

São Paulo, Brasil

2019 



\section{Agradecimentos}

Agradeço primeiramente aos meus pais, Angelina e Orlando, por sempre me fornecerem as condições, materiais e imateriais, mais do que suficientes de uma vida farta, fazendo com que eu pudesse me dedicar exclusivamente aos estudos. Agradeço por sempre respeitarem minhas escolhas, mesmo quando elas pareciam estranhas a vocês. Agradeço pelo amor incondicional, vocês são a base de tudo. Agradeço à Claudia por todo o carinho e cuidado que sempre teve comigo. Agradeço à minha irmã, por ser a certeza de uma amizada eterna e por, junto com nossa amiga Carol Trópia, serem minha família em São Paulo e fazerem da nossa casinha um lugar de aconchego. Agradeço às famílias Zanon e Brenck por todo o apoio de sempre. Agradeço às minhas amigas de BH, as Lulus, Yara, Gabi e Eloah, que estiveram sempre presentes, acompanhando todo o processo do mestrado, desde os estudos para a Anpec até os momentos finais do depósito, com muita paciência e carinho, independente da distância. Eu amo vocês!

Em memória do professor Rodrigo Simões, agradeço a todas as professoras e a todos os professores do CEDEPLAR que fizeram parte importantíssima da minha formação e que muito me incentivaram a seguir uma carreira como acadêmica. Vocês foram o meu primeiro exemplo de excelência em pesquisa e ensino.

Agradeço em seguida à Laura, que para além de excepcional orientadora é também exemplo e inspiração de mulher economista e pesquisadora, em um ambiente tão masculino. Obrigada imensamente pelo incentivo e dedicação no meu processo de admissão no doutorado, por assumi-lo como se fosse seu, e pela sinceridade nas nossas conversas durante os momentos de decisão. Obrigada por todas as reuniões que tivemos, pela paciência com meus erros e dificuldades, pela leitura cautelosa de todos os meus trabalhos, e pela impecável orientação. Todo e qualquer erro desta dissertação são de minha responsabilidade. Agradeço também aos professores Fernando Rugitsky e Gilberto Tadeu Lima pela dedicação ao meu trabalho como se eu também fosse orientanda de vocês, pelos vários comentários e sugestões ao longo do caminho, pelo ambiente estimulante das reuniões do grupo, e também por toda a ajuda nos processos do doutorado. Agradeço ao professor Rafael Ribeiro, por sempre me receber muito bem na FACE (UFMG), pelas portas abertas e pela disposição em ajudar. Agradeço também ao professor Ariaster pela ajuda com o processo do doutorado e com a fase de aprovação do depósito, além da extrema preocupação com a melhora do ambiente da pós graduação em economia, recebendo nossas sugestões e ouvindo desabafos com muito agrado e paciência. Agradeço a todos do "Bonde Hetero" pelas contribuições. Um agradecimento especial à Julia Burle, Eduardo Rawet e Adriano dos Reis por serem os veteranos mais legais, sempre me incentivando a querer e fazer mais. 
Agradeço ao Lucas Freddo por ser minha dupla desde o começo, pelos milhares desabafos, pelas risadas e choros, por todo o carinho.

Agradeço aos meus colegas de sala, em particular ao Fábio, Luis Menon e João, por fazerem os finais de semana de estudo na FEA menos sofridos, pelas dúvidas e angústias compartilhadas e pelas conversas de descontração na salinha do café ou dos computadores. Agradeço especialmente à Marília e ao Felipe, por me receberem de braços abertos desde o primeiro dia de aula e se tornarem grandes amigos em tão pouco tempo. Agradeço às meninas do IPE-USP girls, em especial à Bruna Borges, Bia Garcia, Grazi e Vic, por serem mulheres incríveis e me darem a certeza de que estamos, sim, no lugar certo. À Vic, Marília e Grazi, obrigada também pelos momentos de descontração e fofoca na meia lua, pelo compartilhamento cheio de amor de todas as vitórias conquistadas, e também por serem colo nos momentos de dificuldades. Ao Matias, Digo e Pupo, muito obrigada por me mostrarem um outro mundo da universidade e da política que eu não conhecia e que muito me fizeram crescer. Obrigada pelos vários debates filosóficos e as vezes até meio malucos, pelo companheirismo, pelas viagens incríveis e por sempre me incentivarem a sonhar alto e com um mundo melhor. Vocês são incríveis!

Agradeço às princess do Volei FEA e às meninas da Seleção USP por fazerem dos treinos e jogos um momento de descontração, de muita risada e por sempre me aceitarem como parte do time, independente das várias ausências ao longo destes anos. À Gi Queiroz, Sofia Ferraz, Isa Galindo, Samuelly e Cami, um agradecimento especial pela amizade, pelas noites de vinho, pelas conversas sobre política e feminismo e pelas angústias compartilhadas da pós-graduação e da vida acadêmica. Vocês se tornaram amigas para toda a vida! Ao Renan, um muito obrigado por ser sempre tão dedicado ao time, à nossa saúde física e mental e por ser o melhor técnico que alguém poderia querer.

Por fim, mas não menos importante, agradeço a todos os que garantem o funcionamento da universidade pública e da FEA: os funcionários da limpeza, da portaria, da segurança, das secretarias, do administrativo e do bandejão. Sem vocês nada disso seria possível. 
Igualdade, não estou falando de equidade, porque equidade significa que você trata ricos e pobres da mesma maneira e não é disso que se trata, senão não há distribuição de renda. Estou lutando pela igualdade desde que aqui cheguei. 



\section{Resumo}

Central no debate sobre o aumento da concentração de renda entre os anos 60 e 70 no Brasil, o papel da estrutura produtiva na determinação da distribuição de salários ficou relegado a segundo plano na literatura econômica das últimas décadas. Ao resgatar tais elementos para a análise da relação entre a redução da desigualdade salarial e as alterações na composição do emprego no Brasil no período recente, contribuímos para a literatura teórica e empírica sobre a relação entre distribuição de renda e demanda agregada. Baseando essa análise no arcabouço neo-kaleckiano,contribuímos para a literatura teórica através da construção de um modelo de economia aberta de dois setores que incorpora o efeito da desigualdade salarial sobre o padrão de consumo das famílias. Os resultados revelam as condições para a emergência de um processo circular de causação cumulativa entre a queda da desigualdade salarial e a transferência de empregos para o setor não comercializável, intensivo em mão-de-obra menos qualificada. O capítulo empírico dessa dissertação testa econometricamente a existência desse mecanismo cumulativo no Brasil, separando-o em dois exercícios: um Vetor de Correção de Erros (VEC) para a relação de longo prazo entre composição do produto e índice de Gini entre 1980 a 2014 e um Vetor Autorregressivo (VAR) para a relação de curto prazo entre as variações na desigualdade salarial e na composição do emprego no período entre 2004 e 2019. Os resultados parecem confirmar a hipótese de que as alterações na estrutura produtiva e na distribuição de renda reforçaram-se mutuamente ao longo do tempo.

Palavras-chaves: distribuição, desigualdade salarial, estrutura produtiva, demanda agregada, modelo kaleckiano 



\section{Abstract}

Central to the debate regarding increase in the income concentration between the 1960s and 1970s in Brazil, the role of the productive structure in the determination of wage distribution has been relegated to second place in the economic literature of the last decades. By rescuing these elements to analyze the relationship between the reduction of wage inequality and changes in the composition of employment in Brazil in the recent period, we contribute to the theoretical and empirical literature on the relationship between income distribution and aggregate demand. Basing this analysis on the neo-Kaleckian framework, we contribute to the theoretical literature by constructing an open economy model of two sectors that incorporates the effect of wage inequality on the household consumption pattern. The results reveal the conditions for the emergence of a circular process of cumulative causation between the fall of the wage inequality and the transfer of jobs to the non-tradable sector, intensive in less qualified labor. The empirical chapter of this dissertation econometrically tests the existence of this cumulative mechanism in Brazil, separating it into two exercises: an Error Correction Vector (VEC) for the long-term relationship between product composition and Gini index between 1980 and 2014 and an Autoregressive Vector (VAR) for the short-run relationship between changes in wage inequality and employment composition in the period between 2004 and 2019. The results seem to confirm the hypothesis that changes in the productive structure and income distribution were reinforced over time.

Key-words: distribution, wage inequality, productive structure, agregate demand, Kaleckian model 



\section{Sumário}

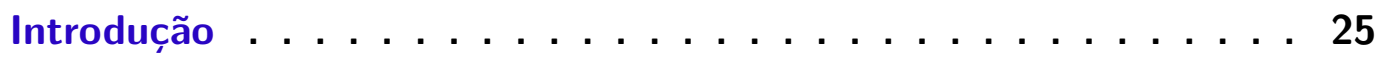

1 ESTRUTURA PRODUTIVA, COMPOSIÇÃO DO EMPREGO E DESIGUALDADE NO BRASIL: OS ANOS 1960-73 E OS ANOS 2000-14 29

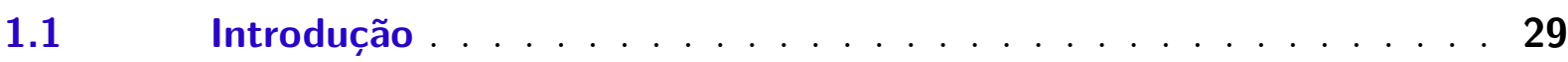

1.2 Crescer para distribuir: industrialização e concentração da renda no Brasil entre 1960 e 1973 . . . . . . . . . . . . . . . . . . . . 32

1.3 Distribuir para crescer: desigualdade salarial e composição do emprego no período $2003-2014 \ldots \ldots$. . . . . . . . . 42

$1.4 \quad$ Limitadores do processo de crescimento recente brasileiro . . . . 52

$1.4 .1 \quad$ A restrição externa . . . . . . . . . . . . . . . . . 52

$1.4 .2 \quad$ A inflação de serviços . . . . . . . . . . . . . . . . . . . 54

1.4.3 Distribuição da renda no topo . . . . . . . . . . . . . . . . 57

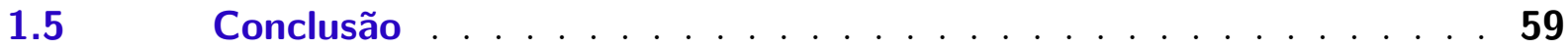

2 MODELO TEÓRICO $\ldots \ldots \ldots \ldots \ldots \ldots \ldots \ldots$

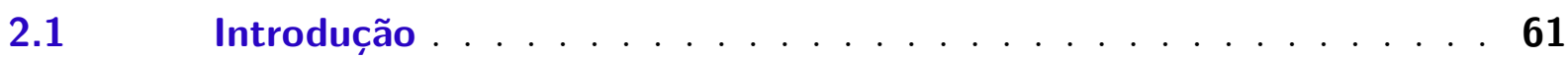

$2.2 \quad$ Estrutura do Modelo . . . . . . . . . . . . . . . . . . . . 62

2.2.1 Exercícios de estática comparativa . . . . . . . . . . . . 66

2.2.2 Análise de estabilidade . . . . . . . . . . . . . . . . 72

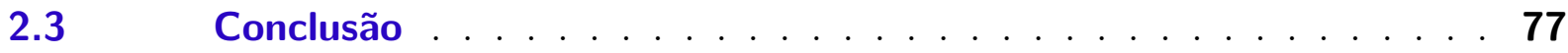

3 ESTUDO ECONOMÉTRICO DA RELAÇÃO ENTRE ESTRUTURA PRODUTIVA E DESIGUALDADE NO BRASIL . . . . . . . 81

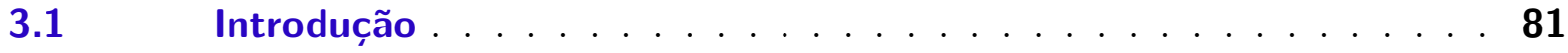

$3.2 \quad$ Metodologia . . . . . . . . . . . . . . . 83

3.3 A relação entre a composição do produto e a desigualdade de renda no Brasil no período 1980-2014 . . . . . . . . . . . . . . . 84

3.3.1 Resultados . . . . . . . . . . . . . . . . . . . . . . . . 89

3.4 A relação entre variações na composição do emprego e na desigualdade salarial no Brasil entre 2003 e 2019 . . . . . . . . . . . . . 94

3.4.1 Resultados . . . . . . . . . . . . . . . . . . . . . . 97

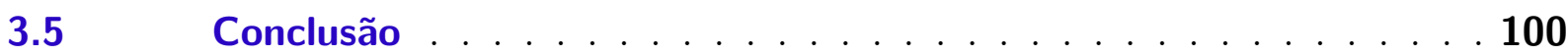

Conclusão . . . . . . . . . . . . . . . . . . . . . . . 103 


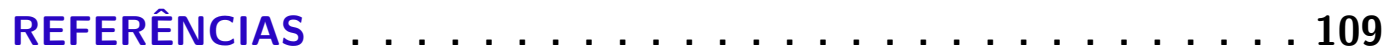

APÊNDICES

APÊNDICE A - TABELA DE TRADUÇÃO DA POF PARA O SCN 117

APÊNDICE B - SETORES EXCLUÍDOS . . . . . . . . . 121

APÊNDICE C - CRITÉRIOS DE SELEÇÃO DOS SETORES $\ldots 123$

APÊNDICE D - TRIMESTRALIZAÇÃO DAS SÉRIES DO PIB DE SERVIÇOS, CONSTRUÇÃO E INDÚSTRIA DA TRANSFORMAÇÃO . . . . . . . . . 125

APÊNDICE E - TESTES NOS RESÍDUOS . . . . . . . . . 127

E.1 Primeiro exercício: “A relação entre a composição do produto e a desigualdade de renda no Brasil no período 1980-2014" . . . . . . 127

E.2 Segundo exercício: “A relação entre variações na composição do emprego e na desigualdade salarial no Brasil entre 2003 e 2019” . . 128 


\section{Lista de ilustrações}

Figura 1 - Evolução do salário mínimo real anual e do índice de Gini, 1960-1990 33

Figura 2 - Evolução da desigualdade salarial e da parcela de salários na renda . . 44

Figura 3 - Evolução das séries de desigualdade salarial entre admitidos e mudanças na composição do emprego a partir dos setores selecionados - média móvel de 12 meses . . . . . . . . . . . . . . . . . . . 5 50

Figura 4 - Evolução das exportações (US\$), Importações (US\$) e Taxa de câmbio (R\$/US\$, eixo secundário) . . . . . . . . . . . . . . . . 53

Figura 5 - Evolução do índice de preços (IPCA) dos bens comercializáveis, nãocomercializáveis e serviços $(2002.01=100) \ldots$. . . . . . . . . . 55

Figura 6 - Evolução das séries de PIB anual da indústria total e da indústria de transformações . . . . . . . . . . . . . . . . . . 85

Figura 7 - Série de indústria de transformação trimestralizadas pelos dois métodos descritos . . . . . . . . . . . . . . . . . 8 86

Figura 8 - Série do PIB do setor de serviços e construção civil sobre o PIB do setor de indústria da transformação concatenada . . . . . . . . . . . . . . . . 88

Figura 9 - Evolução das séries do primeiro exercício econométrico . . . . . . . . 88

Figura 10 - Função resposta-impulso do primeiro exercício . . . . . . . . . . . . . . 90

Figura 11 - Evolução dos componentes internos do setor de serviços (\%) . . . . . . 93

Figura 12 - Evolução das séries de desigualdade salarial entre admitidos e mudanças na composição do emprego a partir dos setores selecionados: dados mensais 96

Figura 13 - Função impulso-resposta: segundo exercício . . . . . . . . . . . . . . . 99

Figura 14 - Função impulso-resposta acumulada: segundo exercício . . . . . . . . . 100 



\section{Lista de tabelas}

Tabela 1 - Distribuição do emprego setorial (\% do total) - regiões I a IV . . . . . 38

Tabela 2 - Crescimento do emprego em por classe de atividade (\%) - regiões I a IV 38

Tabela 3 - Distribuição do emprego setorial (\% do total) nas duas primeiras faixas de salário $(\mathrm{Cr} \$)$ - regiões I a IV . . . . . . . . . . . . . . 40

Tabela 4 - Distribuição do emprego setorial (\% do total) nas duas últimas faixas de salário $(\mathrm{Cr} \$)$ - regiões I a IV . . . . . . . . . . . . . . . . 41

Tabela 5 - Passo a passo para a seleção de setores . . . . . . . . . . . . . . . . . 49

Tabela 6 - Setores selecionados . . . . . . . . . . . . . . . . . 49

Tabela 7 - Evolução da participação na renda de percentis selecionados para o

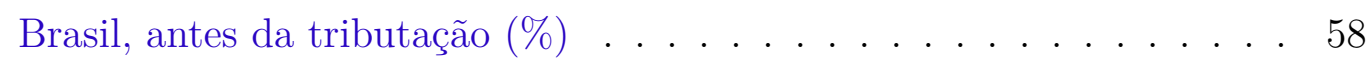

Tabela 8 - Alocações da Renda por grupo . . . . . . . . . . . . . 65

Tabela 9 - Resultados da estática comparativa . . . . . . . . . . . 72

Tabela 10 - Análise de estabilidade . . . . . . . . . . . . . . 76

Tabela 11 - Teste de Raíz unitária: primeiro exercício . . . . . . . . . . . . . . 89

Tabela 12 - Teste de Causalidade de Granger: primeiro exercício . . . . . . . . . . 89

Tabela 13 - Resultado das estimações: primeiro exercício . . . . . . . . . . . . . . 92

Tabela 14 - Teste de Raíz unitária: segundo exercício . . . . . . . . . . . . . . . 96

Tabela 15 - Teste de Causalidade de Granger: segundo exercício . . . . . . . . . . . 97

Tabela 16 - Resultado das estimações: segundo exercício . . . . . . . . . . . . . 98

Tabela 17 - Setores do SCN unificados . . . . . . . . . . . . . . 117

Tabela 18 - Setores excluídos . . . . . . . . . . . . . . . . . . 121

Tabela 19 - Critérios para a seleção de setores . . . . . . . . . . . . . . . . . . . 124

Tabela 20 - Teste LM de correlação serial dos resíduos (VEC) . . . . . . . . . . . 127

Tabela 21 - Raízes do primeiro exercício . . . . . . . . . . . . . . . . 128

Tabela 22 - Teste de normalidade dos resíduos: primeiro exercício . . . . . . . . . 128

Tabela 23 - Teste LM de correlação serial dos resíduos (VAR) . . . . . . . . . . . . 129

Tabela 24 - Raízes do segundo exercício . . . . . . . . . . . . . . . . . . . . 129

Tabela 25 - Teste de normalidade dos resíduos: segundo exercício . . . . . . . . . 130 



\section{Lista de abreviaturas e siglas}

PIB Produto Interno Bruto

PEA População Economicamente Ativa

SCN Sistema de Contas Nacionais

IPEA Instituto de Pesquisa Econômica Aplicada

IBGE Instituto Brasileiro de Geografia e Estatística

PNAD Pesquisa Nacional por Amostra de Domicílios

POF Pesquisa de Orçamento Familiar

PME Pesquisa Mensal do Emprego

WID World Inequality Lab

CAGED Cadastro Geral de Empregados e Desempregados

Funcex Fundação para o Estudo do Comércio Exterior

PAEG o Programa de Ação Econômica do Governo

PBF Programa Bolsa Família

BPC Benefício de Prestação Continuada

SM Salário Mínimo

FMI Fundo Monetário Internacional

INPC Índice Nacional de Preços ao Consumidor

IPCA Índice Nacional de Preços ao Consumidor Amplo

IGPC-Mtb Índice Geral de Preços ao Consumidor do Ministério do Trabalho

ENDEF Estudo Nacional da Despesa Familiar

PETI Programa de Erradicação de Trabalho Infantil

VAR Vetores Auto-Regressivos

VEC Vetor de Correção de Erros 



\section{Lista de símbolos}

\begin{tabular}{|c|c|}
\hline$Y$ & Produto total da economia \\
\hline$Y_{N T}$ & Produto do setor não-comercializável \\
\hline$Y_{T}$ & Produto do setor comercializável \\
\hline$X$ & Componente autônomo das exportações \\
\hline$M$ & Componente autônomo das importações \\
\hline$I_{N T}$ & Investimento no setor não-comercializável \\
\hline$I_{T}$ & Investimento no setor comercializável \\
\hline$W_{N T}$ & Salário no setor não-comercializável \\
\hline$W_{T}$ & Salário no setor comercializável \\
\hline$P_{N T}$ & Preço no setor não-comercializável \\
\hline$P_{T}$ & Preço no setor comercializável \\
\hline$L_{N T}$ & Trabalhadores do setor não-comercializável \\
\hline$L_{T}$ & Trabalhadores no setor comercializável \\
\hline$\Pi_{N T}$ & Lucro no setor não-comercializável \\
\hline$\Pi_{T}$ & Lucro no setor comercializável \\
\hline$K_{N T}$ & Estoque de capital do setor não-comercializável \\
\hline$K_{T}$ & Estoque de capital do setor comercializável \\
\hline$C_{N T}$ & Consumo no setor não-comercializável \\
\hline$C_{T}=A$ & Consumo fixo dos agentes no setor comercializável \\
\hline$g_{N T}$ & Crescimento do setor não-comercializável \\
\hline$g_{T}$ & Crescimento do setor comercializável \\
\hline$a_{N T}$ & $\begin{array}{l}\text { Produtividade do trabalho no setor não-comercializável (normalizado } \\
\text { para 1) }\end{array}$ \\
\hline
\end{tabular}




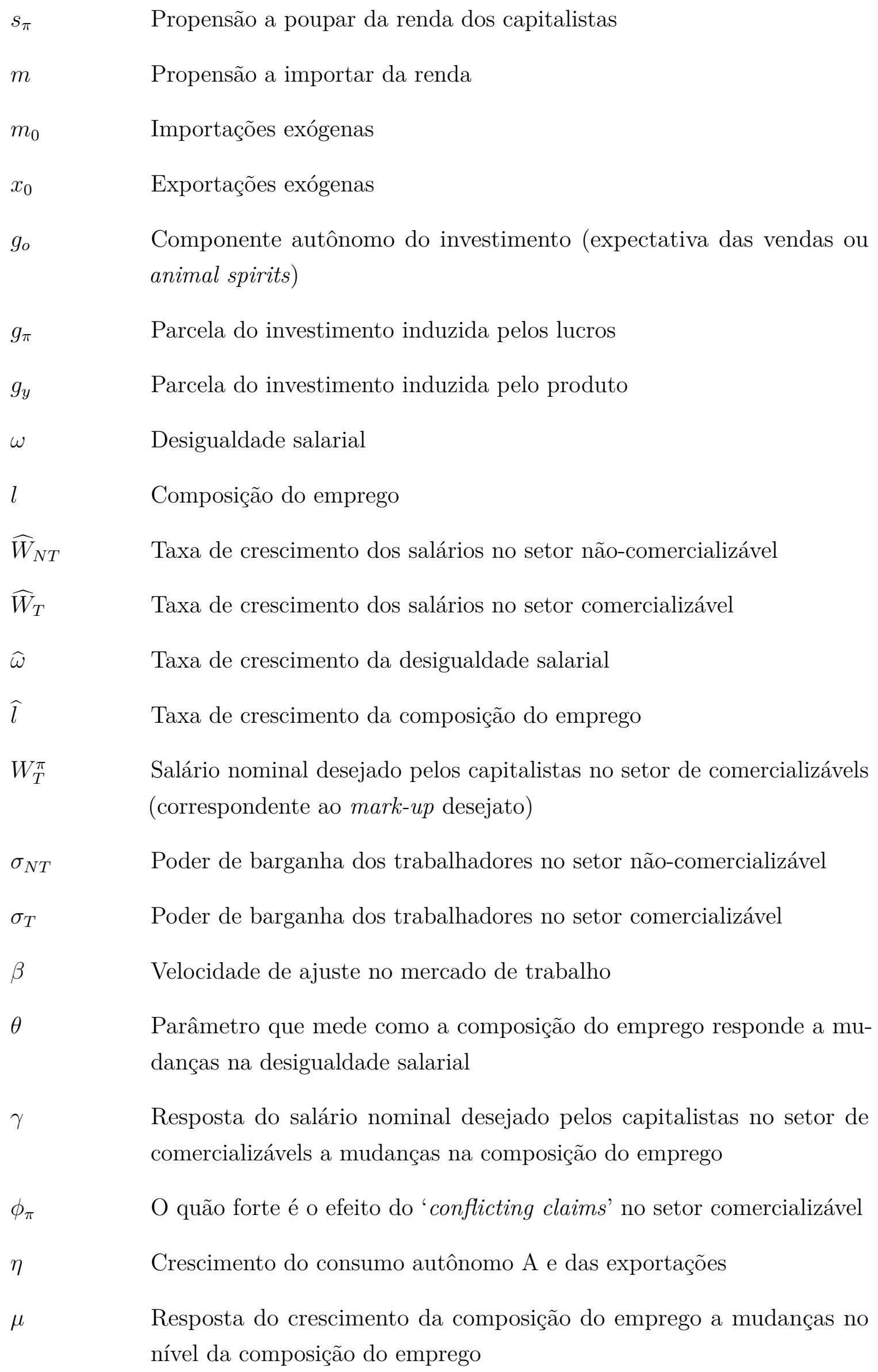
comercializávels a mudanças na composição do emprego

$\phi_{\pi} \quad$ O quão forte é o efeito do 'conflicting claims' no setor comercializável

$\eta \quad$ Crescimento do consumo autônomo A e das exportações

$\mu \quad$ Resposta do crescimento da composição do emprego a mudanças no nível da composição do emprego 


\section{Introdução}

O debate econômico acerca do aumento da concentração de renda no Brasil durante os anos 1960 opôs, de um lado, os diagnósticos fundamentados na teoria neoclássica de determinação da renda e os diferenciais de salário como reflexo da capacitação dos agentes, e, de outro, visões críticas que conferiam papel central ao conflito de classes e às políticas de repressão ao salário mínimo para o aumento da desigualdade (WELLS, 1974). Tavares e Serra (1972) trilham um caminho particular na medida em que, além de concordarem sobre a importância das políticas governamentais, olham também para os efeitos de alterações na estrutura produtiva, que tem uma dinâmica engendrada principalmente pela dinâmica industrial, sobre a distribuição da renda. Em uma abordagem liderada pela demanda agregada, os autores argumentam que o crescimento dos setores de bens industrializados empregadores trabalhadores mais qualificados em relação aos demais e o aumento da desigualdade estavam positivamente relacionados em um processo cumulativo concentrador de renda.

O papel da estrutura produtiva no debate sobre a distribuição de renda foi, contudo, abandonado desde então, fazendo com que o lado neoclássico perdurasse com a explicação da tecnologia e da educação como importantes determinantes da capacitação da mão de obra, enquanto o outro lado ficou com o debate centrado na política, nas instituições e nos conflitos de classes, que seriam resultados do poder de barganha de trabalhadores e capitalistas.

Na macroeconomia, a literatura Kaleckiana atribui à distribuição funcional da renda um fator determinante em seus modelos. Kalecki (1942) formalizou a ideia de que as taxas de poupança sobre as rendas oriundas dos salários e dos lucros são diferentes, de modo que mudanças na distribuição funcional da renda alteram a demanda agregada e o crescimento. Os modelos originais derivados deste arcabouço partem de funções comportamentais para o consumo, investimento, e exportações líquidas e, a depender de como a economia responde às mudanças na distribuição funcional da renda, um país é classificado como wage- ou profit-led. Contudo, ao inicialmente considerar apenas a distribuição funcional da renda e o setor produtivo como gerador de uma commodity única, perde-se várias das análises sobre os efeitos da heterogeneidade da estrutura produtiva e das desigualdades internas às rendas do salário, por exemplo, que se mostram cada vez mais importantes para explicar as trajetórias econômicas de países em desenvolvimento, como o Brasil. Extensões neste sentido foram realizadas na literatura Kaleckiana, como a introdução da desigualdade pessoal na renda por Carvalho e Rezai (2016) e a incorporação da heterogeneidade setorial no modelo básico por Dutt (1990), Dutt (1997), Park (1997), Fujita (2015) e Nishi (2018), 
por exemplo. Esforço similar também será desenvolvido adiante nesta dissertação.

Nos anos 2000, o debate sobre a distribuição e a desigualdade de renda entre os economistas volta à tona após a publicação do livro Capital no século XXI por Piketty (2014), em que é documentado o aumento da concentração de renda nos países desenvolvidos. Sob esta perspectiva, a trajetória do Brasil e de outros países da América do Sul durante a primeira década do século XXI parece fugir à regra, uma vez que eles foram capazes de combinar redução de desigualdade e crescimento econômico num momento em que a desigualdade nos países desenvolvidos estava aumentando ${ }^{1}$.

Sob uma perspectiva similar à de Tavares e Serra (1972), Rugitsky (2017) unifica os argumentos de Giovannetti (2013) de que mudanças na distribuição de renda devido às políticas econômicas de valorização do salário mínimo e de transferências governamentais, principalmente após 2004, alteram o padrão de consumo da sociedade via lei de Engel, fazendo com que a população mais pobre passe a consumir bens com elasticidade renda mais alta, como serviços, e de Carvalho e Rugitsky (2015) de que tais mudanças no padrão de consumo repercutem em mudanças na estrutura de emprego da economia. Acrescentando o efeito final de que estas mudanças na estrutura produtiva, por sua vez, ecoam na melhora da distribuição de renda em favor dos mais pobres, Rugitsky (2017) argumenta que a combinação destes efeitos resulta num processo e causação circular e cumulativa em que a desigualdade e a composição da estrutura produtiva estão relacionadas e reforçam uma a outra, no sentido de que a redistribuição de renda para trabalhadores mais pobres estaria puxando a demanda por serviços e bens intensivos em mão de obra menos qualificada, reduzindo assim as disparidades salariais.

Pretendemos, com esta dissertação, trazer de volta a estrutura produtiva para o centro do estudo da distribuição e desigualdade de renda, resgatando elementos importantes do debate dos anos 60 e início dos anos 70 e incluindo-os na análise do período recente brasileiro. A dissertação está dividida em três capítulos, seguidos de uma conclusão. No primeiro capítulo, realizamos um trabalho empírico-descritivo sobre os anos 60 e início dos 70 e sobre o período de crescimento mais recente, dos anos 2000, com o foco principal na desigualdade e na estrutura produtiva em cada um deles. Além das várias diferenças sociais, organizacionais e políticas que caracterizam estes dois períodos, a dinâmica da estrutura produtiva e da desigualdade também se mostram antagônicas, no sentido de que, enquanto

1 A taxa média anual de crescimento do Brasil subiu de 1.88 (no período 1990-2003) para 4.43 (entre 2004 e 2011), enquanto o índice de Gini caiu de 0.57 em 2003 para 0.52 em 2014, segundo dados do Instituto Brasileiro de Geografia e Estatística (IBGE). O PIB real na Argentina, Bolívia, Equador, Uruguai e Venezuela cresceu $6.2 \%, 4.6 \%, 4.8 \%, 5.9 \%$ e $6.5 \%$ entre 2004 e 2011, respectivamente. Durante o mesmo período, o coeficiente GINI caiu de 0.48 para 0.41 na Argentina; 0.56 (valor de 2005) para 0.44 na Bolívia; 0.52 a 0.44 no Equador; 0.45 (valor de 2006) para 0.41 no Uruguai; e na Venezuela caiu de 0.43 (valor de 2006) para 0.41, segundo dados do Banco Mundial (para a Argentina), do FMI (outros países) e do Banco de Dados Socioeconômico para a América Latina e o Caribe (para os coeficientes GINI). 
no milagre econômico a estrutura produtiva evoluía na direção de aumentar a participação setores com maiores ganhos de produtividade e a distribuição da renda favorecia os mais ricos, nos primeiros anos do século XXI a estrutura produtiva e a desigualdade se moveram no sentido de aumentar a participação relativa de serviços e setores trabalho-intensivos e de reduzir a desigualdade. Raciocinar sob a ótica estruturalista e de valorização do papel da estrutura produtiva também nos permite discutir três dos possíveis limites que um modelo de crescimento tal como o vivenciado no Brasil pode enfrentar - a restrição do balanço de pagamentos, a inflação de serviços e a própria maneira pela qual se deu a distribuição de renda. Ainda que não seja possível concluir sobre a confirmação da hipótese de causação circular e cumulativa, este primeiro capítulo nos dá as motivações suficientes para um aprofundamento nos capítulos subsequentes.

No capítulo 2, contribuímos para a literatura neo-Kaleckiana ao desenvolver um modelo de economia aberta com dois setores em que a desigualdade salarial é incorporada ao modelo. Os resultados de estática comparativa e as dinâmicas de diferentes processos de ajuste da composição do emprego e da desigualdade salarial são analisados a fim de nos auxiliar no melhor entendimento de alguns dos mecanismos teóricos pelos quais a distribuição de renda altera a estrutura produtiva da economia e vice-versa. O capítulo 3 se dedica à análise econométrica desta hipótese de causação circular e cumulativa, em que dois exercícios de série temporal são elaborados para melhor compreender a relação histórica entre desigualdade de renda e a composição do produto (ou do emprego). No primeiro exercício, de mais longo prazo, um VEC é estimado para a relação entre composição do produto e índice de Gini no período entre 1980 e 2014. O segundo exercício estima um VAR para a relação entre as variações no nível de emprego e a desigualdade salarial entre os trabalhadores admitidos no período entre 2004 e 2019. Por fim, concluímos o trabalho com um sumário das principais resultados e contribuições da dissertação para a literatura. 



\section{Estrutura produtiva, composição do em- prego e desigualdade no Brasil: os anos $1960-73$ e os anos 2000-14}

\subsection{Introdução}

Na primeira década do século XXI o Brasil e outros países da América do Sul se destacaram ao conseguirem alcançar altas taxa de crescimento com redução da desigualdade. A taxa de crescimento real do PIB brasileiro passou de uma média de $2.1 \%$ nos anos 1980 e 1990 para 3.7\% na década de 2000, enquanto o índice de Gini passou de 0.57 em 2003 para 0.52 em 2014. Contudo, logo após 2014 o país enfrentou uma forte crise econômica, da qual ainda tenta se recuperar e que, possivelmente, reverteu os ganhos distributivos deste período. Entre abril de 2014 e dezembro de 2016 foram 11 trimestres praticamente contínuos de crescimento negativo do PIB, acumulando uma queda total de aproximadamente $8 \%$. Mesmo que o país tenha voltado a crescer a taxas positivas em 2017, ainda não atingimos o nível de produção de antes da crise.

Este período de crescimento brasileiro, principalmente entre os anos 2004-2010, assim como a desaceleração e crise subsequentes, costuma ser atribuído ao cenário externo. De fato, o aumento do preço internacional das commodities - o índice geral do Fundo Monetário Internacional (FMI) indica que os preços das commodities cresceram 326\% no período entre dezembro de 2001 e abril de 2011 - e o aumento da demanda por essas mercadorias, puxada principalmente pelas altas taxas de crescimento chinesas, representaram um impulso nas exportações brasileiras que, de maneira direta e indireta, beneficiaram o crescimento econômico no período. Segundo um estudo realizado pelo pesquisador Bráulio Borges em agosto de 2015, denominado "Para além dos consensos fáceis: uma investigação abrangente das causas da desaceleração recente do crescimento brasileiro", o cenário externo é responsável por até 45\% da desaceleração brasileira em 201114, se considerarmos a metodologia antiga de cálculo do PIB, enquanto a série nova aponta algo entre $44 \%$ e $63 \%$, restando ainda $56 \%$ e $37 \%$, dependendo da série utilizada, para serem explicados por fatores domésticos. Embora reconheçam a importância do cenário externo para o crescimento econômico do início do século, Carvalho e Rugitsky (2015) argumentam que as políticas internas de estímulo ao consumo de massas e a expansão do investimento público também foram fundamentais para conferir dinamismo à economia doméstica, principalmente entre 2006 e 2010.

No que se refere à desigualdade, alguns estudos recentes que utilizam dados de 
Capítulo 1. Estrutura produtiva, composição do emprego e desigualdade no Brasil: os anos 1960-73 e os 30 anos 2000-14

imposto de renda no Brasil mostram que a queda evidenciada no índice de Gini ficou limitada à base da distribuição, graças à redução da desigualdade salarial, visto que os dados provenientes das pesquisas familiares, tais como as da PNAD, tendem a subestimar a renda no topo da distribuição (MEDEIROS; SOUZA; CASTRO, 2015; GOBETTI; ORAIR et al., 2015; SOUTO, 2015; MEDEIROS; CASTRO, 2018). Medeiros, Souza e Castro (2015) evidenciam que, entre 2006 e 2015, a parcela da renda apropriada pelo 1\% mais rico do Brasil manteve-se em $25 \%$ da renda total, e a do $0,1 \%$ mais rico em $11 \%$. De todo modo, ainda que a redução da desigualdade tenha se restringido a base da distribuição, seus efeitos sobre a composição do consumo e do emprego podem ajudar a explicar o padrão de crescimento observado no período.

O debate sobre desigualdade e crescimento econômico também esteve muito presente nos anos 60 e início dos 70, principalmente após a divulgação do censo de 1970, em que se evidenciou um aumento significativo da desigualdade, com o índice de Gini saindo de 0.535 em 1960 para 0.581 em 1970. O consenso sobre a intensificação da desigualdade no período originou diversos estudos e levantamentos de hipóteses sobre as razões para tal, indo tanto de um espectro neoclássico da teoria de demanda e oferta por trabalho qualificado (principalmente após o milagre econômico, entre os anos de 1968 a 1973, em que se argumentava que foi a expansão do setor urbano e tecnológico a principal causa do aumento do Gini) até os críticos ao governo, que argumentavam serem as políticas de estabilização econômica e de repressão à classe trabalhadora, como a proibição de atividades sindicais iniciadas principalmente após o golpe militar de 1964, os principais responsáveis por tal piora distributiva (WELLS, 1974). Trazendo a estrutura produtiva para o centro do debate sobre crescimento econômico e desigualdade, Tavares e Serra (1972) apresentam um diagnóstico sobre o modelo de crescimento adotado na época, especialmente durante o milagre econômico, entre os anos 1968 e 1973, em que o crescimento dos setores de bens industrializados empregadores de mão de obra qualificada e o aumento da desigualdade estavam positivamente relacionados em um processo cumulativo concentrador de renda. $\mathrm{O}$ aumento da renda em favor dos mais ricos desencadeava mudanças no padrão de consumo das famílias, que passaram a consumir "bens de luxo", ou seja, bens cuja produção é intensiva em trabalhadores mais qualificados. Estas mudanças no padrão de consumo das famílias ricas repercutiam na estrutura produtiva (e de emprego) da economia e, daí, resultavam no incremento da desigualdade ao aumentar o ritmo de crescimento dos salários dos trabalhadores mais qualificados em relação aos demais.

Voltando ao período recente, Giovannetti (2013), ao tratar do fenômeno de inflação de serviços no Brasil entre 2005 e 2013, aplica para o período recente a hipótese de que mudanças na distribuição da renda alteram o padrão de consumo da sociedade e, assim, exercem uma pressão de demanda maior sobre os preços em alguns setores, em relação ao de outros nos quais a demanda cresceu menos. Baseado na Lei de Engel, o aumento na renda 
das famílias mais pobres geraria um aumento mais do que proporcional no consumo de bens cuja elasticidade-renda são mais altas, tais como serviços e bens manufaturados, que antes não eram factíveis a tais famílias. Carvalho e Rugitsky (2015) avançam ao relacionar tais mudanças no padrão de consumo com mudanças na estrutura de emprego da economia. O aumento na demanda faria com que novos postos de trabalho fossem criados nestes setores e, assim, a composição do produto e do emprego se alterariam. Rugitsky (2016), por fim, argumenta como esta mudança na composição do emprego afetaria a própria distribuição de renda da economia, uma vez que aumenta os postos de trabalho em setores intensivos em trabalho pouco qualificado, gerando emprego para a população mais pobre e, assim, cria um canal que viria a potencializar a distribuição da renda.

Apesar de este processo reforçar a distribuição de renda e a redução da desigualdade salarial, ele possui importantes limitações políticas e econômicas, como discutido em Carvalho (2018) e Brenck e Carvalho (2019). Um primeiro limitador está diretamente relacionado à precariedade da estrutura produtiva brasileira, isto é, à dependência externa para a produção e consumo de bens mais sofisticados, que exige a importação de tecnologias ainda não produzidas internamente, e que é potencializada neste período. O câmbio superapreciado e a estrutura produtiva pouco diversificada fazem com que a demanda por produtos manufaturados, que também aumenta com o processo distributivo, vaze para fora do país, especialmente para a China (BIELSCHOWSKY, 2012), contribuindo para a perda de densidade da indústria de transformação e aumentando a participação de setores trabalho-intensivo e de baixa produtividade. Esta dinâmica, em linha com a Lei de Thirwall, poderia gerar importantes restrições de balanço de pagamentos, ainda que a balança comercial não tenha sido deficitária no período e o balanço de pagamentos se manteve superavitário principalmente devido à forte entrada de capitais e o acúmulo de reservas internacionais no país (SERRANO; SUMMA, 2015). Um segundo limitador está relacionado com a própria dinâmica interna da economia: a pressão via demanda e via custo nos bens trabalho-intensivos e não-comercializáveis geram um aumento substancial de preços - fenômeno no qual nos referiremos como "inflação de serviços". Por fim, o último limitador diz respeito à maneira como a distribuição de renda foi feita, com a manutenção da alta parcela da renda apropriada pelo topo da distribuição e uma redução da desigualdade na base. O processo não contou com os efeitos dinâmicos que só a redistribuição do topo para a base da pirâmide poderia conferir, em uma economia como a brasileira, marcada por um nível de desigualdade elevado (BRENCK; CARVALHO, 2019), fazendo com que o escopo para a continuidade da redução da desigualdade ficasse mais limitado e enfrentasse desafios políticos.

O presente capítulo está organizado, então, da seguinte maneira: a próxima seção discute o período dos anos 60 e início do 70 e tem como principal contribuição reviver o debate sobre desigualdade da época, complementando-o com as primeiras pesquisas da 
Capítulo 1. Estrutura produtiva, composição do emprego e desigualdade no Brasil: os anos 1960-73 e os 32

anos 2000-14

PNAD, onde avaliamos a composição da estrutura produtiva e a distribuição salarial. A terceira seção discutirá com mais detalhes o processo ocorrido nos anos 2000 a partir da literatura já existente e dos dados disponíveis. Faremos, ainda, uma seleção dos setores que parecem ter sido mais influenciados por esta causação circular cumulativa, ranqueando-os de acordo com quatro dimensões: o crescimento da participação no consumo das famílias de baixa renda, o crescimento do emprego, o nível de produtividade do setor e o salário médio no setor. Por fim, apresentamos os desafios e limites para o processo de crescimento brasileiro - a restrição externa, a inflação de serviços e a concentração da renda no topo -, seguido da conclusão.

\subsection{Crescer para distribuir: industrialização e concentra- ção da renda no Brasil entre 1960 e 1973}

Como mencionado na introdução deste capítulo, os anos 60 e início dos anos 70 ficaram marcados pela ampliação de desigualdades no Brasil, principalmente após a instauração da ditadura militar em 1964. Logo após o golpe, o primeiro governante, marechal Humberto Castelo Branco, criou o Programa de Ação Econômica do Governo (PAEG), que durou de novembro de 1964 a março de 1967, no intuito de conter a desaceleração da economia e o processo inflacionário que estava em curso no Brasil. As políticas estabilizadoras contaram com um severo controle de salários, com a redução significativa do salário mínimo real que, apesar de iniciada em 1960 (Figura 1), foi intensificada desde então. Os resultados destes primeiros anos de governo militar foram de baixo crescimento do produto e uma considerável recessão na indústria em 1965 (WELLS, 1974).

O período subsequente, entre os anos de 1968 e 1973, por sua vez, ficou conhecido como "milagre econômico brasileiro" devido às altas taxas de crescimento alcançadas, de 11.1\% ao ano em média. O sucesso da economia brasileira pode ser atribuído à capacidade de interação e integração entre a economia doméstica e internacional, mas também contou com uma forte atuação do Estado, que controlava setores dinâmicos da economia (VELOSO; VILLELA; GIAMBIAGI, 2008). Além disso, Tavares e Serra (1972) argumentam que parte deste crescimento econômico é também fruto da continuidade da política de contração salarial e de proibição de atividades sindicais, como greves, aumentando substancialmente os níveis de desigualdade (SOUZA, 2016), como pode ser observado na Figura $1^{1}$.

\footnotetext{
1 A série de salário mínimo real foi obtido pelo IPEA, nos quais os deflatores utilizados foram o IGPCMtb (de janeiro de 1948 e março de 1979) e o Índice Nacional de Preços ao Consumidor (INPC) do IBGE a partir de março de 1979. Na implementação do salário mínimo urbano pelo decreto-lei do presidente Getúlio Vargas, em julho de 1940, o SM poderia assumir valores diferenciados entre estados e sub-regiões, sendo unificado nacionalmente somente em maio de 1984. Até esta data, o salário mínimo nacional foi, então, considerado pelo IPEA como o maior valor dentre os estabelecidos pelos estados e sub-regiões. Para a medida de salário mínimo anual foi feita a média dos 12 meses correspondentes. O
} 
Figura 1 - Evolução do salário mínimo real anual e do índice de Gini, 1960-1990

Fonte: IPEA e Censo Demográfico $(1960,1970,1991)$

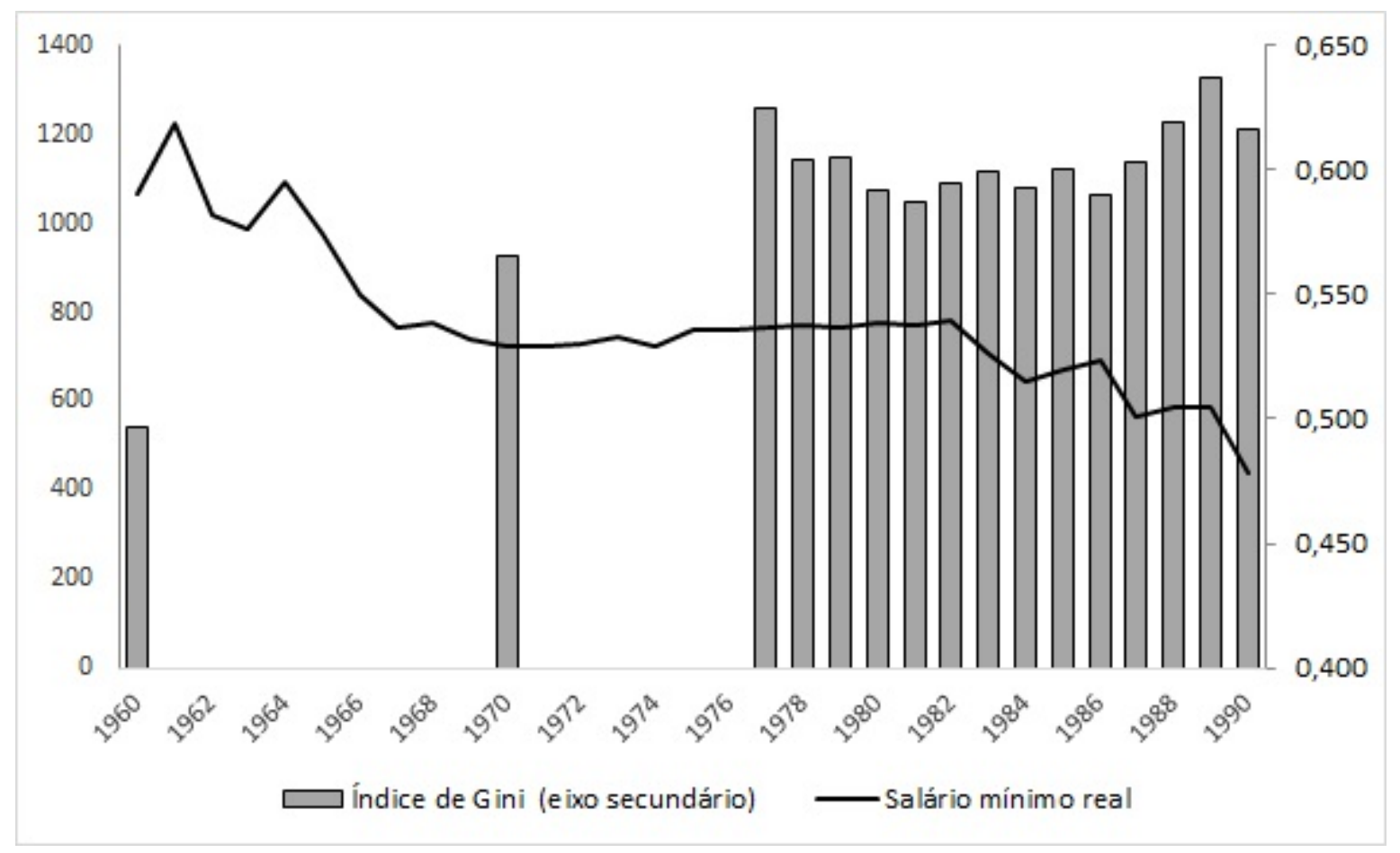

O aumento da desigualdade no período recebeu diferentes interpretações por parte dos economistas,

com alguns autores enfatizando a política governamental (políticas econômicosociais, incluindo a repressão a movimentos sociais), enquanto outros consideravam que a maior dispersão das rendas relativas refletia, essencialmente, um mercado no qual ocorria um crescimento da demanda por mão-de-obra mais qualificada sem o correspondente crescimento da oferta a curto prazo (HOFFMANN, 2001, pg.70).

Esta última interpretação, que utiliza-se do argumento de que o aumento da desigualdade é um processo natural do desenvolvimento econômico a lá Kuznets², ganhou força principalmente quando o alto crescimento econômico durante o "milagre" foi consolidado. Ou seja, como na famosa frase atribuída a Delfim Netto, era preciso crescer o bolo para depois distribuir.

índice de Gini era calculado apenas nos anos de Censo Demográfico, tendo periodicidade decenal e, somente a partir de 1977, ele está disponível anualmente na PNAD.

2 Kuznets (1955) é frequentemente citado na teoria mainstream quando se discute desigualdade de renda. A principal hipótese de Kuznets é que a desigualdade aumenta com o desenvolvimento (e crescimento) econômico, atingindo um nível máximo e, posteriormente com a continuidade do processo de crescimento, diminui, o que resulta em uma curva com formato de U invertido. 
Capítulo 1. Estrutura produtiva, composição do emprego e desigualdade no Brasil: os anos 1960-73 e os 34 anos 2000-14

Langoni (1972) faz um estudo cauteloso dos dados dos censos de 1960 e 1970, na tentativa de entender os efeitos distributivos das mudanças setoriais, regionais e qualitativas da força de trabalho. O autor, ao defender que o aumento da desigualdade é reflexo das mudanças educacionais entre os trabalhadores, mostra que uma das principais causas da mudança distributiva em favor dos mais ricos foi a redução da participação no setor primário - o setor primário teve sua participação relativa reduzida em 14\%, enquanto o secundário aumentou $29 \%$-, com um deslocamento de mão de obra para os centros urbanos.

Esses resultados (menor participação no volume de emprego, e menor contribuição para o produto total por parte do setor primário) são inteiramente consistentes e refletem de um lado, o maior dinamismo da oferta pelo setor urbano onde a produtividade total (isto é, a relação produto total/quantidade de fatores) cresceu a uma taxa mais elevada sem porém que as reduções nos preços relativos de seus produtos (refletindo custos decrescentes de longo prazo), resultasse - face às condições de demanda - em uma diminuição na renda total do setor. [...] Por outro lado, há o fato inexorável de que a taxa de crescimento da demanda agregada por produtos agrícolas é menor do que aquela observada para os outros produtos da economia devido à baixa elasticidade-renda (LANGONI, 1972, p. 22).

Analisando a composição educacional da força de trabalho entre os anos, o autor também encontra evidências de um aumento desproporcional na renda justamente dos grupos que já possuíam um nível de renda mais elevado. A justificativa para tal também se encontraria nas características do mercado de trabalho e do tipo de crescimento econômico do período:

Esses resultados sugerem uma expansão diferenciada da demanda de mão-deobra que beneficia desproporcionalmente os níveis mais elevados de educação. [...] Como a longo prazo a demanda de mão-de-obra depende fundamentalmente da direção do progresso tecnológico, parece haver poucas dúvidas, pela evidência anterior, de que este tem uma característica "intensiva em mãode-obra qualificada" (skill-intensive) no caso brasileiro. Assim, os grupos de educação mais elevada (acima do primário) tiveram aumentos substanciais de sua participação na renda (de $25 \%$ a $99 \%$ ) enquanto que os grupos inferiores e principalmente os analfabetos sofreram reduções sensíveis (LANGONI, 1972, p. 28).

Souza (2016) discute as diferentes interpretações para o aumento da desigualdade e, ao utilizar dados do Imposto de Renda, mostra que o aumento da concentração da renda 
no topo da distribuição vinha ocorrendo desde antes do período do milagre econômico, tornando as interpretações centradas no "U invertido" de Kuznets e na educação pouco convincentes. Em 1960 a fração apropriada pelo 1\% mais rico estava próximo a 20\%, saltando para mais de $25 \%$ já em 1970.

Dentro do arcabouço estruturalista, Tavares e Serra (1972) pensam no crescimento da desigualdade e na transformação da estrutura produtiva brasileira como duas dimensões indissociáveis para o entendimento deste período e, mais do que isso, que estão mutuamente correlacionadas de maneira a se reforçarem. Os autores apresentam um diagnóstico sobre o modelo de crescimento adotado na época, principalmente após 1967, em que o crescimento dos setores de bens industrializados empregadores de mão de obra qualificada e o aumento da desigualdade estavam positivamente relacionados em um processo cumulativo concentrador de renda. Para os autores, o processo de redistribuição de renda a favor dos mais ricos e de mudanças na estrutura produtiva tem início com a aceleração inflacionária em 1961, antes mesmo da ditadura militar. O aumento da inflação restringe a diversificação do consumo nas classes média e baixa, restando apenas a intensificação dos padrões de consumo das classes altas como impulso à economia pelo lado do consumo privado. As políticas restritivas ao salário e de concentração de renda do governo militar irão, então, potencializar e dar continuidade a esse processo.

A política do novo governo militar criou condições para uma nova reorganização do esquema distributivo "conveniente" ao sistema, começando por redistribuir a renda em favor dos setores de classe médias urbanas e contra as classes assalariadas. Esta redistribuição teve início primeiro ao nível do gasto, mediante novos esquemas ampliados de financiamento de bens duráveis e, posteriormente, pelo lado da renda, mantendo a queda dos salários mínimos reais mas permanecendo constantes os médios, permitindo uma abertura do leque da escala de remuneração em favor dos novos grupos médios emergentes. Tudo leva a pensar que a concentração na cúpula continuou e ainda com maior vigor, desde o significativo crescimento do excedente a partir de 1967, possibilitado por um nível de salários reais rebaixado em quase 30\%, no caso do salário mínimo (em relação a 1961), em condições de recuperação e expansão acelerada do nível de atividade econômica urbana (TAVARES; SERRA, 1972, p. 201).

O que é mais interessante na análise destes autores é a atenção dada às características específicas de países subdesenvolvidos e de um país continental como o Brasil, como as particularidades da estrutura produtiva, em uma perspectiva dinâmica. A heterogeneidade da estrutura produtiva brasileira e o modo como se deu a distribuição dos lucros e da renda no período da ditadura permitiram que o processo de crescimento econômico e de aumento 
Capítulo 1. Estrutura produtiva, composição do emprego e desigualdade no Brasil: os anos 1960-73 e os 36

anos 2000-14

de desigualdades, especialmente durante o milagre, tivesse características peculiares e que foram reproduzidas pela própria dinâmica interna dele. Nas palavras dos autores:

O processo capitalista no Brasil, em especial, embora se desenvolva de forma crescentemente desigual, incorporando e excluindo setores da população e extratos econômicos, levando a aprofundar uma série de diferenças relacionadas com consumo e produtividade, conseguiu estabelecer um esquema que lhe permite autogerar fontes internas de estímulo e expansão que lhe conferem dinamismo. Neste sentido, poder-se-ia dizer que, enquanto o capitalismo brasileiro desenvolve-se de maneira satisfatória, a nação, a maioria da população, permanece em condições de grande privação econômica, e isso, em grande medida, devido ao dinamismo do sistema, ou, ainda, ao tipo de dinamismo que o anima (TAVARES; SERRA, 1972, p. 158).

Dividindo a população em grupos de renda, os autores organizam a dinâmica de participação de cada grupo dentro da economia no período deixando claro a apropriação do excedente pelo grupo mais rico (grupo A, equivalente ao $1 \%$ mais rico), enquanto o grupo B (19\% subsequente) representa o núcleo e a base fundamental do mercado moderno, o grupo C (30\% subsequente) é a base principal da extração do excedente e o grupo D (50\% mais pobres) fica fora do mercado consumidor moderno.

A análise de Tavares e Serra (1972), contudo, é desprovida de dados setoriais que descrevam tal processo. De fato, um estudo mais detalhado da composição do emprego entre os setores e da distribuição salarial e da renda durante os anos 60 e início dos anos 70 carece de disponibilidade de dados. Entretanto, na presente dissertação, pretende-se retomar os dados disponíveis nas primeiras $\mathrm{PNADs}^{3}$, para melhor compreender a desigualdade salarial entre os setores e fornecer insights sobre como as dinâmicas da distribuição de renda e da estrutua produtiva podem estar relacionadas.

Antes do início da Pesquisa Nacional por Amostra de Domicílios (PNAD), os dados referentes à renda pessoal e sua distribuição, como o índice de Gini e a renda apropriada pelos decis da distribuição, eram coletados decenalmente e divulgados no censo, fazendo com que periodicidade tão longa impedisse uma análise mais sistemática de movimentos que aconteciam entre estes dez anos. Mesmo após o início da PNAD, em 19674, o estudo da distribuição salarial, especialmente entre as atividades econômicas setoriais, não é trivial. A PNAD foi implementada no segundo trimestre de 1967, sendo os resultados divulgados com periodicidade trimestral até 1973. A pesquisa tinha o principal objetivo

3 Este processo contou com o esforço de transcrever as tabelas das primeiras PNADs, disponíveis somente em PDF. As tabelas em formato txt podem ser solicitadas à autora.

4 Até 1977 as pesquisas estão disponíveis somente no formato das divulgações da época, acessível no catálogo do IBGE - https://biblioteca.ibge.gov.br/index.php/biblioteca-catalogo?view=detalhesid=759. 
de coletar dados referentes à população e mão de obra até o primeiro trimestre de 1970, quando foi interrompida com a realização do Recenseamento Geral. Entre 1971 e 1973 as pesquisas passaram a ser realizadas uma vez por ano, no quarto trimestre. Durante o biênio 1974/1975 a pesquisa não foi realizada devido à realização do ENDEF - Estudo Nacional da Despesa Familiar. Esta pesquisa, por sua vez, objetivava coletar informações que refletissem as condições de vida da população, com ênfase sobre o consumo alimentar. A pesquisa também apresenta dados sobre a população e a mão-de-obra, porém com menos especificidades setoriais quando comparada à PNAD, fazendo com que não existam dados de salário e emprego por classe de atividade setorial, por exemplo ${ }^{5}$.

As primeiras divulgações, referentes ao quarto trimestre de 1967, estão disponíveis somente para as regiões I e II e possuem menos detalhamento sobre a população ocupada por setor, fazendo somente a divisão entre setor agrícola e não-agrícola. Além disso, não há dados para salários. A partir de primeiro trimestre de 1968, entretanto, a divisão setorial da economia ganha uma classificação mais detalhada, tal como a reportada nas Tabelas 1 e 2, mas referente apenas à população ocupada. As tabelas referentes à distribuição salarial por setor de atividade estão disponíveis somente a partir do segundo trimestre de 1968. Até o primeiro trimestre de 1970 a pesquisa apresentou dados somente para as quatro primeiras regiões, impossibilitando uma representação nacional da composição do emprego e da desigualdade salarial.

Todas essas particularidades de cada divulgação inicial da PNAD refletem a dificuldade de se extrair dados precisos referentes à composição do emprego e à desigualdade salarial. Contudo, ainda que durante os anos 60 não se tenham dados para todos os anos e referentes a todo o Brasil, analisar as regiões e séries disponíveis continua relevante, pois nos permite avaliar comparativamente os setores e melhor compreender as dimensões salariais e setoriais da desigualdade naquele período.

Analisando as Tabelas 1 e 2 de participação no empreto total e crescimento do emprego por classe de atividade, percebemos que o crescimento mais significativo da indústria de transformação se deu entre os anos de 1970 e 1973. Por outro lado, este último período de 70 a 73 foi o período em que mais setores tiveram seu nível de emprego reduzido, com destaque para as atividades agrícolas, os serviços industriais e de utilidade pública, prestação de serviços e transporte e armazenamento. A redução significativa de

5 Até 1979, o território nacional era dividido em 7 regiões socioeconômicas constituídas das seguintes unidades da federação: Região I: Guanabara e Rio de Janeiro; Região II: São Paulo; Região III: PR,SC e RS; Região IV: MG e ES; Região V: MA,PI,CE,RN,PB,PE,AL,SE e BA; Região VI: Brasília - DF; Região VII: AM,AC,PA,AP,RO,RR,GO e MT. Em 1971 temos apenas dados para as primeiras três regiões, "[e]m decorrência da realização do Censo Demográfico de 1970, as operações da pesquisa, temporariamente suspensas, reiniciaram-se no $4^{\circ}$ trimestre de 1971 nos Estados da Guanabara, Rio de Janeiro, São Paulo, Paraná, Santa Catarina e Rio Grande do Sul." (PNAD, 1971). Em 1972 foram representadas as seis primeiras regiões e os dados referentes às 7 regiões estão disponíveis somente a partir de 1973. 
Capítulo 1. Estrutura produtiva, composição do emprego e desigualdade no Brasil: os anos 1960-73 e os 38

Tabela 1 - Distribuição do emprego setorial (\% do total) - regiões I a IV Fonte: PNAD

\begin{tabular}{|c|c|c|c|c|c|c|c|c|c|c|c|}
\hline \multirow{2}{*}{ Classes de atividade } & \multicolumn{4}{|c|}{1968} & \multicolumn{4}{|c|}{1969} & \multirow{2}{*}{$\begin{array}{c}1970 \\
\text { T1 }\end{array}$} & \multirow{2}{*}{$\begin{array}{c}1971^{*} \\
\text { T4 } \\
\end{array}$} & \multirow{2}{*}{$\begin{array}{c}1973 \\
\text { ano }\end{array}$} \\
\hline & T1 & $\mathrm{T} 2$ & T3 & T4 & T1 & $\mathrm{T} 2$ & T3 & T4 & & & \\
\hline ATIVIDADES AGRÍCOLAS & $37.75 \%$ & $36.62 \%$ & $35.14 \%$ & $36.24 \%$ & $36.16 \%$ & $35.06 \%$ & $33.88 \%$ & $34.97 \%$ & $35.86 \%$ & $32.60 \%$ & $30.85 \%$ \\
\hline ATIVIDADES NÃO AGRICOLAS & $62.25 \%$ & $63.38 \%$ & $64.83 \%$ & $63.76 \%$ & $63.79 \%$ & $64.94 \%$ & $66.12 \%$ & $65.03 \%$ & $64.14 \%$ & $67.40 \%$ & $69.15 \%$ \\
\hline Extração vegetal & $0.47 \%$ & $0.64 \%$ & $0.74 \%$ & $0.41 \%$ & $0.59 \%$ & $0.61 \%$ & $0.82 \%$ & $0.31 \%$ & $0.48 \%$ & $0.00 \%$ & $0.00 \%$ \\
\hline Extração mineral & $0.63 \%$ & $0.81 \%$ & $0.78 \%$ & $0.72 \%$ & $0.75 \%$ & $0.79 \%$ & $0.79 \%$ & $0.67 \%$ & $0.67 \%$ & $0.38 \%$ & $0.37 \%$ \\
\hline Caça e pesca & $0.22 \%$ & $0.23 \%$ & $0.21 \%$ & $0.20 \%$ & $0.22 \%$ & $0.21 \%$ & $0.22 \%$ & $0.23 \%$ & $0.25 \%$ & $0.00 \%$ & $0.00 \%$ \\
\hline Indústria da transformação & $13.77 \%$ & $14.13 \%$ & $14.28 \%$ & $13.87 \%$ & $14.10 \%$ & $14.22 \%$ & $14.58 \%$ & $14.35 \%$ & $14.11 \%$ & $16.34 \%$ & $18.51 \%$ \\
\hline Indústria da construção & $4.59 \%$ & $4.75 \%$ & $4.83 \%$ & $4.74 \%$ & $4.56 \%$ & $4.90 \%$ & $5.22 \%$ & $5.17 \%$ & $4.82 \%$ & $4.84 \%$ & $5.64 \%$ \\
\hline Comércio & $8.69 \%$ & $8.78 \%$ & $9.00 \%$ & $9.23 \%$ & $9.12 \%$ & $8.99 \%$ & $9.75 \%$ & $9.76 \%$ & $9.64 \%$ & $11.42 \%$ & $9.86 \%$ \\
\hline Prestação de serviços & $15.62 \%$ & $15.81 \%$ & $16.40 \%$ & $16.18 \%$ & $16.33 \%$ & $16.58 \%$ & $16.03 \%$ & $15.94 \%$ & $15.37 \%$ & $15.12 \%$ & $15.26 \%$ \\
\hline Transporte e comunicação & $5.27 \%$ & $4.96 \%$ & $5.97 \%$ & $4.82 \%$ & $4.82 \%$ & $4.86 \%$ & $5.01 \%$ & $4.93 \%$ & $4.95 \%$ & $4.90 \%$ & $4.82 \%$ \\
\hline Profissionais liberais & $1.19 \%$ & $0.99 \%$ & $1.06 \%$ & $1.02 \%$ & $1.12 \%$ & $1.11 \%$ & $1.20 \%$ & $1.22 \%$ & $1.26 \%$ & $1.35 \%$ & $1.55 \%$ \\
\hline Serviços sociais & $4.83 \%$ & $5.35 \%$ & $5.40 \%$ & $5.47 \%$ & $5.30 \%$ & $5.62 \%$ & $5.63 \%$ & $5.57 \%$ & $5.42 \%$ & $5.48 \%$ & $5.75 \%$ \\
\hline Administração pública & $2.32 \%$ & $2.26 \%$ & $2.44 \%$ & $2.37 \%$ & $2.43 \%$ & $2.36 \%$ & $2.33 \%$ & $2.19 \%$ & $2.49 \%$ & $3.99 \%$ & $3.93 \%$ \\
\hline Outros & $3.93 \%$ & $3.99 \%$ & $3.98 \%$ & $3.95 \%$ & $3.74 \%$ & $3.94 \%$ & $3.78 \%$ & $3.99 \%$ & $3.97 \%$ & $2.80 \%$ & $2.88 \%$ \\
\hline Ignorado & $0.14 \%$ & & & & & & & & & & \\
\hline
\end{tabular}

Tabela 2 - Crescimento do emprego em por classe de atividade (\%) - regiões I a IV Fonte: PNAD

\begin{tabular}{|l|c|c|c|}
\multicolumn{1}{|c|}{ Classes de atividade } & $\begin{array}{c}\text { D(1968 T1 x } \\
\mathbf{1 9 6 9} \text { T1)\% }\end{array}$ & $\begin{array}{c}\text { D(1969 T1 x } \\
\mathbf{1 9 7 0} \text { T1)\% }\end{array}$ & $\begin{array}{c}\mathbf{D}(\mathbf{1 9 7 0} \text { T1 x } \\
\mathbf{1 9 7 3} \%\end{array}$ \\
\hline TOTAL & $1 \%$ & $3 \%$ & $-9 \%$ \\
\hline ATIVIDADES AGRícOLAS & $-3 \%$ & $2 \%$ & $-21 \%$ \\
\hline ATIVIDADES NÃo AGRICOLAS & $4 \%$ & $4 \%$ & $-2 \%$ \\
\hline Extração vegetal & $27 \%$ & $-21 \%$ & $-100 \%$ \\
\hline Extração mineral & $20 \%$ & $-8 \%$ & $-50 \%$ \\
\hline Caça e pesca & $2 \%$ & $17 \%$ & $-100 \%$ \\
\hline Indústria da transformação & $4 \%$ & $3 \%$ & $20 \%$ \\
\hline Indústria da construção & $1 \%$ & $9 \%$ & $7 \%$ \\
\hline Serviços industriais de utilidade pública & $25 \%$ & $0 \%$ & $-24 \%$ \\
\hline Comércio & $6 \%$ & $10 \%$ & $-7 \%$ \\
\hline Prestação de serviços & $6 \%$ & $-3 \%$ & $-9 \%$ \\
\hline Transporte e comunicação & $-7 \%$ & $5 \%$ & $-11 \%$ \\
\hline Profissionais liberais & $-4 \%$ & $16 \%$ & $12 \%$ \\
\hline Serviços sociais & $11 \%$ & $6 \%$ & $-3 \%$ \\
\hline Administração pública & $6 \%$ & $6 \%$ & $44 \%$ \\
\hline Outros & $-3 \%$ & $9 \%$ & $-34 \%$ \\
\hline
\end{tabular}

emprego nos setores agrícolas e de extração podem simbolizar o movimento da população rural em direção às cidades, que também contribui para o aumento das desigualdades (LANGONI, 1972). A indústria de construção, por sua vez, teve crescimento positivo nos três períodos analisados, ainda que em um patamar relativamente baixo no acumulado, quando comparado à indústria de transformação. O crescimento do emprego na adminstração pública também se destaca, principalmente entre os anos 70 e 73 , no qual cresceu $44 \%$. Além disso, a redução do emprego total no último período analisado faz com que os setores cujo nível de emprego aumentou neste período tenham um ganho significativo na sua participação. A indústria da transformação, por exemplo, consistia em 13.8\% do total do 
emprego no primeiro trimestre de 1968, passando para $18.5 \%$ em 1973, e a indústria da construção passou de $4.6 \%$ para $5.6 \%$ do total no mesmo período.

Wells (1974), ao calcular os índices de dispersão dos rendimentos e de desigualdade internos aos setores, conclui que o efeito setorial mais significativo para o aumento dos índices de Gini e Theil foi o aumento da desigualdade interna aos setores, especialmente no setor industrial, por ser a dimensão mais afetada pelas mudanças no salário mínimo:

Within the industrial sector, which adds employment and earnings in construction, mining and electrical energy to those in manufacturing industry, the degree of inequality is unchanged between 1966 and 1968, increases between 1969 and 1970 and is unchanged between 1970 and 1971. The similarity with the years 1966-70 is surprising in view of the very rapid growth of very poorly paid employment in construction, and indicates that changes in the over-all degree of inequality reflect changes in the degree of inequality within each sector much more than changes in the composition of employment between the sectors (WELLS, 1974, p. 14).

The general conclusions are that in an economy characterized by abundant supplies of unskilled labour, the minimum wage plays a critical role in determining the over-all distribution of earnings. During the stabilization period, the government was more successful at controlling the wages of the lower-paid and was, therefore, responsible for the observed deterioration in earnings distribution (WELLS, 1974, p. 20).

Decidimos, então, incluir uma segunda dimensão da análise: a de desigualdade salarial interna aos setores. Até 1970, as faixas de salário eram definidas em valores absolutos de salário, como reportadas nas Tabelas 3 e $4^{6}$. No ano de 1971 os dados estão disponíveis somente para as 3 primeiras regiões e as faixas de salário passaram a ser divididas em relação ao salário mínimo - " até $1 / 4$ de SM", " de 1/4 a 1/2", etc. - e, além disso, para os dados de salário no ano de 1971, na mesma divisão de classes de atividade, há dados somente para os Empregadores e Trabalhadores por conta própria, retirando da "conta" os Empregados e os Membros da família, sem remuneração, que somam um total de 6.854.000 trabalhadores nas três regiões ${ }^{7,8}$.

6 Nos dados originais há 6 faixas de salário, mas somamos duas delas para facilitar a vizualização da tabela: as faixas de até 49,99 com a seguinte, de 50 a 149,99; e a de 300 a 499,99 com a seguinte, de 500 a 999,99 .

7 1.639.000 para a região I, 3.551 .000 para a região II e 1.664 .000 para a região III.

8 Para o ano de 1972, as tabelas por faixa de remuneração estão disponíveis somente para a divisão entre Grupos de Ocupação. Como a divisão por grupos de ocupação coloca em uma mesma categoria as indústrias de transformação e de construção civil, assim como serviços sociais, serviços industriais e prestação de serviços, os dados para estes anos não seriam comparáveis aos demais e, por isso, optamos por não reportar os dados dos anos de 1971 e 1972 para salários. 
Capítulo 1. Estrutura produtiva, composição do emprego e desigualdade no Brasil: os anos 1960-73 e os 40 anos 2000-14

Tabela 3 - Distribuição do emprego setorial (\% do total) nas duas primeiras faixas de salário (Cr\$) - regiões I a IV

Fonte: PNAD

\begin{tabular}{|c|c|c|c|c|c|c|c|c|c|c|}
\hline & $1968 \mathrm{~T} 2$ & $1968 \mathrm{~T} 3$ & $1968 \mathrm{~T} 4$ & 1969T1 & 1969T2 & $1969 \mathrm{~T} 3$ & 1969T4 & $1970 \mathrm{T1}$ & $\begin{array}{l}\mathrm{D}(1968 \mathrm{~T} 2 \mathrm{x} \\
1969 \mathrm{~T} 2) \%\end{array}$ & $\begin{array}{l}\text { D(1969 T2 x } \\
1970 \text { T1)\% }\end{array}$ \\
\hline \multicolumn{11}{|c|}{ até 149,99} \\
\hline TOTAL & & & & & & & & & $94 \%$ & $-7 \%$ \\
\hline Extração vegetal & $1.41 \%$ & $7.85 \%$ & $11.06 \%$ & $10.87 \%$ & $8.23 \%$ & $11.47 \%$ & \begin{tabular}{|l|}
$12.10 \%$ \\
\end{tabular} & $13.40 \%$ & $1033 \%$ & $52 \%$ \\
\hline Extração mineral & $2.94 \%$ & $1.91 \%$ & $1.40 \%$ & $1.56 \%$ & $1.88 \%$ & $2.01 \%$ & $1.84 \%$ & $1.49 \%$ & $24 \%$ & $-26 \%$ \\
\hline Caça e pesca & $1.76 \%$ & $4.08 \%$ & $4.05 \%$ & $4.22 \%$ & $4.78 \%$ & $4.64 \%$ & $4.37 \%$ & $5.50 \%$ & $427 \%$ & $8 \%$ \\
\hline $\begin{array}{c}\text { Indústria da } \\
\text { transformação }\end{array}$ & $7.41 \%$ & $11.72 \%$ & $13.22 \%$ & $14.63 \%$ & $13.01 \%$ & $15.61 \%$ & $14.26 \%$ & $14.95 \%$ & $241 \%$ & $7 \%$ \\
\hline Indústria da construção & $0.82 \%$ & $0.27 \%$ & $0.05 \%$ & $0.06 \%$ & $0.18 \%$ & $0.00 \%$ & $0.00 \%$ & $0.00 \%$ & $-57 \%$ & $-100 \%$ \\
\hline Comércio & $19.18 \%$ & $18.73 \%$ & $16.84 \%$ & $17.06 \%$ & $17.12 \%$ & $15.42 \%$ & $15.97 \%$ & $14.05 \%$ & $74 \%$ & $-23 \%$ \\
\hline Prestação de serviços & $57.41 \%$ & $48.28 \%$ & $46.84 \%$ & $45.40 \%$ & $49.18 \%$ & $44.58 \%$ & $45.44 \%$ & $43.88 \%$ & $67 \%$ & $-17 \%$ \\
\hline $\begin{array}{l}\text { Transporte e } \\
\text { comunicação }\end{array}$ & $4.94 \%$ & $3.45 \%$ & $2.81 \%$ & $2.43 \%$ & $2.54 \%$ & $1.88 \%$ & $2.34 \%$ & $2.20 \%$ & $0 \%$ & $-19 \%$ \\
\hline Profissionais liberais & $0.24 \%$ & $0.21 \%$ & $0.43 \%$ & $0.35 \%$ & $1.09 \%$ & $0.69 \%$ & $0.63 \%$ & $0.58 \%$ & $800 \%$ & $-50 \%$ \\
\hline Serviços sociais & $1.65 \%$ & $1.64 \%$ & $1.73 \%$ & $1.45 \%$ & $0.79 \%$ & $1.76 \%$ & $1.01 \%$ & $1.88 \%$ & $-7 \%$ & $123 \%$ \\
\hline Outros & $2.24 \%$ & $1.86 \%$ & $1.57 \%$ & $1.97 \%$ & $1.21 \%$ & $1.94 \%$ & $2.03 \%$ & $2.27 \%$ & $5 \%$ & $75 \%$ \\
\hline \multicolumn{11}{|c|}{ de 150 a 299,99} \\
\hline TOTAL & & & & & & & & & $40 \%$ & $8 \%$ \\
\hline Extração vegetal & $0.19 \%$ & $0.67 \%$ & $0.40 \%$ & $0.42 \%$ & $0.83 \%$ & $0.56 \%$ & $1.09 \%$ & $1.41 \%$ & $500 \%$ & $83 \%$ \\
\hline Extração mineral & $0.77 \%$ & $0.81 \%$ & $1.06 \%$ & $1.39 \%$ & $2.21 \%$ & $0.70 \%$ & $0.41 \%$ & $0.77 \%$ & $300 \%$ & $-63 \%$ \\
\hline Caça e pesca & $1.16 \%$ & $1.35 \%$ & $1.72 \%$ & $1.94 \%$ & $1.10 \%$ & $1.40 \%$ & $1.90 \%$ & $1.79 \%$ & $33 \%$ & $75 \%$ \\
\hline $\begin{array}{c}\text { Indústria da } \\
\text { transformação }\end{array}$ & $7.72 \%$ & $6.47 \%$ & $7.12 \%$ & $7.49 \%$ & $7.87 \%$ & $9.40 \%$ & $7.07 \%$ & $5.38 \%$ & $43 \%$ & $-26 \%$ \\
\hline Indústria da construção & $1.74 \%$ & $1.08 \%$ & $0.13 \%$ & $4.72 \%$ & $0.83 \%$ & $0.42 \%$ & $0.14 \%$ & $0.13 \%$ & $-33 \%$ & $-83 \%$ \\
\hline Comércio & $32.24 \%$ & $35.98 \%$ & $34.96 \%$ & $33.56 \%$ & $32.46 \%$ & $40.39 \%$ & $36.55 \%$ & $34.74 \%$ & $41 \%$ & $15 \%$ \\
\hline Prestação de serviços & $39.58 \%$ & $38.68 \%$ & $41.56 \%$ & $42.86 \%$ & $41.85 \%$ & $38.29 \%$ & $43.21 \%$ & $44.62 \%$ & $48 \%$ & $15 \%$ \\
\hline $\begin{array}{l}\text { Transporte e } \\
\text { comunicação }\end{array}$ & $12.55 \%$ & $11.05 \%$ & $9.23 \%$ & $7.91 \%$ & $8.56 \%$ & $6.17 \%$ & $5.57 \%$ & $7.82 \%$ & $-5 \%$ & $-2 \%$ \\
\hline Profissionais liberais & $0.77 \%$ & $1.48 \%$ & $1.85 \%$ & $1.11 \%$ & $1.10 \%$ & $1.26 \%$ & $3.67 \%$ & $1.28 \%$ & $100 \%$ & $25 \%$ \\
\hline Serviços sociais & $1.16 \%$ & $0.54 \%$ & $0.66 \%$ & $0.83 \%$ & $1.24 \%$ & $0.56 \%$ & $0.54 \%$ & $0.26 \%$ & $50 \%$ & $-78 \%$ \\
\hline Outros & $1.93 \%$ & $1.89 \%$ & $1.45 \%$ & $1.25 \%$ & $1.80 \%$ & $0.84 \%$ & $2.31 \%$ & $1.79 \%$ & $30 \%$ & $8 \%$ \\
\hline
\end{tabular}

Nas Tabelas 3 e 4 temos, então, a distribuição de empregados por faixa de salário e classe de atividade e o crescimento deste emprego em dois períodos: o primeiro do segundo trimestre de 1968 ao segundo trimestre de 1969, e o segundo do segundo trimestre de 1969 ao primeiro de 1970. A primeira característica notável nas duas últimas colunas, referentes ao crescimento do emprego, é o aumento quase que gradativo do emprego entre as faixas de renda, isto é, para os dois intervalos de tempo analisados, as faixas de renda mais altas tiveram um aumento maior no emprego total quando comparado às mais baixas (exceto para a primeira faixa entre o segundo trimestre de 1968 e o segundo trimestre de 1969). A indústria de transformação aumentou muito o emprego na primeira ( até Cr $\$ 149,99$ ) e última faixas de renda (mais de Cr\$1.000,00) - 248\% no total para a primeira faixa e $121 \%$ na última -, representando o aumento do distanciamento do leque salarial interno neste setor. O aumento no emprego da construção civil, por sua vez, parece ter se dado 
Tabela 4 - Distribuição do emprego setorial (\% do total) nas duas últimas faixas de salário (Cr\$) - regiões I a IV

Fonte: PNAD

\begin{tabular}{|c|c|c|c|c|c|c|c|c|c|c|}
\hline & $1968 \mathrm{~T} 2$ & $1968 \mathrm{~T} 3$ & $1968 \mathrm{~T} 4$ & 1969T1 & 1969T2 & $1969 \mathrm{~T} 3$ & 1969T4 & 1970T1 & $\begin{array}{l}\mathrm{D}(1968 \mathrm{~T} 2 \mathrm{x} \\
1969 \mathrm{~T} 2) \%\end{array}$ & $\begin{array}{l}\text { D(1969 T2 x } \\
\text { 1970 T1)\% }\end{array}$ \\
\hline \multicolumn{11}{|c|}{ de 300 a 999,99} \\
\hline TOTAL & & & & & & & & & $64 \%$ & $12 \%$ \\
\hline Extração vegetal & $0.51 \%$ & $0.40 \%$ & $0.60 \%$ & $0.56 \%$ & $0.62 \%$ & $0.70 \%$ & $0.29 \%$ & $0.65 \%$ & $100 \%$ & $17 \%$ \\
\hline Extração mineral & $0.68 \%$ & $0.53 \%$ & $0.48 \%$ & $0.44 \%$ & $0.52 \%$ & $0.70 \%$ & $0.49 \%$ & $1.21 \%$ & $25 \%$ & $160 \%$ \\
\hline Caça e pesca & $0.17 \%$ & $0.79 \%$ & $0.36 \%$ & $0.67 \%$ & $0.62 \%$ & $0.40 \%$ & $0.29 \%$ & $0.75 \%$ & $500 \%$ & $33 \%$ \\
\hline $\begin{array}{c}\text { Indústria da } \\
\text { transformação }\end{array}$ & $11.62 \%$ & $9.62 \%$ & $8.81 \%$ & $8.90 \%$ & $9.16 \%$ & $7.63 \%$ & $9.15 \%$ & $9.41 \%$ & $29 \%$ & $15 \%$ \\
\hline Indústria da construção & $1.71 \%$ & $1.45 \%$ & $0.95 \%$ & $1.22 \%$ & $0.83 \%$ & $1.00 \%$ & $1.36 \%$ & $1.12 \%$ & $-20 \%$ & $50 \%$ \\
\hline Comércio & $36.92 \%$ & $36.50 \%$ & $36.67 \%$ & $36.26 \%$ & $36.94 \%$ & $37.15 \%$ & $36.22 \%$ & $37.84 \%$ & $64 \%$ & $14 \%$ \\
\hline Prestação de serviços & $24.62 \%$ & $26.75 \%$ & $29.76 \%$ & $30.48 \%$ & $31.01 \%$ & $31.43 \%$ & $30.19 \%$ & $31.22 \%$ & $107 \%$ & $12 \%$ \\
\hline $\begin{array}{l}\text { Transporte e } \\
\text { comunicação }\end{array}$ & $15.90 \%$ & $16.47 \%$ & $15.24 \%$ & $14.24 \%$ & $13.74 \%$ & $14.96 \%$ & $14.41 \%$ & $12.49 \%$ & $42 \%$ & $2 \%$ \\
\hline Profissionais liberais & $6.50 \%$ & $4.35 \%$ & $4.05 \%$ & $3.67 \%$ & $3.64 \%$ & $3.51 \%$ & $4.58 \%$ & $3.17 \%$ & $-8 \%$ & $-3 \%$ \\
\hline Serviços sociais & $0.68 \%$ & $1.05 \%$ & $0.60 \%$ & $1.33 \%$ & $0.73 \%$ & $0.70 \%$ & $0.97 \%$ & $0.47 \%$ & $75 \%$ & $-29 \%$ \\
\hline Outros & $2.39 \%$ & $2.11 \%$ & $2.50 \%$ & $2.22 \%$ & $2.19 \%$ & $1.81 \%$ & $2.04 \%$ & $1.68 \%$ & $50 \%$ & $-14 \%$ \\
\hline \multicolumn{11}{|c|}{ mais de 1000} \\
\hline TOTAL & & & & & & & & & $97 \%$ & $31 \%$ \\
\hline Extração vegetal & $1.02 \%$ & $1.22 \%$ & $0.60 \%$ & $0.55 \%$ & $1.04 \%$ & $0.39 \%$ & $0.00 \%$ & $0.40 \%$ & $100 \%$ & $-50 \%$ \\
\hline Extração mineral & $1.02 \%$ & $0.61 \%$ & $1.20 \%$ & $0.55 \%$ & $0.52 \%$ & $1.18 \%$ & $1.15 \%$ & $0.40 \%$ & $0 \%$ & $0 \%$ \\
\hline \multicolumn{11}{|l|}{ Caça e pesca } \\
\hline $\begin{array}{c}\text { Indústria da } \\
\text { transformação }\end{array}$ & $16.33 \%$ & $17.68 \%$ & $15.66 \%$ & $21.31 \%$ & $17.10 \%$ & $15.69 \%$ & $17.62 \%$ & $15.08 \%$ & $106 \%$ & $15 \%$ \\
\hline Indústria da construção & $4.08 \%$ & $1.83 \%$ & $2.41 \%$ & $4.37 \%$ & $3.11 \%$ & $1.57 \%$ & $1.53 \%$ & $2.38 \%$ & $50 \%$ & $0 \%$ \\
\hline Comércio & $29.59 \%$ & $28.05 \%$ & $31.33 \%$ & $31.15 \%$ & $36.27 \%$ & $37.65 \%$ & $39.08 \%$ & $38.89 \%$ & $141 \%$ & $40 \%$ \\
\hline Prestação de serviços & $13.27 \%$ & $12.20 \%$ & $8.43 \%$ & $6.56 \%$ & $6.22 \%$ & $11.76 \%$ & $11.49 \%$ & $13.10 \%$ & $-8 \%$ & $175 \%$ \\
\hline $\begin{array}{l}\text { Transporte e } \\
\text { comunicação }\end{array}$ & $6.12 \%$ & $7.93 \%$ & $7.83 \%$ & $9.84 \%$ & $8.81 \%$ & $8.24 \%$ & $6.90 \%$ & $6.35 \%$ & $183 \%$ & $-6 \%$ \\
\hline Profissionais liberais & $18.37 \%$ & $20.73 \%$ & $22.29 \%$ & $16.39 \%$ & $16.58 \%$ & $19.61 \%$ & $19.92 \%$ & $19.05 \%$ & $78 \%$ & $50 \%$ \\
\hline Serviços sociais & $3.06 \%$ & $2.44 \%$ & $3.01 \%$ & $5.46 \%$ & $6.22 \%$ & $0.78 \%$ & $0.38 \%$ & $0.40 \%$ & $300 \%$ & $-92 \%$ \\
\hline Outros & $7.14 \%$ & $7.32 \%$ & $7.23 \%$ & $3.83 \%$ & $4.15 \%$ & $3.14 \%$ & $1.92 \%$ & $3.97 \%$ & $14 \%$ & $25 \%$ \\
\hline
\end{tabular}

quase que unicamente na última faixa de renda até 1970. O setor de prestação de serviços também apresenta uma trajetória curiosa: entre 1968 e 1969 o emprego nas três primeiras faixas de renda aumentou significativamente, em especial na terceira (107\%), de Cr $\$ 300,00$ a Cr\$999,99, enquanto a última faixa de renda teve o número de empregados reduzido em $8 \%$. No período seguinte, por outro lado, o emprego na última faixa de renda (mais de $\mathrm{Cr} \$ 1.000,00$ ) aumentou $175 \%$, enquanto nas demais ele reduziu seu ritmo de crescimento, ficando negativo (-17\%) para a primeira, de até Cr\$149,99.

É importante ressaltar, contudo, que reportar o número de empregados com uma unidade de 1.000 trabalhadores pode superestimar os aumentos e quedas no emprego, devido às aproximações feitas para que esta escala pudesse ser utilizada. Contudo, ainda que as magnitudes não sejam exatas, os sinais e as magnitudes comparadas nos fornecem informação suficiente para investigar os setores. Assim como apontado por Langoni (1972), 
uma segregação dos dados a ponto de identificar exatamente o processo que desejamos é praticamente impossível. "Normalmente o que se tem é - como no caso brasileiro - dados censitários [ou de outras pesquisas, como a PNAD] que são comparáveis do ponto de vista metodológico, mas que descrevem muito mais do que efeitos puramente distributivos.". O autor argumenta que, para entender as mudanças distributivas é preciso raciocinar, então, sobre a combinação de três movimentos, ainda que eles não estejam puramente representados pelos dados: o primeiro se refere "ao impacto da variação na participação relativa de cada grupo no total da PEA [População Economicamente Ativa] sem que haja mudanças nas rendas médias ou no grau de concentração dentro de cada grupo"; o segundo é "o impacto de variações nas rendas médias de cada grupo"; e, "[finalmente], há ainda o impacto dos aumentos de desigualdade dentro de cada grupo, mantendo porém constante, a renda média e sua participação no total da PEA.” (LANGONI, 1972, p. 21).

Ainda que esta seção tenha se dedicado apenas ao primeiro e último pontos apontados pelo autor, é possível pensar no efeito total resultante da combinação deles. Um setor cuja participação no emprego total aumentou no período e que teve sua desigualdade interna também ampliada poderia impactar de maneira mais expressiva na expansão da desigualdade total da economia, como parece ter sido o caso da indústria de transformação. Além disso, se a redução da participação no emprego do setor de prestação de serviços, por exemplo, é traduzida numa exclusão mais do que proporcional dos trabalhadores pior remunerados em detrimento dos presentes nas faixas mais altas de renda poderia também refletir um aumento mais significativo nos índices de desigualdade.

As mudanças distributivas nos anos 60 e início dos anos 70 contaram, então, com uma multiplicidade de fatores, que vão desde as políticas governamentais até a dinâmica interna de consumo e mudança estrutural, tal como argumentado por Tavares e Serra (1972). Dissociar tais dimensões não parece plausível do ponto de vista da análise econômica, uma vez que tanto a dinâmica interna setorial só foi possível e sustentada devido às restrições salariais e laborais, assim como o resultado do plano econômico do Estado só foi alcançado por conta da dinâmica interna da economia que resultou em mudanças na composição da estrutura produtiva e na distribuição de renda. Neste sentido, é também necessário analisar o período recente de crescimento econômico e redução das desigualdades no Brasil sob esta perspectiva de interação das políticas do governo com movimentos internos da demanda agregada e do setor produtivo. A próxima sessão pretende cumprir esta tarefa.

\subsection{Distribuir para crescer: desigualdade salarial e compo- sição do emprego no período 2003-2014}

Para além do cenário externo favorável, o crescimento econômico mais acelerado do Brasil na primeira década dos anos 2000 teria contado com dois pilares principais: a 
expansão do consumo de massas via políticas de inclusão social e aumento do crédito às famílias; e um aumento no investimento público em infraestrutura física e social (CARVALHO; RUGITSKY, 2015). A expansão do consumo, se acompanhada de mudanças no padrão deste, junto com o progresso técnico, constituem um vetor fundamental do processo de mudança estrutural que caracteriza o desenvolvimento econômico (MEDEIROS, $2015)^{9}$.

Já no primeiro ano do governo Lula, foi criado o programa Fome Zero e em 20042005 implementou-se um programa que reuniu diversas ações que objetivavam a redução da pobreza extrema: o Programa Bolsa Família $(\mathrm{PBF})^{10}$. O programa ampliou seu escopo ao longo dos anos: beneficiava 3.6 milhões de famílias no início de 2004 e, em 2010, esse número já atingia 12.8 milhões, segundo seus registros administrativos.

Além das transferências diretas de renda do governo para as famílias via Bolsa Família, a valorização do salário mínimo (SM) também representou um importante canal de redução da desigualdade. Entre 2002 e 2013, o salário mínimo real cresceu 73\% se deflacionado pelo Índice Nacional de Preços ao Consumidor (INPC), resultando em dois efeitos principais: a redução da desigualdade intra-salarial, ao reduzir a diferença entre o salário mínimo e médio; e a alteração da distribuição funcional da renda, ao elevar a participação dos trabalhadores na renda nacional (KOMATSU; FILHO, 2015). Além disso, a valorização do salário mínimo representa um importante canal de distribuição de renda, uma vez que alguns programas de transferências governamentais são indexados a ele. Exemplos destes programas são: o Benefício de Prestação Continuada (BPC) ${ }^{11}$, o piso dos benefícios da Previdência (aposentadorias, pensões e auxílios) ${ }^{12}$ e o seguro desemprego.

9 Como apontado em Carvalho (2018), o período entre 2003 e 2010 pode ser separado em dois, dependendo do principal motor de crescimento de cada um. O primeiro período vai de 2003 a 2005 e teria contado principalmente com o crescimento de $11.7 \%$ ao ano, em média, das exportações, com o PIB crescendo $3.4 \%$ ao ano em média, enquanto o segundo consiste nos anos de 2006 a 2010 e o crescimento do PIB de $4.5 \%$ ao ano em média teria contado principalmente com o crescimento dos investimentos públicos, que cresceram $27.6 \%$ ao ano. Trataremos nesta dissertação, contudo, do período como um todo, ainda que esta distinção entre os dois motores de crescimento diferentes por período é importante para melhor compreender o papel das políticas realizadas e também os limitadores deste processo, dos quais trataremos na seção 1.4 deste capítulo.

10 "O Bolsa Família é um programa federal destinado às famílias em situação de pobreza e extrema pobreza, com renda per capita de até $\mathrm{R} \$ 154$ mensais, que associa à transferência do benefício financeiro do acesso aos direitos sociais básicos - saúde, alimentação, educação e assistência social"(bolsafamilia.datasus.gov.br). O programa foi uma combinação de vários outros programas préexistentes: o Bolsa Escola Federal, o Cartão Alimentação, o Bolsa Alimentação e o Auxílio Gás. Em 2005, o PBF também incorporou o Programa de Erradicação de Trabalho Infantil (PETI). Através do Bolsa Família, o governo federal concede mensalmente benefícios em dinheiro para famílias mais necessitadas. As contrapartidas para recebimento do benefício incluem a frequência escolar de jovens e crianças e o acompanhamento médico de gestantes e crianças da família.

11 O Benefício de Prestação Continuada (BPC) é a garantia de um salário mínimo mensal à pessoa com deficiência e ao idoso com 65 anos ou mais que comprovem não possuir meios de prover a própria manutenção, nem de tê-la provida por sua família. Em 2015 existiam 9 milhões de beneficiários da clientela rural e 4 milhões de beneficiários do BPC, segundo dados do Boletim Estatístico da Previdência Social, vol. 20, n. 1, jan. 2015.

12 Em 2015, quase dois terços dos benefícios da Previdência Social possuíam o valor de um salário mínimo, 
Figura 2 - Evolução da desigualdade salarial e da parcela de salários na renda

Fonte: Parcela de salários na renda: Rugitsky (2017), apêndice 1; Índice de Gini para a renda e salários: PNAD (2017); Salário mínimo/médio: IPEA/PME.

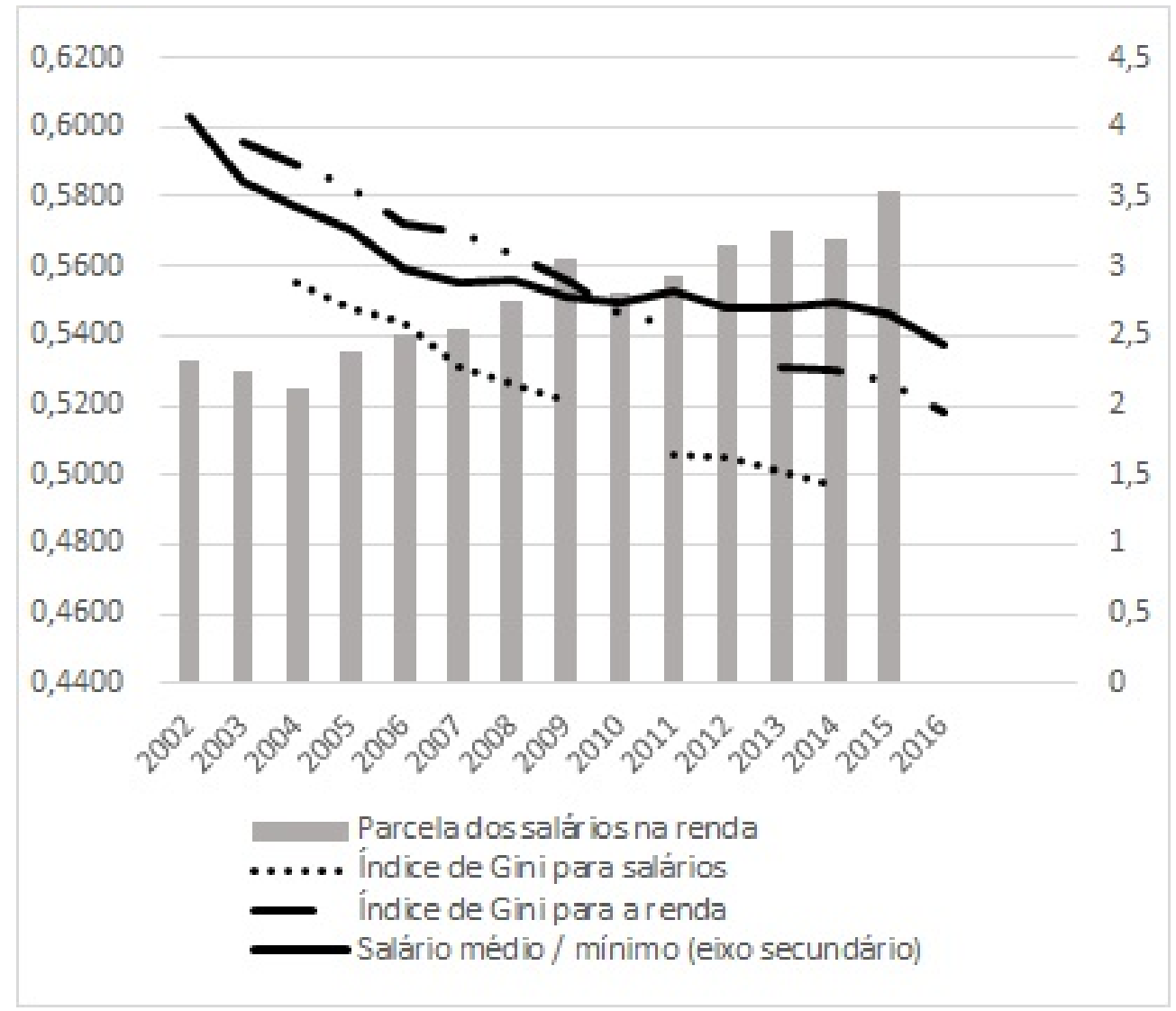

Como podemos observar na Figura 2, a parcela de salários na renda aumenta significativamente no período, passando de $52.52 \%$ em 2004 para $58.12 \%$ em 2015 e o índice de Gini para salários e para a renda caem substancialmente. O êxito especialmente do PBF, do BPC e da valorização do salário mínimo em reduzir a desigualdade foi documentado por diversos estudos sobre a distribuição de renda no Brasil, ainda que as magnitudes dos efeitos variem com a metodologia utilizada (SOARES et al., 2007; HOFFMANN; OLIVEIRA, 2014; MEDEIROS, 2015; KOMATSU; FILHO, 2015; MAURIZIO; VAZQUEZ, 2016). Komatsu e Filho (2015) e Maurizio e Vazquez (2016) realçam o papel do aumento do salário mínimo real em reduzir a desigualdade salarial, especialmente na cauda inferior da distribuição de salários do Brasil ${ }^{13}$. Hoffmann e Oliveira (2014), por sua vez, concluem que entre 2002 e 2012, "44\% da redução do índice de Gini está associado a mudanças nas remunerações dos empregados no setor privado e $18 \%$ se deve a mudanças no componente de juros, repartições, transferências governamentais e outras rendas". A parcela correspondente

totalizando mais de 17 milhões de benefícios, segundo dados do Boletim Estatístico da Previdência Social, vol. 20, n. 1, jan. 2015.

13 Komatsu e Filho (2015) também estimam o efeito de aumentos do salário mínimo real na desigualdade na Argentina, Chile e Uruguai, além do Brasil, e encontram o mesmo efeito equalizador na Argentina e no Uruguai, mas não no Chile. 
às menores pensões (aquelas próximas ou abaixo de um SM) na renda familiar per capita também aumentou de $4.11 \%$ em 2001 para $6.58 \%$ em 2012, aumento que pode ser explicado principalmente pela valorização do salário mínimo. Loureiro (2018) decompõe as fontes de renda para cada percentil da distribuição da renda familiar per capita para melhor entender o efeito de cada programa dentre elas, e conclui que as transferências diretas do governo foram mais relevantes para a redução da extrema pobreza, ou seja, na base da distribuição, enquanto um aumento da formalização do emprego beneficiou principalmente o primeiro quartil da distribuição e a valorização do salário mínimo e as pensões o segundo (e, em alguma medida, o terceiro).

A partir das duas Pesquisas de Orçamento Familiar (POF) disponíveis, de 2002-03 e 2008-09, Hoffmann (2010) analisa a renda familiar per capita e mostra que a renda real média da economia aumentou em 20.4\%. Analisando as camadas mais inferiores da distribuição, destaca-se o aumento de $30 \%$ na renda familiar per capita para as $50 \%$ famílias mais pobres e o aumento de $36 \%$ para as $25 \%$ mais pobres. Como consequência do aumento da renda, a parcela no consumo destas famílias também cresce significativamente: a parcela do consumo das famílias com renda de até dois salários mínimos no consumo total da economia foi de $4.8 \%$ para $6.5 \%$, e daquelas com renda entre dois e cinco salários mínimos foi de $17.9 \%$ para $28.7 \%$. O efeito significativo do aumento no consumo, oriundo do aumento na renda da população mais pobre, pode ser explicado pela maior propensão a consumir destas famílias, quando comparadas com as mais ricas. Segundo Medeiros (2015), a expansão do número de famílias nas faixas de renda mais baixas (até $5 \mathrm{SM}$ ) se afirmou como uma das principais transformações do período, uma vez que representa um maior poder de consumo para a massa trabalhadora, resultando na redução (ao menos parcial) da forte polarização do consumo na sociedade brasileira.

O aumento do consumo, contudo, não se deu de maneira homogênea entre os bens consumidos: "a distribuição de renda, adicionalmente ao seu impacto na demanda efetiva, pode afetar a composição da demanda, se as cestas de consumo das famílias forem significativamente diferentes entre as diferentes classes de renda" (RUGITSKY, 2017). Ao recordamos a Lei de Engel, este processo pode ser melhor compreendido. O aumento do poder de compra dos indivíduos de baixa renda faz com que fiquem disponíveis para eles bens que não eram disponíveis anteriormente, ou seja, eles passam a consumir mais serviços e bens manufaturados (ou mais tecnológicos), que tem, caracteristicamente, uma elasticidade renda mais alta. Dito de outra maneira, o consumo total destes bens na economia aumenta mais do que proporcionalmente aos demais. Carvalho et al. (2016) olham para a participação do consumo de alguns produtos específicos e mostram que, de fato, para as classes que recebem renda abaixo de dois salários mínimos, entre 2003 e 2008, a participação no consumo total de alimentos frescos e industrializados caiu de $14.25 \%$ e $18.52 \%$ para $10.61 \%$ e $13.31 \%$ do total, respectivamente, enquanto a parcela de 
Capítulo 1. Estrutura produtiva, composição do emprego e desigualdade no Brasil: os anos 1960-73 e os 46

anos 2000-14

equipamentos eletrônicos e de comunicação e de outros serviços ${ }^{14}$ passou de $1.45 \%$ e $1.12 \%$ para $3.04 \%$ e 1.39, respectivamente. Além disso, de acordo com dados fornecidos pelo Banco Central do Brasil, a parcela de serviços no consumo total das famílias aumentou substancialmente na base da distribuição de renda, aumentando cada vez menos à medida que se sobe na escala de distribuição (CARVALHO; RUGITSKY, 2015).

Mudanças no padrão da demanda repercutem em mudanças na estrutura produtiva e nos preços da economia, mas elas se deram de maneira especial no Brasil nos anos 2000. Tendo em vista a sobrevalorização do Real e as características da estrutura produtiva brasileira, parte dos novos produtos consumidos pelas famílias e uma parcela dos bens intermediários e da tecnologia de produção destes produtos foram importados. A taxa de câmbio nominal passou de 2.98R \$/US\$ em 2003 e alcançou 1.67R \$/US\$ em 2010, o menor valor dentro do período analisado. Como argumentado por Loureiro (2018):

Import penetration, defined as imports divided by total domestic supply, increased from 6.6 to $7.5 \%$ for the whole economy between 2003 and 2013.[...] The macroeconomically most relevant rises of import penetration were in three products, which jointly accounted for about $13 \%$ of imports in 2013. These products were electronic machinery and telecommunications equipment, whose import penetration increased from 33.6\% in 2003 to $44.5 \%$ in 2013, inorganic chemicals (from 23.9 to 32.8\%), and automobiles (from 7.6 to 17.8\%)(LOUREIRO, 2018, p. 99).

Santos et al. (2015) mostram que o aumento das importações também contou com o efeito indireto do aumento da renda das famílias. Embora os bens de consumo final, duráveis e não duráveis, como veículos, eletroeletrônicos, móveis, produtos farmacêuticos, vestuário e alimentos industrializados, tenham alta elasticidade-renda e câmbio, eles representavam menos de 10\% de total das importações, em média, entre 2000 e 2013, segundo dados da Fundação para o Estudo do Comércio Exterior (Funcex). Já as importações de bens intermediários, o grupo mais relevante nas importações brasileiras, representaram em média 18\% do total das importações entre 2000 e 2013. Os bens de capital, por outro lado, são estimulados principalmente pela demanda interna, pois sua elasticidade-renda é alta. Isso significa que, para fornecer alguns dos produtos demandados pelas famílias brasileiras, os produtores precisavam recorrer às importações.

Os setores cuja produção interna cresceram mais seriam, então, majoritariamente os de bens não-comercializáveis, como serviços e construção civil ${ }^{15}$, tendo sua capacidade

14 "Outros serviços" incluem serviços de manutenção e reparação, serviços associativos e serviços prestados para empresas.

15 A seguir trataremos mais a fundo o processo aqui descrito nos dados, a fim de melhor avaliar quais foram estes setores mais impactados. Por ora, seguimos a introdução ao processo de causação circular e cumulativa tratando destes setores de maneira mais ampla. 
expandida e aumentando a demanda por força de trabalho. Consequentemente, teríamos uma alteração na composição da estrutura do produto e do emprego na economia, com a participação destes setores aumentando relativamente mais do que dos outros.

O aumento da demanda por emprego nestes setores, juntamente com medidas pelo incentivo à formalização do trabalho, garantiu o aumento do poder de barganha dos trabalhadores e fez com que o salário médio deles crescesse mais do que proporcionalmente ao salário nos demais setores.

Conforme aqui se argumenta, a formalização do emprego na última década pode ser explicada pela interação de diversos processos econômicos e institucionais.

No plano econômico, tal como se observou, o principal movimento [para a maior formalização do emprego] foi o aumento da demanda global, decorrente do aumento do consumo interno e das mudanças nos padrões de consumo associadas tanto ao aumento de renda quanto à difusão do crédito. Houve deslocamento do consumo para bens e serviços regularmente oferecidos nos estabelecimentos mercantis, levando ao aumento do emprego nos estabelecimentos maiores. [...] Além disso, aumentou a fiscalização do mercado de trabalho tanto urbano quanto rural e criaram-se mecanismos favorecedores da formalização da pequena empresa; por fim, com o mercado de trabalho aquecido, os trabalhadores passaram a demandar maior formalização devido aos salários indiretos associados à carteira e, sobretudo, como via de acesso ao crédito (MEDEIROS, 2015, p. 88).

Baseado em dados do IBGE, Medeiros (2015) mostra que o número total de empregos formais cresceu 63.3\% no Brasil entre 2001 e 2011. Além disso, o autor conclui que a maior formalização do emprego no período analisado se deu principalmente nos setores de serviços e construção civil. No caso dos trabalhadores domésticos, o número de contratos formais cresceu $32.8 \%$, enquanto os informais cresceram apenas $6 \%$.

Como formalizado por Rugitsky (2017), este movimento pode ter gerado mais um elemento importante para a redução da desigualdade. Os setores cuja demanda cresceu substancialmente e que, consequentemente, aumentaram sua participação no produto e no emprego, são setores caracteristicamente trabalho-intensivos e que empregam mão de obra pouco qualificada. A população mais pobre se via, então, com mais oportunidades de emprego que, juntamente com a valorização do salário mínimo e a consequente elevação da remuneração relativa dos salários mais baixos, consistiria num mecanismo circular e cumulativo que potencializou a distribuição da renda. Ao comparar com o processo descrito por Tavares e Serra (1972) sobre os primeiros anos da ditadura militar e, mais 
Capítulo 1. Estrutura produtiva, composição do emprego e desigualdade no Brasil: os anos 1960-73 e os 48 anos 2000-14

especificamente o milagre econômico, desenvolvido na seção 1.2 anterior, Rugitsky (2017) chama este processo de "antimilagre" devido ao seu caráter inclusivo, contrário ao milagre.

A fim de melhor compreender quais os setores foram os mais impactados pelo fenômeno de causação circular e cumulativa descrito acima, analisamos mais a fundo os dados setoriais referentes a emprego, importação, salário, produtividade e consumo e fizemos uma seleção dos setores que aparentam ter sido mais afetados por este processo. Para selecionar estes setores foram utilizados dados das Pesquisas de Orçamentos Familiares (POF) de 2002-03 e 2008-09 para o consumo e do Sistema de Contas Nacionais (SCN) para o emprego, valor agregado ${ }^{16}$, importações e salário médio para os anos de 2003 a 2008. Utilizamos estes anos do SCN para garantir compatibilidade com as duas POFs disponíveis. Em primeiro lugar, eliminamos os setores da classificação do $\mathrm{SCN}^{17}$ nos quais as famílias não consomem diretamente, como metalurgia de metais não-ferrosos, minério de ferro, administração pública e segurança social. Estamos cientes dos prováveis problemas que esta primeira exclusão pode gerar, uma vez que ela ignora as possíveis relações que esses setores intermediários tem com os produtos finais consumidos diretamente pelas famílias. Contudo, dada a dificuldade adicional de tais considerações, a incorporação dos canais intermediários fica reservada para trabalhos futuros. A segunda eliminação baseou-se nos coeficientes de importação, calculados pela razão entre o total das importações e a oferta total em cada setor. Aqueles com coeficientes acima da média foram eliminados, como produtos químicos, máquinas e equipamentos de escritório e material eletrônico. $\mathrm{O}$ Apêndice B mostra os setores excluídos.

Em seguida, analisamos os demais setores de acordo com o consumo das famílias com menos de três salários mínimos, o crescimento do emprego, a produtividade e o salário médio $^{18}$. O corte de famílias que recebem até três salários mínimos foi escolhido com base no número de famílias que sofreram o impacto mais significativo da distribuição de renda e que representam parte significativa da demanda doméstica. Além disso, as famílias com menos de três salários mínimos foram responsáveis por $10.6 \%$ do consumo total em 2002-03, que cresceu para 14.3\% em 2008-09. Medeiros (2015) também argumenta que a principal transformação do período foi o aumento de $25 \%$ da renda real das famílias mais pobres (que recebem menos do que dois salários mínimos). Criamos, então, uma tabela conjunta para comparar as quatro dimensões da análise, apresentada no Apêndice C.

Os setores selecionados tiveram que atender a quatro requisitos: crescimento positivo do consumo, crescimento positivo do emprego e nível de produtividade e salário médio

16 Usaremos valor agregado ao calcular uma proxy para produtividade do emprego: a razão entre Valor Adicionado e Emprego.

17 Foram usadas as tabelas com as 55 classificações do SCN. A tradução para classificação da POF para o SCN se encontra no Apêndice A e foi feita com a ajuda do dicionário disponível no portal do IBGE.

18 Para produtividade utilizamos o dado de valor adicionado dividido pelo emprego em 2003 como referência, uma vez que nos interessávamos produtividade no início do ciclo. Para os salários médios, também usamos o valor do início do período (2003). 
Tabela 5 - Passo a passo para a seleção de setores

1) Traduzir a POF para o SCN e excluir os setores intermediários e que não são diretamente consumidos pelas famílias (Apêndices A e B)

2) Eliminar os produtos com coeficiente de importação acima da média (Apêndice B)

3) Selecionar os setores restantes com base nos quatro critérios (Apêndice C):

3.1) Crescimento positivo do consumo nas famílias que recebem até $3 \mathrm{SM}$

3.2) Crescimento positivo do emprego

3.3) Produtividade em 2003 - medido por VA/emprego - abaixo da média

3.4) Salário médio em 2003 abaixo da média

abaixo da média. O passo a passo para a seleção dos setores está resumido na Tabela 5.

O resultado dessa seleção é mostrado na Tabela 6. Os setores selecionados corresponderam a $30.3 \%$ do emprego, na média, entre 2004 e 2015, e por $13.7 \%$ do PIB, na média, durante o mesmo período, segundo dados do Sistema de Contas Nacionais do IBGE.

Tabela 6 - Setores selecionados

\begin{tabular}{l}
\hline Vestuário, calçados e têxteis \\
\hline Construção civil \\
\hline Móveis e produtos de diversas indústrias \\
\hline Serviços de manutenção e reparo \\
\hline Serviços prestados a famílias e associações \\
\hline Serviços domésticos \\
\hline Serviços de Alojamento e Alimentação \\
\hline
\end{tabular}

Na Figura 3, plotamos o resultado das séries de média móvel de 12 meses da diferença no saldo de contratações nos setores selecionados e nos demais e do salário médio das contratações nos setores selecionados sobre o salário médio dos admitidos nos demais setores da economia, disponíveis no CAGED. Houve uma mudança metodológica referente à divisão dos setores ao longo da série: até dezembro de 2006 só havia dados referentes à divisão setorial número 95 da CNAE, enquanto a partir de 2008 só se tem dados referentes à divisão 2.0. Como em 2007 há dados para as duas classificações, utilizamos este ano como base inicial para concatenar as séries, a partir de uma lógica de médias móveis, para 
os dados de Janeiro de 2004 a Dezembro de 2006:

$$
\text { série_concatenada } a_{t}=\text { série_CNAE95 } \frac{\sum_{i=1}^{12} \text { série_CNAE2.0 }}{\sum_{i+1}^{12} \text { série_CNAE } 95_{t+i}}
$$

Figura 3 - Evolução das séries de desigualdade salarial entre admitidos e mudanças na composição do emprego a partir dos setores selecionados - média móvel de 12 meses

\section{Fonte: CAGED}

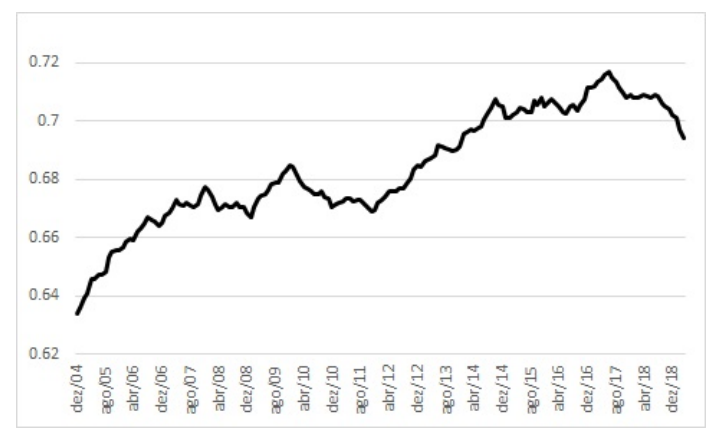

(a) Razão do salário médio dos trabalhadores admitidos nos setores selecionados sobre os demais setores (média móvel de 12 meses)

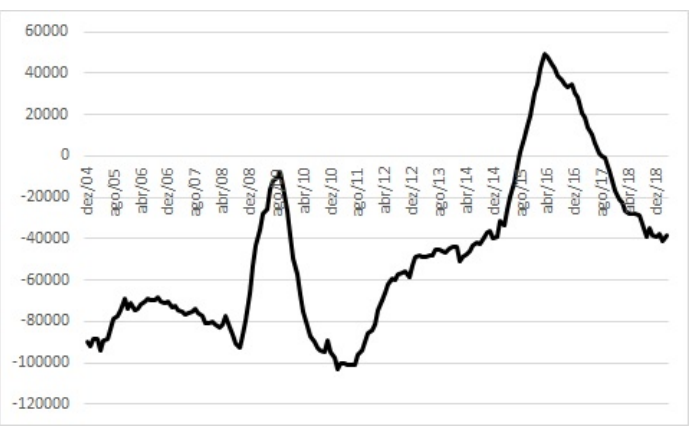

(b) Diferença no saldo de contratações nos setores selecionados no dos demais (média móvel de 12 meses)

Os dados de admissão, desligamento e salário médio dos admitidos foram dessazonalizados pelo método X-12-ARIMA e, em seguida, calculamos os respectivos indicadores razão entre o salário médio dos admitidos nos setores selecionados e nos demais e diferença no saldo de contratações dos setores selecionados e dos demais - e a média móvel de 12 meses de cada um deles para suavizar as variações mensais e melhor observar a tendência da série. Optamos por utilizar este indicador devido à compatibilização da classificação setorial disponível no CAGED com a seleção de setores realizada.

No gráfico do diferencial de salarios entre os admitidos, percebemos uma tendência crescente deste indicador, simbolizando o aumento mais do que proporcional no salário inicial nos setores selecionados, em relação aos demais. Esta tendência pode refletir o efeito da maior demanda por força de trabalho nestes setores juntamente com um momento em que o desemprego estava muito baixo, fazendo com que os trabalhadores pudessem exigir salários mais altos já no momento de admissão. Além disso, há também um efeito da valorização do salário mínimo, que dentre os setores selecionados, impacta mais na média salarial, já que estes setores caracteristicamente pagam salários mais baixos. Há, contudo, uma pequena queda entre 2010 e 2011, mas que se recupera posteriormente até voltar a cair em junho de 2017. Esta queda no final do gráfico pode sinalizar os efeitos que a crise de 2014 a 2016 ainda exercem sobre o Brasil, como o aumento do desemprego e da informalidade no mercado de trabalho. 
O segundo gráfico, da média móvel de 12 meses da diferença no saldo de contratações dos setores selecionados e os demais, também apresenta uma tendência geral de crescimento, porém com a presença de dois ciclos ao longo destes anos. O primeiro está associado à crise de 2008, quando o indicador calculado apresenta o primeiro pico mais significativo - média de agosto de 2008 até agosto de 2009 - indicando uma redução mais do que proporcional nas contratações dos outros setores, que incluem a indústria de transformação e a produção agrícola, por exemplo. Entre novembro de 2008 e abril de 2009, o saldo de contratações foi negativo tanto para os setores selecionados quanto para os demais, porém em magnitude muito maior para o segundo - os setores selecionados tiveram um saldo médio de aproximadamente 7.400 demissões, enquanto os demais setores da economia tiveram um saldo negativo de aproximadamente 34.550 no mesmo período. A partir de maio de 2009, contudo, a economia já voltava a se recuperar e o saldo de contratações nos outros setores supera o dos setores selecionados, trazendo o indicador para próximo de seu valor pré-crise. Contudo, esta diferença no saldo das contratações vai ficando cada vez mais próxima de zero, cruzando o eixo X em abril de 2015, no meio da crise econômica mais recente. Os motivos para esse crescimento acelerado do indicador aqui construído são similares ao observado na crise de 2008: os demais setores demitiram mais em relação aos aqui selecionados. A partir do segundo pico, em abril de 2016, observa-se uma queda no indicador como reflexo dos efeitos da crise nos setores selecionados, que parecem ter sido proporcionalmente mais atingidos do que os demais. De abril de 2016 até março de 2019, o saldo médio mensal de emprego nos setores de construção civil, serviços de alimentação e alojamento, serviços domésticos, serviços de manutenção e reparação, serviços prestados a famílias e assossiações, vestuário, calçados e têxteis e móveis foi de aproximadamente 15.300 negativo, ou seja, 15.300 demissões a mais do que contratações por mês, em média, contra um saldo positivo de aproximadamente 100 em média por mês nos demais setores.

Ainda que as duas séries apresentem uma tendência geral crescente, atribuí-las algum tipo de causalidade a partir de análises descritivas nos parece precipitado. Elas serão melhor exploradas econometricamente no Capítulo 3, seção 3.4.1, em que utilizaremos estes mesmos dados de diferença nos saldos de emprego entre os setores selecionados e os demais e de desigualdade salarial entre os admitidos nos setores selecionados e nos demais, em um modelo de séries de tempo, no qual poderemos tirar conclusões mais específicas sobre a relação entre estas variáveis no período selecionado. Resta neste capítulo, então, refletir sobre algumas características deste processo de causação circular e cumulativa, tal como ocorrido na primeira década do século XXI no Brasil, e discutir os possíveis limites que ele enfrenta. 


\subsection{Limitadores do processo de crescimento recente bra- sileiro}

Em entrevista para o livro "Desenvolvimento e Igualdade" (CORREAA; SIMIONI, 2010), Maria da Conceição Tavares relembra três eixos essenciais que devem ser considerados quando se analisa uma economia periférica: o desenvolvimento das forças produtivas, a inclusão social e o cenário internacional. Tratar de crescimento e distribuição de renda tendo em mente a importância da estrutura produtiva não somente é importante para entender como se dá a relação entre estas dimensões, mas é também essencial para entender quais limites os modelos de crescimento enfrentam e com quais restrições eles podem acabar se defrontando. Nesta seção iremos, então, discutir os três principais possíveis limitadores deste processo: a restrição externa, a inflação de serviços e a distribuição (ou concentração) da renda no topo.

\subsubsection{A restrição externa}

O primeiro possível limitador do processo de crescimento brasileiro, tal como ocorreu na primeira década do século XXI, é o desequilíbrio externo. Apesar de a precariedade da estrutura produtiva brasileira ter origem na liberalização do comércio internacional - iniciada no final dos anos 1980 e aprofundada nos anos 1990 -, ela foi acelerada nestes últimos anos (NASSIF; FEIJO; ARAÚJO, 2014). Como mencionado na seção 1.3, a sobrevalorização do real, juntamente com as lacunas já existentes na estrutura produtiva, poderia ter feito com que parte da dinâmica de consumo e investimento vazasse para fora do país.

A valorização do real possui um efeito duplo sobre a balança comercial: além de estimular as importações, também desestimula as exportações, uma vez que encarece os produtos nacionais fazendo com que a indústria doméstica perca participação no mercado internacional. As importações cresceram 113\% no acumulado entre 2006 e 2010, em termos reais, também fruto do efeito da elasticidade-renda dos produtos que foram importados. Santos et al. (2015) analisam a elasticidade-renda e a elasticidade-câmbio dos bens e serviços importados pelo Brasil e concluem que, dada a estrutura produtiva brasileira, a evolução das importações na última década também contou com um efeito indireto do aumento da renda familiar (LOUREIRO, 2018).

Nesse contexto de valorização do real e de distribuição de renda, em que, de um lado, estimula-se o consumo de serviços e a geração de empregos em setores de baixa produtividade e, de outro, leva-se à expansão das importações de bens tecnológicos sem promover o desenvolvimento interno de setores de mais alto valor agregado, os desequilíbrios no balanço de pagamentos são quase inevitáveis. Na Figura 4 fica claro o movimento de aumento mais acelerado das importações em relação às exportações, concomitantemente 
Figura 4 - Evolução das exportações (US\$), Importações (US\$) e Taxa de câmbio (R\$/US\$, eixo secundário)

Fonte: Banco Central do Brasil

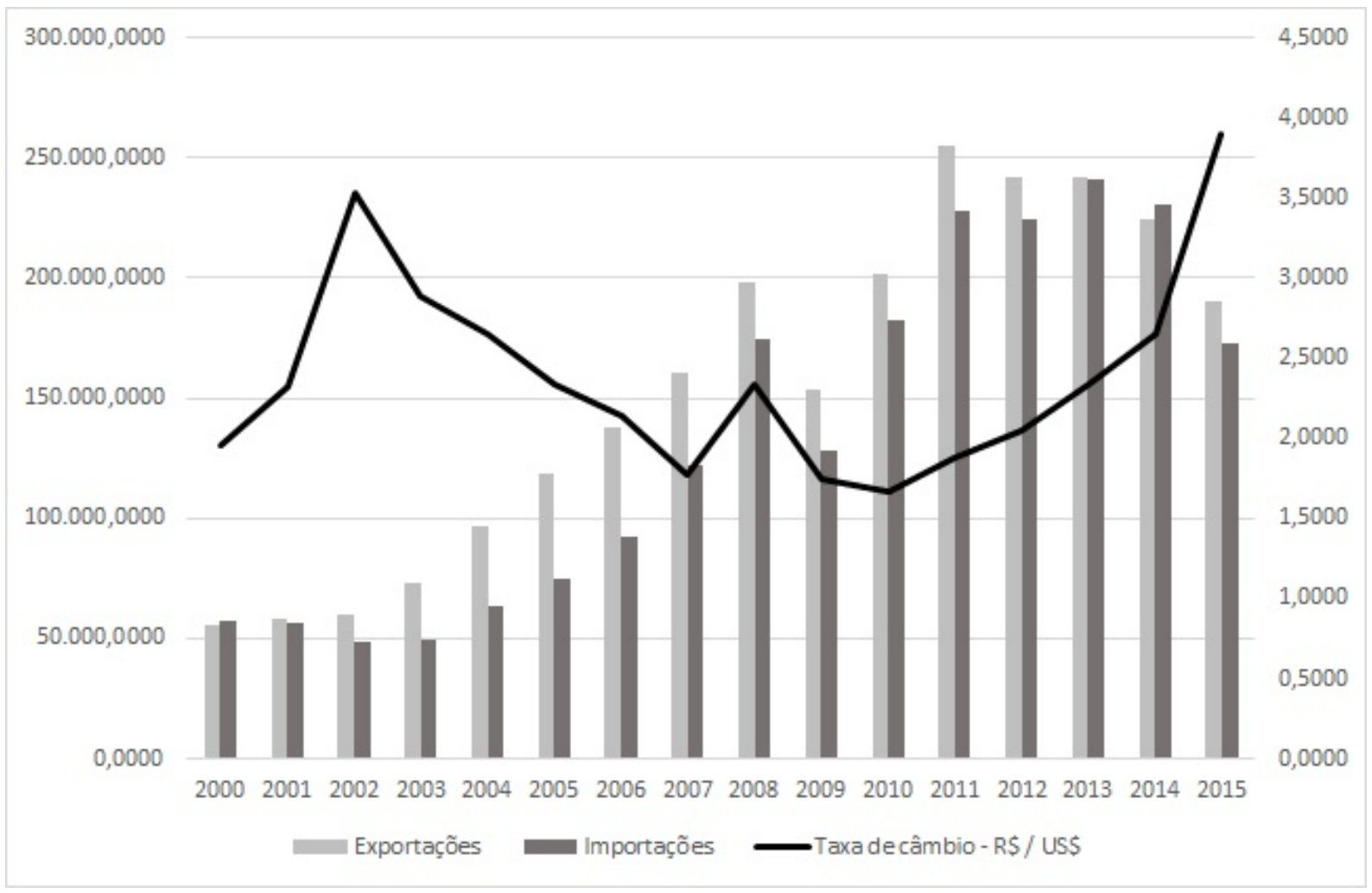

com a valorização do real, apesar de a balança comercial (de bens e serviços) ter sido deficitária somente em 2014, e em um patamar relativamente baixo.

Thirlwall (1979), partindo de um modelo em equilíbrio e assumindo a ausência de mudanças nos termos de troca reais e que as exportações são o único elemento autônomo da demanda, deriva uma taxa de crescimento do equilíbrio da balança de pagamentos (balance-of-payments equilibrium growth rate), também conhecida como Lei de Thirlwall. Thirlwall (1979) estabelece que a diferença entre a taxa de crescimento econômico de um país em particular e a taxa de crescimento econômico mundial depende da relação entre as elasticidades-renda da demanda por exportações e importações. Em outras palavras, o resultado formal de seu modelo é que a taxa de crescimento de um determinado país será igual à razão entre a taxa de crescimento das exportações e a elasticidade-renda da demanda por importações.

Differences in the income elasticities of demand for exports and imports reflect the non-price characteristics of goods (or the structure of production). The more favorable the non-price characteristics of goods, the higher their income elasticity is likely to be and the lower the income elasticity of demand for import substitutes (THIRLWALL, 1997, pag. 383). 
Capítulo 1. Estrutura produtiva, composição do emprego e desigualdade no Brasil: os anos 1960-73 e os 54 anos 2000-14

Ao estimar as elasticidades-renda das importações e exportações para o Brasil, Nassif, Feijo e Araújo (2014) mostram que a elasticidade-renda das exportações foi marginalmente reduzida entre os dois subperíodos analisados (o primeiro de 1980 a 1998 e o segundo de 1999 a $2010^{19}$ ), mas a elasticidade-renda das importações aumentou $70 \%$ (passando de 1.967 para 3.361). Desse modo, um país cuja estrutura produtiva é dependente da tecnologia estrangeira, como é o caso do Brasil, tenderia a ter um crescimento menos acelerado, uma vez que a restrição externa seria mais apertada.

Ainda que as importações e as despesas com serviços tenham crescido significativamente no Brasil no referente período, o cenário externo favorável contribuiu para o crescimento das exportações das commodities e para o aumento das receitas, aliviando as consequências econômicas da restrição do balanço de pagamentos. Contudo, esse processo contínuo de apreciação prejudica o desenvolvimento de novos setores industriais e impede uma maior diversificação da estrutura produtiva, além de gerar desequilíbrios comerciais, que poderiam tornar-se problemáticos no longo prazo (CARVALHO, 2018).

\subsubsection{A inflação de serviços}

Ao olhar para a trajetória dos índices de preço durante os últimos anos, o segundo limitador do modelo de crescimento brasileiro vem à tona. O processo de causação circular e cumulativa entre redução da desigualdade na base e aumento mais do que proporcional no emprego de setores menos produtivos, combinado com a valorização do salário mínimo, também afetou a estrutura de preços relativos da economia, de modo que o crescimento recente brasileiro contou com uma trajetória diferenciada entre os preços de bens comercializáveis e não-comercializáveis. Como pode ser observado na Figura 5, o índice de preços dos bens não-comercializáveis, que são majoritariamente serviços, cresceu mais rapidamente do que o índice para os bens comercializáveis, principalmente a partir de 2009. O índice de preços dos bens não-comercializáveis e o índice de preços para serviços possuem basicamente a mesma trajetória, o que nos permite, a partir de aqui, tratar desse fenômeno como "inflação de serviços".

Carvalho e Giovannetti (2016) levantam dois principais canais responsáveis por esse aumento diferenciado de preços: o canal de pressão de demanda e o canal de pressão de custos. A primeira hipótese está relacionada justamente com o processo de mudança no padrão de consumo da população, em decorrência na melhora da distribuição da renda, tal como descrito na seção 1.3. O aumento mais que proporcional do consumo de serviços e bens não-comercializáveis, como consequência do aumento da renda, cria uma pressão inflacionária nestes setores pelo lado da demanda. Como recordado anteriormente, a

19 Os autores definiram os subperíodos a partir de testes econométricos para quebras estruturais nas séries de importações e exportações. Foram realizados os testes de soma cumulativa (CUSUM), resíduos recursivos e testes de Chow. Os resultados demonstraram uma quebra estrutural na série de importações em 1999, mas nenhuma quebra na série de exportações. 
Figura 5 - Evolução do índice de preços (IPCA) dos bens comercializáveis, nãocomercializáveis e serviços $(2002.01=100)$

Fonte: IBGE

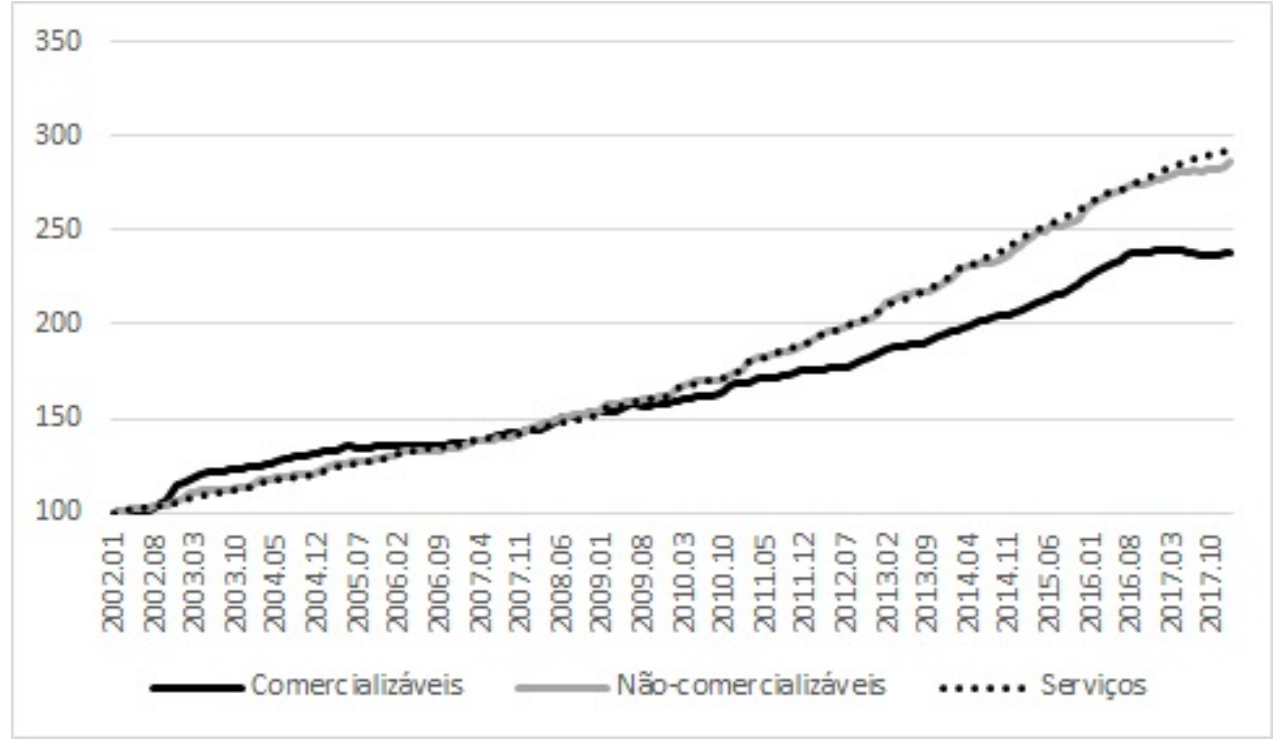

Lei de Engel, que postula que os padrões e a composição da cesta de consumo mudam conforme a renda, nos auxilia na compreensão deste fenômeno. À medida que a renda de um indivíduo aumenta, aumenta também a parcela do consumo destinada a serviços e bens manufaturados, dado que, caracteristicamente, estes bens têm uma elasticidade renda mais alta.

A explicação para a dinâmica do setor de serviços desenvolvida por Clark (1940) também se encaixa no referente contexto. Clark pioneiramente argumentou que os serviços são bens superiores, isto é, bens com elasticidade renda superior à unidade, de maneira que aumentos na renda de um indivíduo (ou de uma sociedade) geram aumentos mais do que proporcionais no consumo total de serviços. Ainda que alguns serviços possam ser comercializados internacionalmente - como serviços de gerenciamento e de tecnologia de informação (TI) - a maioria deles não enfrenta concorrência internacional. Além disso, no processo especifico ocorrido no Brasil neste começo dos anos 2000, o crescimento no consumo de serviços se deu especialmente nos serviços de baixa qualificação e trabalhointensivos, como setores de alimentação fora de casa e serviços pessoais (lavanderias, cabeleireiros, tratamentos de beleza, entre outros). Santos et al. (2016) decompõem o Índice de Preços ao Consumidor (INPC) para os serviços e identificam que, de fato, os setores que mais cresceram - serviços de alimentação, serviços pessoais, saúde e educação - foram os principais responsáveis pelo aumento do índice de preços.

A segunda hipótese para o crescimento mais acelerado dos preços dos serviços vem do lado dos custos. A partir de um arcabouço em que os preços são definidos a partir de uma regra de mark-up sobre o custo unitário do trabalho, combinada a um 
componente baseado nos preços do período anterior, conclui-se que a taxa de inflação é tanto maior, quanto maior é o conflito distributivo entre capitalistas e trabalhadores. Além disso, quanto mais rápido é o repasse para preços do custo com a mão-de-obra e menor a produtividade do trabalho, maior também é a taxa de inflação e mais acirrado será o conflito distributivo. Carvalho e Giovannetti (2016) ressaltam duas características do setor de serviços que deixam os canais para o aumento de preço mais prováveis do que no caso dos bens manufaturados: primeiro, os setores de serviços são mais intensivos em mão-deobra, tendo uma produtividade média menor; segundo, por serem majoritariamente não comercializáveis, esses setores não enfrentam concorrência estrangeira, podendo repassar mais livremente suas elevações de custo com a mão de obra para os preços. Adicionalmente, em linha com a formulação original de Baumol e Bowden (1965), custos e preços dos setores com ganhos de produtividade relativamente baixos - como é característico do setor de serviços - tendem a crescer proporcionalmente mais do que aqueles de setores com ganhos de produtividade maiores.

Nesse contexto, a valorização do salário real e o aumento da formalização no emprego de setores de mais baixa qualificação estariam exercendo uma pressão via custos nos preços dos bens não-comercializáveis. A partir de um modelo VAR de referência para a relação entre salários nominais e inflação de serviços entre 2003 e 2013, Carvalho e Giovannetti (2016) concluem que as pressões de demanda foram menos relevantes para explicar o processo de crescimento de preços observado, sendo o repasse dos maiores custos de mão de obra o fator mais relevante para tal. O aumento nos preços do setor de serviços, além de afetar o índice de preços geral da economia, podendo causar instabilidade e influenciar o governo a realizar políticas contracionistas para controlar os preços, também afeta o crescimento pelo lado da demanda das famílias. A inflação, se não acompanhada de aumento na renda em igual proporção, simboliza uma perda de poder de consumo das famílias, atuando como um freio na demanda. Isso, além de impactar o crescimento, pode afetar a própria distribuição de renda, uma vez que este processo de causação circular e cumulativa seria interrompido.

Apesar desta dinâmica diferenciada do setor de serviços e do consequente aumento de preços, a inflação esteve dentro da meta durante o período mais expressivo de crescimento brasileiro:

Ainda que se tenha observado o crescimento dos preços nos setores de serviços e outros bens não comercializáveis, a inflação se manteve dentro da meta durante os anos de 2006 a 2010. Os motivos para isso se relacionam com o cenário externo favorável e a atração do capital internacional, que fizeram com que o real ficasse apreciado, inibindo o aumento de preços dos produtos comercializáveis devido ao receio de perda de competitividade internacional e barateando as 
importações. Contudo, como visto na seção anterior, a sustentação de um crescimento com câmbio valorizado enfrenta uma maior restrição da balança de pagamentos (BRENCK; CARVALHO, 2019).

O fenômeno da inflação de serviços será também explorado no modelo teórico, no Capítulo 2.2 desta dissertação. No referente capítulo, desenvolvemos um modelo de dois setores - comercializáveis e não-comercializáveis - no qual, partindo de um arcabouço Kaleckiano e baseado nos argumentos apresentados nesta seção, a formação de preços difere entre os setores, resultando, em um dos casos de instabilidade, num episódio que chamamos de inflação de serviços, devido ao crescimento explosivo dos preços no setor de bens não-comercializáveis.

\subsubsection{Distribuição da renda no topo}

O terceiro limite do processo de crescimento brasileiro nos anos 2000 é a própria maneira através da qual a distribuição de renda foi feita. Como mencionado na introdução deste capítulo, ao utilizar dados de declarações de Imposto de Renda obtidas na Receita Federal do Brasil, Medeiros, Souza e Castro (2015) mostram que a queda da desigualdade neste período foi menor do que a estimada com os dados referentes às pesquisas domiciliares, uma vez que estas tendem a subestimar a renda no topo da distribuição. A redução da desigualdade se restringiu à base da distribuição (com a diminuição da disparidade salarial), e a parcela de renda apropriada pelos mais ricos se manteve estável: entre 2006 e 2015, a fração da renda apropriada pelo $1 \%$ mais rico no Brasil é um pouco menos de $25 \%$ da renda total, e o $0.1 \%$ mais rico detém $11 \%$. Esta redução da desigualdade na base da distribuição, junto com um aumento no topo da distribuição, resultaria num processo de squeezed middle ("miolo espremido"), como chamado por Morgan (2017). A partir de dados do World Inequality Database (WID), reportados na Tabela 7, é possível ilustrar este movimento: enquanto os $50 \%$ mais pobres aumentaram sua participação na renda total (antes da tributação) de $12.6 \%$ para $13.9 \%$ entre 2001 e 2015, o $1 \%$ mais rico subiram a sua parcela de $26.2 \%$ para $28.3 \%$ e os $40 \%$ intermediários reduziram sua participação na renda de 33.1 para $30.6 \%$.

"Redistribuir a renda a partir do processo chamado por Morgan de 'squeezed middle' por si só apresenta uma limitação econômica: as margens para expandir tal modelo de distribuição são bem menores do que se a transferência de renda fosse feita do topo para a base da distribuição. " (BRENCK; CARVALHO, 2019). Além de reduzir as margens para garantir a continuidade deste processo de distribuição de renda, a sensação de perda da "classe média" exacerbou conflitos distributivos, que também configuram um limitador político para a manutenção do crescimento. O aumento do preços de serviços, mencionado na seção anterior, cria uma sensação de desconforto nesta classe, que passa a ter que pagar 
Capítulo 1. Estrutura produtiva, composição do emprego e desigualdade no Brasil: os anos 1960-73 e os 58 anos 2000-14

Tabela 7 - Evolução da participação na renda de percentis selecionados para o Brasil, antes da tributação (\%)

Fonte: World Inequality Database (WID)

\begin{tabular}{ccccc} 
Ano & $50 \%$ mais pobre & $40 \%$ intermediário & top 10\% & top 1\% \\
\hline 2001 & 12,6 & 33,1 & 54,3 & 26,2 \\
2002 & 12,3 & 32,0 & 55,7 & 27,4 \\
2003 & 12,5 & 32,2 & 55,3 & 27,2 \\
2004 & 12,9 & 32,3 & 54,8 & 27,3 \\
2005 & 13,0 & 31,9 & 55,1 & 27,9 \\
2006 & 13,0 & 31,5 & 55,5 & 28,2 \\
2007 & 13,2 & 31,9 & 54,9 & 28,3 \\
2008 & 13,2 & 30,6 & 56,2 & 29,3 \\
2009 & 13,6 & 31,5 & 55,0 & 27,4 \\
2010 & 13,8 & 30,9 & 55,2 & 28,2 \\
2011 & 13,6 & 29,9 & 56,5 & 29,6 \\
2012 & 14,0 & 30,6 & 55,4 & 27,7 \\
2013 & 14,1 & 31,0 & 54,9 & 27,2 \\
2014 & 14,3 & 31,1 & 54,6 & 27,5 \\
2015 & 13,9 & 30,6 & 55,6 & 28,3
\end{tabular}

mais caro pelos serviços antes facilmente acessíveis, concomitantemente a um crescimento menos acelerado da sua renda.

Como argumentam Martins e Rugitsky (2018), o processo de crescimento recente brasileiro descrito neste capítulo representou uma mudança estrutural no Brasil, com o aumento significativo do nível de emprego que tem como consequência o esmagamento dos lucros e o aumento da parcela de salários na renda. Em sua conclusão, os autores declaram:

A strategic question remains for those interested in the prospects of a less unequal Brazilian society. Countercyclical macroeconomic policies are certainly crucial in order to overcome the weak character of the expansions, which keep unemployment at high levels and hinders workers ability to shift the distribution in their favor. [...] The struggle for equality will require, it seems, more than foreign bonanzas, countercyclical policies, and long expansions. It will require a deeper transformation of society, shifting the power balance in favor of the great majority, so that, in the future, when class conflicts result once more in cyclical profit squeezes, democracy can be preserved and social regression can be avoided (MARTINS; RUGITSKY, 2018, p. 24).

Ou seja, uma distribuição mais equitativa dos ganhos salariais também poderia contribuir para evitar que os conflitos distributivos crescentes levassem à coalizão entre 
assalariados que perderam participação na renda e a classe capitalista, que teve seus lucros espremidos.

\subsection{Conclusão}

No presente capítulo objetivou-se analisar mais a fundo dois períodos de crescimento brasileiro cuja relação entre a estrutura produtiva, a composição do emprego e a desigualdade estão relacionados: os anos 1960-70 e a primeira década do século XXI. Além das várias diferenças sociais, organizacionais e políticas que caracterizam estes dois períodos, a dinâmica da estrutura produtiva e da desigualdade também se mostram antagônicas. Enquanto nos anos 60, mais especificamente no milagre econômico, a estrutura produtiva evoluía no sentido de aumentar a participação da produção de bens de luxo e com maior sofisticação tecnológica e a distribuição da renda favorecia os mais ricos, nos primeiros anos do século XXI a estrutura produtiva e a desigualdade se moveram em sentido oposto, aumentando a participação relativa de serviços e setores trabalho-intensivos e reduzindo a desigualdade (pelo menos na base da distribuição). Estudar estes dois períodos sob a perspectiva estruturalista de Tavares e Serra (1972) nos mostra a importância de se levar em consideração os canais pelo qual a estrutura produtiva e as demais variáveis econômicas (distribuição de renda, balanço de pagamentos e crescimento, por exemplo) estão relacionadas. Os resultados para a desigualdade e para as mudanças na composição do produto devem ser analisados historicamente em conjunto com o contexto político-institucional, de modo que tanto as medidas tomadas pelos governos em relação ao aumento de salários e ao incentivo a formalização do trabalho, por exemplo, quanto a própria dinâmica interna da economia são responsáveis pelos resultados obtidos.

Apesar das dificuldades com os dados dos anos 60, as alterações na composição setorial do emprego e na desigualdade salarial interna aos setores nos permitem raciocinar sobre a dupla dimensão da desigualdade, fruto de uma combinação das políticas de repressão aos trabalhadores e da mudança na estrutura produtiva e na qualificação da força de trabalho. Os dados atestam a redução no emprego dos setores agrícolas e extrativos frente a um aumento nos setores urbanos, principalmente na indústria de transformação, que, por si só, representa um canal relevante para a desigualdade. Além disso, o aumento da desigualdade interna nos setores reforça o ponto de Wells (1974) de que a distribuição intrasetorial foi muito expressiva para esta redistribuição a favor dos mais ricos, de modo que a qualificação de parte da mão de obra e a migração da população para as áreas urbanas não explicam completamente os resultados para a desigualdade. O trabalho feito nesta seção nos permitiu relacionar, apesar das divergências teóricas, os trabalhos de Langoni (1972) e Tavares e Serra (1972).

A importância da política governamental, em especial de valorização do salário 
mínimo e de transferência de renda, também aparece na análise da relação entre a estrutura produtiva e a melhora na distribuição de renda e no período recente. A dinâmica da demanda agregada e da estrutura produtiva teria resultado em uma redução da desigualdade e um aumento relativo dos setores de baixa produtividade e intensivos em mao de obra menos qualificada, que são majoritariamente serviços e construção civil, em relação aos demais. Os dados do CAGED, de 2004 a 2019, confirmam a tendência de aumento mais do que proporcional no emprego dos setores resultantes da nossa seleção assim como o aumento no salário inicial destes setores em comparação aos demais, corroborando com a hipótese formalizada por Rugitsky (2017).

Além de nos permitir melhor compreender os períodos de crescimento econômico brasileiro, raciocinar sob a ótica estruturalista nos permitiu discutir três dos possíveis limites que um modelo de crescimento tal como este pode enfrentar - a restrição do balanço de pagamentos, a inflação de serviços e e os conflitos distributivos sobre a renda.

Concluir, a partir dos dados apresentados neste capítulo, que o mecanismo de causação circular e cumulativa de fato ocorreu nos parece precipitado, mas nos dá motivações suficientes para um aprofundamento dessa discussão nos capítulos subsequentes desta dissertação. A construção do modelo no Capítulo 2 nos auxilia no melhor entendimento de alguns dos mecanismos teóricos pelos quais a distribuição de renda altera a estrutura produtiva da economia, além de fornecer insights sobre possíveis resultados da interação entre essas variáveis em uma perspectiva dinâmica. Adicionalmente, o Capítulo 3 utiliza de exercícios econométricos que nos permitem inferir relações de causalidade entre a composição do emprego (ou a estrutura produtiva) e a desigualdade salarial (ou da renda) ao longo da história recente brasileira. 


\section{Modelo Teórico}

\subsection{Introdução}

A literatura pós-keynesiana sempre atribuiu um papel importante para a distribuição de renda no que tange aos seus efeitos sobre a demanda agregada. Em particular, ao considerar que a propensão a poupar pode diferir entre indivíduos, a distribuição de renda altera o consumo das famílias e o produto. O estudo do papel da desigualdade, no entanto, pode ser conduzido em várias dimensões: desigualdade de renda ou riqueza entre países, regiões, gêneros, classes ou trabalhadores.

No arcabouço Kaleckiano, a dimensão mais comum da desigualdade analisada é a desigualdade na distribuição funcional da renda, em que se presume que a taxa de poupança da renda salarial seja menor do que a taxa de poupança da renda do lucro. Além disso, o investimento dos capitalistas pode ser estimulado por uma taxa ou parcela maior dos lucros. Se o aumento da participação nos lucros aumenta o investimento de modo que mais do que compensa a redução do consumo, afetando positivamente o grau de utilização da capacidade, o regime de demanda é dito profit-led e, portanto, seu regime de crescimento também será profit-led, já que a taxa de acumulação de capital responde positivamente ao aumento na utilização da capacidade. Por outro lado, se a participação dos lucros na renda reduz o grau de utilização da capacidade, ou seja, a sensibilidade do consumo à participação nos lucros é maior do que a do investimento, o regime de demanda do país é chamado de wage-led. O regime de crescimento, neste caso, pode ser wage- ou profit-led, dependendo da forma da função de investimento e dos parâmetros da economia.

Outras dimensões da desigualdade, no entanto, estão sendo incorporadas nos modelos Kaleckianos. Carvalho e Rezai (2016) introduzem a distribuição pessoal da renda ao modelo e concluem que a redução da desigualdade salarial tem um impacto positivo sobre a demanda, mesmo quando o regime de demanda do país é profit-led. Além disso, "changes in the saving rate [due to changes in personal distribution of income] also reduces the multiplier and capacity utilization with more subtle effects on investment and saving and, overall, ambiguous effects on the demand regime", isto é, "higher inequality pushes the demand regime towards being more 'profit-ledness.'" (CARVALHO; REZAI, 2016, p. 497-8).

Taylor e Bacha (1976), Taylor (1989), Dutt (1990), Dutt (1997), Park (1997), Fujita (2015) e Nishi (2018) incorporam a heterogeneidade setorial no modelo básico, onde a desigualdade é incorporada nos níveis de produtividade dos setores. Taylor e Bacha (1976) também incorporam desigualdades salariais entre trabalhadores qualificados e não qualificados. Taylor (1989) mostra que mudanças na demanda por produtos intensivos 
em mão-de-obra afetam a distribuição funcional da renda tanto a curto quanto a longo prazo, e que as diferenças na distribuição entre salários e lucros dependem da diferença de produtividade entre os dois setores, enquanto o crescimento depende da resposta da função de investimento de cada setor em relação à taxa de lucro. Taylor e Bacha (1976) concluem que a participação de bens de "luxo" (bens que usam mão de obra mais qualificada para ser produzida) na estrutura produtiva tende a aumentar, reduzindo a parcela dos salários ao longo do tempo.

Essas contribuições foram especialmente significativas para entender economias ou eventos específicos. Como argumentado por Rugitsky (2017), embora as economias desenvolvidas tendam a ser mais homogêneas em termos de produtividade setorial, ainda são necessários modelos multissetoriais para entender as economias em desenvolvimento. Deixar de lado a suposição de commodity única também pode lançar luz sobre os padrões de consumo e comportamento que são relevantes para os resultados de desigualdade, como mostrado por Taylor e Bacha (1976).

Para entender melhor como a composição do emprego (e do produto) e a desigualdade salarial estão relacionadas, construímos um modelo Kaleckiano de dois setores, no qual analisamos alguns resultados de estática comparativa e as dinâmicas de diferentes processos de ajuste. Embora a recente experiência brasileira tenha nos inspirado, a construção de um modelo teórico para a representação da realidade nos obriga a simplificar diversos de seus aspectos. A próxima seção apresenta o modelo teórico desenvolvido e algumas estáticas comparativas. A terceira seção analisa a estabilidade do equilíbrio encontrado levando em consideração os diferentes processos de ajuste da composição do emprego e dos salários relativos. Finalmente, um resumo e as principais conclusões são apresentadas na última seção.

\subsection{Estrutura do Modelo}

Assumimos uma economia aberta com dois setores simplificados da seguinte maneira: o setor NT produz bens não-comercializados internacionalmente com produtividade (relacionada tanto ao trabalho e ao capital) mais baixa, e o setor T produz bens comercializáveis internacionalmente ${ }^{1}$. Se comparado com o outro setor - de comercializáveis (T) - o setor NT é intensivo em trabalho, representando setores como os de serviços e construção. O segundo setor (T) produz bens comercializáveis que podem ser usados tanto para investimento como para consumo, e são pensados como produtos essenciais como comida, energia e roupas. Mudanças tecnológicas não serão consideradas de modo que as produtividades permanecem constantes. O consumo de bens sofisticados e tecnológicos

1 A partir de aqui trataremos dos produtos (não-)comercializáveis internacionalmente somente como (não-)comercializáveis a fim de evitar o carregamento do texto. 
será suprido pelas importações, dado que consideramos um período do modelo no qual é impossível que ocorram mudanças estruturais significativas na economia. Dito de outra maneira, a estrutura produtiva nacional não é capaz de suprir tal demanda por bens manufaturados. Relembrando a experiência brasileira, essa especificação representa o que Bielschowsky (2012) denominou de "consumo em massa no Brasil, produção em massa na China", isto é, um aumento na renda nacional aumenta o consumo de bens sofisticados, porém, uma vez que a produção destes bens é feita majoritariamente no exterior, ocorre um "vazamento de demanda" representado pelo aumento das importações².

Tal como em Taylor $(1989)^{3}$, o capital é pré-determinado em cada setor, permitindoos ter diferentes taxas de lucro e diferentes níveis de capacidade utilizada. A função de produção setorial é do tipo Leontieff com coeficientes fixos, existe excesso de capacidade em ambos setores e a mão de obra cresce na mesma velocidade que o estoque de capital, de modo que trabalho e capital não impõem restrições de oferta. Cada setor contrata apenas um tipo de trabalhador e paga salários diferentes de modo que a desigualdade salarial entre os setores é incorporada. A produção determina o nível de emprego em cada setor:

$$
L_{j}=Y_{j} a_{j}
$$

em que $a_{j}=\frac{L_{j}}{Y_{j}}$ é a razão trabalho-produto de cada setor $j=N T, T$.

O emprego total da economia é $L=L_{T}+L_{N T}$ e a composição do emprego será representada por $l=L_{T} / L_{N T}$. Apesar de não considerarmos uma situação de pleno emprego, mudanças na composição do emprego afetam cada setor de maneira diferente. Porque a produtividade no setor comercializável é mais alta, quanto maior a razão $l$, mais difícil é para os capitalistas do setor de comercializáveis encontrar trabalhadores qualificados. Em outras palavras, o "exército de reserva" dos dois setores não é proporcionalmente igual. Trabalhadores do setor de comercializáveis podem ser contratados no setor de não-comercializáveis, porém com um salário menor, enquanto os trabalhadores do setor de não-comercializáveis não podem facilmente mover para o setor de comercializáveis sem algum tipo de treinamento. Essa suposição não afeta os resultados dessa seção, mas terá um papel importante na análise de estabilidade.

Preços são definidos por uma regra de mark-up, mas possuem uma dinâmica

2 Numa extensão futura do modelo podemos flexibilizar esta suposição e modificar a especificação para que que apenas uma fração destes produtos são importados, medido por algum parâmetro ou delimitando algum valor fixo, baseado nos dados.

3 Taylor (1989) assume que o estoque de capital em ambos os setores é pré-determinado, não se deprecia e não existe mobilidade de capital entre os setores, de modo que as taxas de lucro não necessariamente serão iguais no curto prazo. O estado estacionário, contudo, é definido como o momento em que as taxas de crescimento do estoque de capital de cada setor são iguais, de modo que a taxa de lucro e a razão entre o produto dos dois setores se equalizam. No modelo aqui desenvolvido, o capital será pré-determinado mesmo quando o ajuste de quantidades e preços ocorre. 
diferente entre os setores: o setor NT possui preços flexíveis e um mark-up exógeno enquanto o setor $\mathrm{T}$ possui preços definidos internacionalmente e um mark-up flexível. O pressuposto de que o setor de comercializáveis enfrenta uma competição externa e tem baixo conteúdo tecnológico, o que justifica a exclusão do papel da diferenciação de produtos, sustenta essa suposição, de modo que é o mercado internacional que determina os preços deste setor. No setor T, é o mark-up, então, que tem que se ajustar a qualquer variação de custos, enquanto o setor NT pode ajustar seus preços sem alterar seu mark-up, que é definido exogenamente e mantido fixo. Para simplificar, a taxa de câmbio nominal será considerada fixa e igual a um.

$$
P_{j}=\left(1+\tau_{j}\right) W_{j} a_{j}
$$

Em que $\tau_{j}$ é o mark-up do setor $j=N T, T-\bar{\tau}_{N T}$ fixo. Por causa do modo em que os setores foram caracterizados, $a_{N T}>a_{T}$ e $W_{N T}<W_{T}$, onde $W_{j}$ é o salário nominal. A desigualdade salarial será medida pelo parâmetro $\omega=\left(W_{T} / W_{N T}\right)>1$. Por simplificação, normalizamos $a_{N T}$ na unidade, de modo que $a_{T}=a<1$.

A função de investimento é a mesma em ambos os setores e é do tipo Kalecki-Steindl (mas em termos do nível do produto, ao invés de normalizada pelo estoque de capital). O investimento depende, então, do produto setorial nominal $\left(P_{j} Y_{j}\right)$, dos lucros setoriais $\left(\Pi_{j}\right)$, para $j=N T, T$, e de um termo autônomo $\left(\frac{g_{0}}{2}\right)$ que representa o espírito animal dos investidores ou a expectativa de crescimento das vendas.

$$
I_{j}=\frac{g_{0}}{2}+g_{\pi} \Pi_{j}+g_{y} P_{j} Y_{j}
$$

Duas classes são consideradas (trabalhadores e capitalistas) em cada setor, de modo que temos quatro grupos de renda: (i) trabalhadores contratados pelo setor NT, (ii) trabalhadores contratados pelo setor T, (iii) capitalistas do setor NT e (iv) capitalistas do setor T. Como usualmente assumido nos modelos Kaleckianos, trabalhadores não poupam e capitalistas poupam uma fração $1<s_{\pi}<0$ dos lucros. Os quatro grupos de renda consomem uma quantia $0<A<W_{N T}$ do bem comercializável (do setor T), representando um consumo de subsistência, que cresce a uma taxa exógena $\eta$. A renda restante será, então, usada para consumo no setor de não-comercializáveis ou para consumo de bens importados. Tal suposição é sustentada pela Lei de Engel: apesar de não termos as elasticidades-renda explícitas no modelo, consideramos que a renda restante, após o consumo de subsistência, será dispendida em serviços e "bens de luxo", ou seja, bens sofisticados e tecnológicos, cujas elasticidade-renda são mais altas.

A propensão a importar da renda restante, após o consumo de subsistência A, $0<m<1$, é igual para todos os grupos de renda e as importações totais também contam com um termo exógeno $m_{0}$. As exportações são consideradas exógenas $\left(X=x_{0}>0\right)$ uma 
vez que elas dependem da renda no resto do mundo, e crescem à mesma taxa $\eta$ do consumo autônomo $\mathrm{A}^{4}$. Em nosso modelo, o efeito da taxa de câmbio na balança comercial tem um efeito negligenciável. Estamos cientes do grau de simplificação que essa suposição traz, mas incluir seu impacto poderia comprometer alguns aspectos do modelo que consideramos mais relevantes para responder nosso interesse primário: entender a relação entre a composição do emprego e os salários relativos. Além disso, definimos os setores de tal maneira que os quatro grupos de renda importam bens tecnológicos justamente devido à deficiência da produção interna, de modo que a substituição via preços inexiste. Essa suposição pode ser sustentada empiricamente por Santos et al. (2015), que mostra que a elasticidade-câmbio relativa dos bens importados pelo Brasil é muito baixa dentro do período analisado (19962013), especialmente quando comparada à elasticidade-renda das importações, concluindo que o principal fator para o aumento das importações na última década foi o ganho de renda das famílias.

Cada grupo de renda e sua alocação estão resumidas na Tabela 8 abaixo, onde utilizamos a equação (2.1) para substituir o nível do emprego, uma vez que as produtividades são constantes. $P_{T} C_{T}$ e $P_{N T} C_{N T}$ são o consumo nos setores T e NT, respectivamente.

Tabela 8 - Alocações da Renda por grupo

\begin{tabular}{l|lccll} 
& \multicolumn{1}{c}{ Renda } & Poupança & $P_{T} C_{T}$ & \multicolumn{1}{c}{$P_{N T} C_{N T}$} & \multicolumn{1}{c}{ Importações } \\
\hline (i) & $W_{N T} Y_{N T}$ & 0 & $\mathrm{~A}$ & $n\left(W_{N T} Y_{N T}-A\right)$ & $m\left(W_{N T} Y_{N T}-A\right)$ \\
\hline (ii) & $W_{T} a Y_{T}$ & 0 & $\mathrm{~A}$ & $n\left(W_{T} a Y_{T}-A\right)$ & $m\left(W_{T} a Y_{T}-A\right)$ \\
\hline (iii) & \multirow{2}{*}{$\tau_{N T} W_{N T} Y_{N T}$} & $s_{\pi}\left(\tau_{N T} W_{N T} Y_{N T}\right)$ & $\mathrm{A}$ & $\begin{array}{l}n\left(\tau_{N T} W_{N T} Y_{N T}-\right. \\
\left.A-s_{\pi} \tau_{N T} W_{N T} Y_{N T}\right)\end{array}$ & $\begin{array}{l}m\left(\tau_{N T} W_{N T} Y_{N T}-A\right. \\
\left.-s_{N T} W_{N T} Y_{N T}\right)\end{array}$ \\
\hline (iv) & \multirow{2}{*}{$\tau_{T} W_{T} a Y_{T}$} & \multirow{2}{*}{$s_{\pi}\left(\tau_{T} W_{T} a Y_{T}\right)$} & $\mathrm{A}$ & $\begin{array}{l}n\left(\tau_{T} W_{T} a Y_{T}-\right. \\
\left.A-s_{\pi} \tau_{T} W_{T} a Y_{T}\right)\end{array}$ & $\begin{array}{l}m\left(\tau_{T} W_{T} a Y_{T}-A\right. \\
\left.-s_{\pi} \tau_{T} W_{T} a Y_{T}\right)\end{array}$
\end{tabular}

em que $n=1-m$ é a fração da renda gasta no consumo de produtos nacionais. $\mathrm{O}$ produto nominal total da economia é

$$
P_{N T} Y_{N T}+P_{T} Y_{T}=P_{N T} C_{N T}+P_{T} C_{T}+I_{N T}+I_{T}+X-M
$$

A taxa de acumulação (ou de crescimento) em cada setor será medido pela função de investimento normalizada pelo estoque de capital. Porque a produtividade é constante, a taxa de acumulação de capital é igual à taxa de crescimento do produto. Assim, nos referiremos a $g_{j}$ como a taxa de crescimento.

$$
g_{j}=\frac{I_{j}}{K_{j}}=\frac{1}{K_{j}}\left[\frac{g_{0}}{2}+g_{\pi} \Pi_{j}+g_{y} P_{j} Y_{j}\right], \quad j=N T, T
$$

4 Para que seja possível solucionar o modelo analiticamente, tratamos as taxas de crescimento dos componentes autônomos da demanda - as exportações e o consumo autônomo no setor comercializável, neste caso - como iguais e exógenas. 
Resolvemos o modelo para o nível do produto em cada setor. É importante ressaltar que, devido à hipótese de produtividades constantes, mudanças no produto também podem ser representadas por mudanças no emprego. Substituindo a equação (2.3) na determinação do produto do setor de comercializáveis e usando as funções de consumo resumidas na Tabela 8, temos o seguinte sistema:

$$
\begin{gathered}
{\left[\begin{array}{cc}
P_{N T}\left(s_{\pi}+m-s_{\pi} m\right)-(1-m) s_{\pi} W_{N T} & -(1-m)\left[W_{T} a s_{\pi}+\left(1-s_{\pi}\right) P_{T}\right. \\
-\left[P_{N T}\left(g_{y}+g_{\pi}\right)-g_{\pi} W_{N T}\right] & P_{T}\left(1-g_{y}-g_{\pi}\right)+g_{\pi} W_{T} a
\end{array}\right]\left[\begin{array}{c}
Y_{N T} \\
Y_{T}
\end{array}\right]=} \\
=\left[\begin{array}{c}
-(1-m) 4 A \\
4 A+g_{0}+\left(x_{0}-m_{0}\right)
\end{array}\right]
\end{gathered}
$$

Resolvendo o sistema pela regra de Cramer, temos as seguintes soluções:

$$
\begin{gathered}
Y_{N T}^{*}=\frac{\Delta_{N T}}{\Delta} \\
Y_{T}^{*}=\frac{\Delta_{T}}{\Delta}
\end{gathered}
$$

em que $\Delta$ representa o determinante da matriz de coeficientes e $\Delta_{j}$ é o determinante da matriz obtida ao substituirmos uma coluna pelo vetor do lado direito da equação:

$$
\begin{array}{r}
\Delta=P_{N T} P_{T}\left(s_{\pi}+m-s_{\pi} m-g_{y}-g_{\pi}\right) \\
-P_{N T} W_{T} a\left[m g_{\pi}-s_{\pi} g_{y}(1-m)\right]+ \\
+W_{N T} P_{T}(1-m)\left[s_{\pi}\left(g_{y}-1\right)+g_{\pi}\right]
\end{array}
$$

$\Delta_{N T}=(1-m)\left\{P_{T}\left[4 A\left(g_{\pi}+g_{y}-s_{\pi}\right)+\left(1-s_{\pi}\right)\left(g_{o}+x_{0}-m_{0}\right)\right]+W_{T} a\left[4 A\left(s_{\pi}-g_{\pi}\right)+s_{\pi}\left(g_{0}+x_{0}-m_{0}\right)\right]\right\}$

$$
\begin{array}{r}
\Delta_{T}=P_{N T}\left[\left(4 A+g_{0}+x_{0}-m_{0}\right)\left(s_{\pi}+m-s_{\pi} m\right)-4 A(1-m)\left(g_{\pi}+g_{y}\right)\right]- \\
-W_{N T}(1-m)\left[4 A\left(s_{\pi}-g_{\pi}\right)+s_{\pi}\left(g_{o}+x_{0}-m_{0}\right)\right]
\end{array}
$$

\subsubsection{Exercícios de estática comparativa}

Ao analisar o resultado para os produtos de cada setor, algumas estáticas comparativas já podem ser feitas. Aumentar o componente autônomo do investimento $\left(g_{0}\right)$ ou o saldo da balança de pagamentos $\left(x_{0}-m_{0}\right)$ aumentará o produto total da economia devido 
ao aumento na demanda agregada em ambos os setores. Para o setor de comercializáveis, existe um primeiro efeito direto uma vez que estes são elementos que definem o próprio produto deste setor. O efeito no setor de não-comercializáveis origina-se de um transbordamento de demanda pelo aumento na renda (e no emprego) no setor de comercializáveis, que faz com que o consumo no setor de não-comercializáveis aumente. O aumento na renda aumenta também o investimento e, assim, ocorre o efeito multiplicador. Este efeito será tanto menor quanto maior for a propensão a poupar dos lucros e a propensão a importar da renda devido aos vazamentos de demanda que eles representam. Um efeito menos óbvio é o de mudanças no consumo de subsistência $(A)$. Para o setor não-comercializáveis este efeito é ambíguo:

$$
\frac{\partial Y_{N T}}{\partial A}=\frac{4(1-m)}{\Delta}\left[P_{T} g_{y}-\left(s_{\pi}-g_{\pi}\right)\left(P_{T}-W_{T} a\right)\right]
$$

Para que os lucros sejam positivos, $P_{T}>W_{T}$ a, de modo que este efeito será negativo se $s_{\pi}>g_{\pi}$ e $P_{T} g_{y}<\left(s_{\pi}-g_{\pi}\right)\left(P_{T}-W_{T} a\right)$. A condição Keynesiana de estabilidade nos dá que $s_{\pi}>g_{\pi}$, mas a ambiguidade permanece. O motivo para tal ambiguidade também está relacionado com o efeito multiplicador: mesmo que um aumento no consumo autônomo $(A)$ represente uma redução da renda disponível, que é em parte gasta no setor de não-comercializáveis, esse aumento pode representar um incremento no produto do setor de comercializáveis e, assim, produzir um efeito no sentido contrário do primeiro. O efeito no setor comercializável também é ambíguo devida à possibilidade do efeito negativo no setor de não-comercializáveis, que pode reduzir o investimento.

$$
\frac{\partial Y_{T}}{\partial A}=\frac{4}{\Delta}\left\{(1-m)\left[\left(s_{\pi}-g_{\pi}\right)\left(P_{N T}-W_{N T}\right)-g_{y} P_{N T}\right]+m P_{N T}\right\}
$$

A condição de estabilidade no mercado de bens (condição Keynesiana) é encontrada ao analisarmos as condições de ajustamento do produto para eliminar excessos de demanda (BLECKER, 2011). O produto total da economia é:

$$
\begin{aligned}
& P Y=(1-m)\left\{W_{N T} Y_{N T}+W_{T} a Y_{T}+\left(1-s_{\pi}\right)\left[\left(P_{N T}-W_{N T}\right) Y_{N T}+\left(P_{T}-W_{T} a\right) Y_{T}\right]\right\}+ \\
& +4 A m+g_{0} g_{\pi}\left[\left(P_{N T}-W_{N T}\right) Y_{N T}+\left(P_{T}-W_{T} a\right) Y_{T}\right]+g_{y}\left[P_{N T} Y_{N T}+P_{T} Y_{T}\right]+x_{0}-m_{0}
\end{aligned}
$$

A condição Keynesiana de estabilidade é representada, então, pelas seguintes relações: $\frac{\partial(L D-L E)}{\partial Y_{j}}<0$, para $j=N T, T$, onde LD e LE representam, respectivamente, o "lado direito" e o "lado esquerdo" da equação (2.8). Nos deparamos, então, com as duas 
desigualdades abaixo:

$$
\begin{gathered}
\frac{\partial(L D-L E)}{\partial Y_{N T}}=-\left[\left(P_{N T}-W_{N T}\right)\left(s_{\pi}-s_{\pi} m-g_{\pi}\right)+P_{N T}\left(m-g_{y}\right)\right]<0 \\
\frac{\partial(L D-L E)}{\partial Y_{T}}=-\left[\left(P_{T}-W_{T} a\right)\left(s_{\pi}-s_{\pi} m-g_{\pi}\right)+P_{T}\left(m-g_{y}\right)\right]<0
\end{gathered}
$$

Duas condições suficientes para que a condição Keynesiana de estabilidade seja satisfeita são: $s_{\pi}>g_{\pi}+s_{\pi} m$ e $m>g_{y}$.

A formulação de um modelo de dois setores que incorpore a desigualdade salarial entre eles nos permite analisar como mudanças nesta desigualdade afetam o produto dos setores individualmente, assim como o efeito no produto tota da economia e na composição do produto entre os setores. A diferenciação dos setores, principalmente quanto ao consumo e inserção no mercado externo, proporciona a possibilidade de análise de diferentes canais pelos quais estas mudanças podem afetar os componentes da demanda agregada. Mudanças na desigualdade de renda, que podem ser representadas por mudanças em $W_{N T}$, se $W_{T}$ se mantém constante, impacta os dois setores, mas de maneira diferente, já que os padrões de consumo são diferentes e o investimento é feito todo no setor T. Para ver como os produtos de cada setor são afetados basta, então, calcular a derivada com relação a $W_{N T}$.

$$
\frac{\partial Y_{N T}}{\partial W_{N T}}=-\Delta_{N T} \frac{P_{T}(1-m)\left[s_{\pi}\left(g_{y}-1\right)+g_{\pi}\right]}{\Delta^{2}}
$$

O sinal do impacto de $W_{N T}$ em $Y_{N T}$ é, aparentemente, ambíguo e depende se $s_{\pi}\left(g_{y}-1\right)+g_{\pi}$ é positivo ou negativo. Dado que $1>g_{y}>0$, o primeiro termo é negativo. A derivada será positiva se $s_{\pi}>g_{\pi}+s_{\pi} g_{y}{ }^{5}$. Incrementos no salário do setor não-comercializável aumentam o consumo dos trabalhadores, uma vez que eles não poupam e toda a renda adicional é gasta em consumo, seja no setor não-comercializável seja nas importações. O efeito final dependerá, contudo, do que acontece com os lucros em ambos os setores, já que afetam o consumo dos capitalistas. Se os lucros no setor não-comercializável caem, não só o consumo oriundo dos lucros é reduzido, mas também é seguido de uma pressão para baixo no investimento. Esta baixa no investimento pode, por consequência, reduzir os lucros no setor de comercializáveis e, assim, reduzir mais ainda o consumo no setor NT. Estes sinais contrários fazem com que o efeito total neste setor seja ambíguo. A condição Keynesiana de estabilidade, por sua vez, nos garante duas condições suficientes

5 Note que a ambiguidade deste resultado se dá devido ao tipo Kalecki-Steindl da função de investimento. Se considerássemos a função de investimento "canônica", como definido por Lavoie (2014), isto é, se $g_{\pi}=0$, a derivada é com certeza positiva, já que tanto $s_{\pi}$ quando $g_{y}$ são inferiores do que a unidade. 
que garantem o resultado positivo da derivada. Uma vez que estabelece que $s_{\pi}>g_{\pi}+s_{\pi} m$ e $m>g_{y}$, segue-se que $s_{\pi}>g_{\pi}+s_{\pi} g_{y}$. O impacto no crescimento, por outro lado, pode ser negativo mesmo se as condições suficientes para garantir que a condição Keynesiana de estabilidade seja válida forem assumidas. Esta ambiguidade é resultado da possível queda dos lucros, uma vez que a função investimento é do tipo Kalecki-Steindl, isto é, leva em consideração a taxa de lucro - que é representada pela massa de lucros no nosso modelo, já que resolvemos o produto para o nível e não normalizado pelo estoque de capital - nas decisões de investimento.

$$
\frac{\partial g_{N T}}{\partial W_{N T}}=\frac{1}{K_{N T}}\left\{-g_{\pi} Y_{N T}+\left[g_{\pi}\left(P_{N T}-W_{N T}\right)+g_{y} P_{N T}\right] \frac{\partial Y_{N T}}{\partial W_{N T}}\right\}
$$

Para o setor comercializável, entretanto, o sinal de $\frac{\partial Y_{T}}{\partial W_{N T}}$ é ambíguo, mesmo se a condição Keynesiana for válida:

$$
\frac{\partial Y_{T}}{\partial W_{N T}}=-\frac{(1-m)\left\{4 A\left(s_{\pi}-g_{\pi}\right)+s_{\pi}\left(g_{0}+x_{0}-m_{0}\right)+Y_{T} P_{T}\left[\left(g_{y}-1\right) s_{\pi}+g_{\pi}\right]\right\}}{\Delta}
$$

O efeito será positivo se $Y_{T} P_{T}\left[\left(1-g_{y}\right) s_{\pi}-g_{\pi}\right]>4 A\left(s_{\pi}-g_{\pi}\right)+s_{\pi}\left(g_{0}+x_{0}-m_{0}\right)$. Ambos os lados da desigualdade são positivos, se as condições suficientes para a estabilidade Keynesiana forem atingidas ${ }^{6}$. O resultado dependerá, então, das magnitudes dos coeficientes. Porque o consumo no setor de bens comercializáveis é fixo, seu produto muda relativamente ao investimento. Apesar de um aumento nos salários do setor não-comercializável significar maiores custos para este setor, os lucros podem aumentar, uma vez que o produto aumenta, como visto anteriormente, de modo que o impacto final no investimento dependerá dos parâmetros $s_{\pi}, g_{\pi}$ e $g_{y}$. Dado que a produtividade é constante, o custo total no setor comercializável muda com mudanças no emprego, se $W_{T}$ é considerado fixo, mudando, então, na mesma direção do produto. O impacto final no investimento dependerá, então, dos dois parâmetros da função investimento $\left(g_{y}\right.$ e $\left.g_{\pi}\right)$. Se os capitalistas poupam grande parte dos lucros, isto é, se $s_{\pi}$ é alto, o efeito é mais provável de ser negativo, uma vez que os lucros não serão convertidos em consumo e o multiplicador será menor. O crescimento do setor de comercializáveis, nesse caso, apresenta a mesma direção do produto ${ }^{7}$.

É interessante notar que esta ambiguidade também aparece quando analisamos o efeito no produto (ou no emprego) total da economia, isto é, $Y=Y_{T}+Y_{N T}$. Ainda que o

6 O lado esquerdo da desigualdade é exatamente o resultado de $\frac{\partial Y_{N T}}{\partial W_{N T}}$, multiplicado por $Y_{T}$. O lado direito será positivo porque todos os termos dentro do colchete são positivos, uma vez que a condição Keynesiana garante que $g_{\pi}<s_{\pi}$.

7 Aumentar o salário do setor não-comercializável não afeta diretamente os lucros no setor comercializável, isto é, $\frac{\partial g_{T}}{\partial W_{N T}}=\frac{1}{K_{T}} g_{y} P_{T} \frac{\partial Y_{T}}{\partial W_{N T}}$, de modo que o efeito no crescimento é o mesmo do que no produto, multiplicado por $g_{y}$. 
efeito no setor de bens não-comercializáveis seja positivo, o efeito total pode ser negativo, dependendo do tamanho e magnitude do efeito no setor de bens comercializáveis:

$\frac{\partial Y}{\partial W_{N T}}=\frac{\partial Y_{N T}}{\partial W_{N T}}+\frac{\partial Y_{T}}{\partial W_{N T}}=-(1-m) \frac{P_{T}}{\Delta}\left\{Y\left[s_{\pi}\left(g_{y}-1\right)+g_{\pi}\right]+4 A\left(s_{\pi}-g_{\pi}\right)+s_{\pi}\left(g_{0}+x_{0}-m_{0}\right)\right\}$

Este efeito será positivo se $Y\left[s_{\pi}\left(1-g_{y}\right)+g_{\pi}\right]>4 A\left(s_{\pi}-g_{\pi}\right)+s_{\pi}\left(g_{0}+x_{0}-m_{0}\right)$. Se assumirmos a validade da condição Keynesiana de estabilidade, a possibilidade de o efeito total ser positivo é maior do que a possibilidade de ele ser negativo, visto que a condição Keynesiana garante que o efeito no setor de bens não-comercializáveis é positivo de modo que, para que o efeito total seja negativo, o efeito no setor de comercializáveis tem que ser também negativo e maior do que o primeiro. Ainda assim, a ambiguidade não pode ser descartada.

Ao construir um modelo de dois setores, torna-se relevante averiguar não só o que acontece com cada setor separadamente quando ocorrem choques nos parâmetros e em variáveis exógenas, mas também o que acontece com a composição do produto (ou emprego) entre os setores. Uma medida natural para essa análise é a razão entre os produtos dos dois setores $\frac{Y_{T}}{Y_{N T}}=\frac{\Delta_{T}}{\Delta_{N T}}$. Um aumento no salário nominal no setor não-comercializável (ou uma redução da desigualdade salarial) tem um efeito, a priori, ambíguo nesta razão:

$$
\begin{gathered}
\frac{\partial \frac{\Delta_{T}}{\Delta_{N T}}}{\partial W_{N T}}=\frac{\frac{\partial \Delta_{T}}{\partial W_{N T}} \Delta_{N T}-\frac{\partial \Delta_{N T}}{\partial W_{N T}} \Delta_{T}}{\Delta_{N T}^{2}} \\
\frac{\partial \frac{\Delta_{T}}{\Delta_{N T}}}{\partial W_{N T}}=\frac{-(1-m)\left[4 A\left(s_{\pi}-g_{\pi}\right)+s_{\pi}\left(g_{0}+x_{0}-m_{0}\right)\right]}{\Delta_{N T}}
\end{gathered}
$$

O efeito será negativo se $4 A\left(g_{\pi}-s_{\pi}\right)<s_{\pi}\left(g_{0}+x_{0}-m_{0}\right)$. A condição de estabilidade Keynesiana mais uma vez garante uma condição suficiente para que a desigualdade acima seja satisfeita, uma vez que $g_{\pi}<s_{\pi}$. Se o efeito da redução da disparidade salarial reduzir o produto no setor de bens comercializáveis, este resultado surge como uma conclusão trivial. Entretanto, mesmo se o aumento do salário no setor não-comercializável produzir um aumento no produto do setor comercializável, este incremento será proporcionalmente menor do que aquele no produto do setor não-comercializável, alterando a composição do produto na direção deste último. É válido relembrar que a composição do emprego se move na mesma direção, uma vez que a produtividade é constante. Relacionando este efeito com os dados observados no Capítulo 1, a redução da desigualdade salarial, oriunda de um aumento nos salários mais baixos da economia, isto é, dos setores de baixa produtividade e intensivos em mao de obra menos qualificada, seria seguido de um aumento mais do que proporcional no emprego destes setores em relação aos demais. Este parece ter sido o caso do Brasil nos anos 2000-2014, em que a participação dos setores selecionados na seção 
1.3 aumentou relativamente mais do que os outros, concomitantemente com a redução da desigualdade salarial.

Outra importante dimensão analítica a ser considerada é o efeito da redução na desigualdade salarial sobre a propensão média a importar. Souto (2015), ao estimar as elasticidades-renda das importações no Brasil, usando dados da POF 2002-03 e 2008-09, mostra que a elasticidade-renda das importações aumentou no período, especialmente para famílias mais pobres, que foram as mais beneficiadas pelos programas sociais adotados, fazendo com que a indústria brasileira sofresse com o vazamento de demanda. A propensão média a importar da renda é:

$$
\bar{m}=m\left[1-\frac{4 A+s_{\pi}\left(\tau_{T} W_{T} a Y_{T}+\tau_{N T} W_{N T} Y_{N T}\right)}{P Y}\right]
$$

Para sabermos qual o efeito da redução da desigualdade salarial nesta propensão em nosso modelo, realizamos um último exercício de estática comparativa:

$$
\begin{aligned}
\frac{\partial \bar{m}}{\partial W_{N T}}=\frac{m}{P Y} & \left\{-s_{\pi}\left(\tau_{T} W_{T} a \frac{\partial Y_{T}}{\partial W_{N T}}+\tau_{N T} Y_{N T}+\tau_{N T} W_{N T} \frac{\partial Y_{N T}}{\partial W_{N T}}\right)\right\}+ \\
& +\frac{m}{(P Y)^{2}}\left\{\frac{\partial Y}{\partial W_{N T}}\left[4 A+s_{\pi}\left(\tau_{T} W_{T} a Y_{T}+\tau_{N T} W_{N T} Y_{N T}\right)\right]\right\}
\end{aligned}
$$

O efeito é ambíguo e as razões para tal são exatamente as ambiguidades do impacto da redução da desigualdade no setor de bens comercializáveis e, consequentemente, no produto total da economia $(P Y)$. É importante relembrar que aumentar salários no setor NT aumenta o produto neste mesmo setor, quando a condição Keynesiana de estabilidade é considerada, de modo que o efeito sobre a propensão média a importar dependerá da magnitude deste aumento. Se o aumento nos salários do setor não-comercializável reduz o produto no setor comercializável, mas aumenta o produto total da economia, o efeito na propensão média a importar tenderá a ser positivo. Mesmo que a redução na renda gerada pelo setor comercializável, devido à redução no seu produto, impacte negativamente a propensão média a importar, o aumento mais do que proporcional do setor não-comercializável, garante o aumento do produto total da economia e compensa este efeito adverso vindo do setor comercializável nas importações.

Se o efeito do aumento do salário do setor não-comercializável no produto do setor comercializável é positivo, o efeito na propensão média a importar pode também ser positivo, porém será menor do que no caso anterior. A razão para isso, provavelmente, é o efeito do denominador: o aumento em $P Y$ será maior do que no caso anterior, fazendo com que o aumento em $\bar{m}$ seja menor. Quanto menor a propensão a poupar, maiores as chances de esta derivada ser positiva, por duas razões: quanto menor a propensão a poupar maior o efeito multiplicador e maior o aumento do produto total da economia; e quanto 
menor a propensão a poupar, maior é a renda gasta em consumo pelos capitalistas, que é em parte importada. Assim como em Blecker (2011), ainda que a redução da desigualdade salarial possa ser expansionista no nível do produto, ela pode também gerar um efeito adverso na balança de pagamentos, fazendo com fiquemos com um trade-off ao reduzir a desigualdade em um modelo de economia aberta.

Por fim, se o efeito no setor comercializável é negativo, assim como no produto total da economia, o efeito na propensão média a importar também será negativo, uma vez que a renda será reduzida de maneira a deprimir as importações.

Um resumo dos resultados de estática comparativa está relatado na Tabela 9, abaixo.

Tabela 9 - Resultados da estática comparativa

\begin{tabular}{|c|c|c|c|}
\hline Variável de choque & Variável resposta & Sinal & Condição \\
\hline$g_{0 N T}+g_{0 T}$ & $Y_{N T}, Y_{T}$ & + & \\
\hline$A$ & $Y_{N T}, Y_{T}$ & $+/-$ & \\
\hline \multirow{5}{*}{$W_{N T}$} & $Y_{N T}$ & + & se estabilidade Keynesiana \\
\hline & $Y_{T}$ & $+/-$ & \\
\hline & $Y=Y_{N T}+Y_{T}$ & $+/-$ & \\
\hline & $Y_{T} / Y_{N T}$ & - & se estabilidade Keynesiana \\
\hline & $\bar{m}$ & $+1-$ & \\
\hline
\end{tabular}

\subsubsection{Análise de estabilidade}

Na seção anterior analisamos como mudanças exógenas ("choques") nos componentes do produto e na desigualdade salarial afetam o produto (ou emprego) em ambos os setores desta economia. Agora, contudo, é preciso discutir a estabilidade dos processos de ajustamento da desigualdade salarial e da composição do emprego ao longo do tempo. A produtividade ainda será considerada constante ao longo do tempo de modo que mudanças no produto são equivalentes a mudanças no emprego. Dito isso, mudanças na composição do emprego $l=L_{T} / L_{N T}$ podem ser representadas pela diferença de crescimento entre os dois setores. A equação (2.13) formaliza essa relação, em que as variáveis estão expressas em taxa de crescimento, isto é, $\widehat{X}=\frac{\partial X}{\partial t} \frac{1}{X}$. O parâmetro $\beta>0$ mede o quão rápido ocorrem mudanças no mercado de trabalho, que podem variar de acordo com a burocracia para contratações e demissões e com a rigidez do mercado de trabalho, por exemplo. Quanto maior o $\beta$, mais fácil é para os capitalistas contratarem novos trabalhadores, assim como demitir no caso de situações adversas.

$$
\widehat{l}=\beta\left(g_{T}-g_{N T}\right)
$$


Substituindo a equação de investimento (2.3) e usando a constância das produtividades (2.1), a expressão (2.13) torna-se:

$$
\widehat{l}=\beta\left\{g_{\pi}\left[\left(P_{T} / a-W_{T}\right) L_{T}-\left(P_{N T}-W_{N T}\right) L_{N T}\right]+g_{y}\left(P_{T} L_{T} / a-L_{N T} P_{N T}\right)\right\}
$$

Como desenvolvido na seção 2.2.1, a composição do emprego responde a mudanças na desigualdade salarial, que será representada pelo parâmetro $\theta$ :

$$
\frac{\partial \widehat{l}}{\partial \omega}=\beta \theta \quad \frac{>}{<} 0
$$

Onde $\theta$ será negativo (positivo) se $\frac{\partial \frac{\Delta_{T}}{\Delta_{N T}}}{\partial W_{N T}}$ é positivo (negativo), ou seja, se a redução na desigualdade salarial muda a composição do emprego de maneira a reduzir (aumentar) o tamanho relativo do setor não-comercializável ${ }^{8}$.

Mudanças na composição do emprego $l$ também afetam $\widehat{l}^{9}$ :

$$
\begin{array}{r}
\frac{\partial \widehat{l}}{\partial l}=\beta\left\{g_{\pi}\left[\left(P_{T} / a-W_{T}\right) L_{N T}+\left(P_{N T}-W_{N T}\right) l^{-2} L_{T}\right]+g_{y}\left(P_{T} L_{N T} / a+l^{-2} L_{T} P_{N T}\right)\right\} \\
=\beta \mu \quad>0
\end{array}
$$

onde $\mu=g_{\pi}\left[\left(P_{T} / a-W_{T}\right) L_{N T}+\left(P_{N T}-W_{N T}\right) l^{-2} L_{T}\right]+g_{y}\left(P_{T} L_{N T} / a+l^{-2} L_{T} P_{N T}\right)>0$

Também esperamos que os preços e o salário nominal se ajustem a variações na composição do emprego, no poder de barganha dos trabalhadores e capitalistas e nos preços internacionais. Os salários nominais crescem de acordo com as equações (2.16) e (2.17), abaixo. Os parâmetros $\sigma_{j}>0$, para $j=N T, T$, representam o poder de barganha dos trabalhadores em cada setor - que pode diferir entre eles. Uma maior formalização no setor de serviços, por exemplo, afeta o poder de barganha dos trabalhadores no setor de bens não-comercializáveis, mas não altera significativamente o poder de barganha no outro setor $(\mathrm{T})$.

$$
\widehat{W}_{N T}=\sigma_{N T} l^{-1}
$$

8 Na seção 2.2.1 vimos que a condição de estabilidade Keynesiana é uma condição suficiente para que $\theta$ seja positivo, mas não é necessária.

9 Para essa derivada dividimos e multiplicamos o nível de emprego em um setor pelo de outro a fim de explicitar a razão $l$ na expressão, isto é, $\widehat{l}=\beta\left\{g_{\pi}\left[\left(P_{T} / a-W_{T}\right) l L_{N T}-\left(P_{N T}-W_{N T}\right) l^{-1} L_{T}\right]+\right.$ $\left.g_{y}\left(P_{T} l L_{N T} / a-l^{-1} L_{T} P_{N T}\right)\right\}$. 


$$
\widehat{W}_{T}=\sigma_{T} l-\phi_{\pi}\left[W_{T}-W_{T}^{\pi}(l)\right]
$$

De acordo com a abordagem dos 'conflicting claims' pós-Keynesiana, como denominado por Blecker (2011) e originalmente postulado por Weintraub (1958) e Rowthorn (1977), o crescimento dos salários nominais no setor de bens comercializáveis enfrentará a resistência dos capitalistas, uma vez que eles não conseguem transferir aumentos de custos para os preços, como no setor não-comercializável. Como definimos na seção 2.2, o setor de bens comercializáveis tem seus preços definidos internacionalmente e é o mark-up que precisa se ajustar a qualquer mudança de custo, fazendo com que os capitalistas sejam, então, mais resistentes a aumentos de salários. Assim como em Blecker (2011) ${ }^{10}$, apesar de os trabalhadores serem mais preocupados com o seu salário real, o conflito com os capitalistas usualmente se dá sobre os salários nominais. Nesse sentido, os capitalistas do setor de bens comercializáveis definem um salário nominal desejado, representado por $W_{T}^{\pi}(l)$, que é o salário nominal compatível com o seu mark-up desejado, ou com a taxa de lucro desejada. Se o salário nominal neste setor $\left(W_{T}\right)$ é maior do que o desejado, os salários no setor comercializável crescerão a uma taxa menor, uma vez que $\left(W_{T}-W_{T}^{\pi}\right)>0$. Por outro lado, se o salário nominal vigente é menor do que o desejado pelos capitalistas, isto é, se $\left(W_{T}-W_{T}^{\pi}\right)<0$, a taxa de crescimento dos salários no setor comercializável é maior, já que os capitalistas estarão menos resistentes a perder margem de lucro. O quão forte este efeito é depende do parâmetro $\phi_{\pi}(>0)$.

O salário nominal desejado pelos capitalistas do setor de bens comercializáveis, por sua vez, depende inversamente da composição do emprego da economia (a razão $l$ ), ou seja:

$$
\frac{\partial W_{T}^{\pi}(l)}{\partial l}=\gamma<0
$$

em que $\gamma>0$ representa o poder de barganha dos capitalistas sobre a taxa de lucro desejada, compatível com o salário nominal desejado por eles. A razão para tal formulação está relacionada com a suposição, feita na definição dos setores, de que o exército de reserva para cada setor é diferente. Ao assumirmos que os trabalhadores do setor T necessitam de treinamento ou habilidade especial, mudanças na composição do emprego terão um impacto mais substancial neste setor. Quanto mais trabalhadores são incorporados no setor T, maiores são os custos de contratar novos trabalhadores para o setor, uma vez que trabalhadores menos qualificados demandam um custo adicional de treinamento para o

10 Em Blecker (2011), trabalhadores e capitalistas barganham pelo wage share ao definirem a parcela de salários na renda desejada, que determinam a trajetória dos preços e salários. Aqui, por sua vez, consideramos que somente os salários do setor comercializável são afetados pelo conflito, devido à característica do setor de participar da competição internacional, e são somente os capitalistas que definem o seu salário nominal desejado (que é aquele compatível ao mark-up desejado), ainda que este seja também influenciado pelo poder de barganha dos trabalhadores, como definido em (2.18). 
contratante. Ou seja, os capitalistas exigirão um salário menor para compensar este custo adicional e evitar a redução do mark-up.

Combinando as equações (2.17) e (2.16), a equação (2.19) mostra como a desigualdade salarial evolui:

$$
\widehat{\omega}=\widehat{W}_{T}-\widehat{W}_{N T}=\sigma_{T} l-\phi_{\pi}\left[W_{T}-W_{T}^{\pi}(l)\right]-\sigma_{N T} l^{-1}
$$

O crescimento da desigualdade salarial responde de maneira ambígua à composição do emprego da economia e negativamente ao nível de desigualdade ${ }^{11}$ :

$$
\begin{gathered}
\frac{\partial \widehat{\omega}}{\partial l}=\sigma_{T}+\sigma_{N T} l^{-2}-\phi_{\pi} \gamma \\
\frac{\partial \widehat{\omega}}{\partial \omega}=-\phi_{\pi} W_{N T}
\end{gathered}
$$

Inspirada no processo de ajuste dual, como desenvolvido por Bruno (1999) e Bhaduri (2008), a análise de estabilidade pode ser separada em dois processos diferentes e, dependendo da maneira como eles interagem, a estabilidade final do sistema pode variar. Temos, então, um sistema de equações diferenciais referentes a estes ajustes:

$$
\begin{aligned}
\widehat{l} & =f(l, \omega) \\
\widehat{\omega} & =h(l, \omega)
\end{aligned}
$$

Para avaliar a estabilidade precisamos olhar para a matriz Jacobiana relacionada às equações (2.13) e (2.19):

$$
J=\left[\begin{array}{ll}
\frac{\partial \hat{l}}{\partial l} & \frac{\partial \hat{l}}{\partial \omega} \\
\frac{\partial \hat{\omega}}{\partial \omega} & \frac{\partial \widehat{\omega}}{\partial l}
\end{array}\right]=\left[\begin{array}{cc}
\beta \mu & \beta \theta \\
\sigma_{T}+\sigma_{N T} l^{-2}-\phi_{\pi} \gamma & -\phi_{\pi} W_{N T}
\end{array}\right]
$$

em que

$$
\begin{gathered}
\operatorname{Det}(J)=\mu \phi_{\pi} W_{N T}-\beta \theta\left(\sigma_{T}+\sigma_{N T} l^{-2}-\gamma \phi_{\pi}\right) \\
\operatorname{Tr}(J)=\beta \mu-\phi_{\pi} W_{N T}
\end{gathered}
$$

Os resultados de estabilidade dependem do sinal do determinante e do traço da matriz J. Estes resultados nos levam a seis possibilidades, resumidas na Tabela (10).

11 Aqui também dvidimos e multiplicamos a equação (2.19) por $W_{N T}$ a fim de explicitar o parâmetro $\omega$. 
Tabela 10 - Análise de estabilidade

\begin{tabular}{|c|c|c|c|}
\hline $\operatorname{Det}(\mathrm{J})$ & \multicolumn{3}{|c|}{$-\beta\left[\mu \phi_{\pi} W_{N T}+\theta\left(\sigma_{T}+\sigma_{N T} l^{-2}-\gamma \phi_{\pi}\right)\right]$} \\
\hline $\operatorname{Tr}(\mathrm{J})$ & \multicolumn{3}{|l|}{$\left.\beta \mu-\phi_{\pi} W_{N T}\right)$} \\
\hline \multicolumn{3}{|c|}{ Condições } & Estabilidade geral \\
\hline \multirow{3}{*}{$\theta>0$} & $\operatorname{Det}(J)>0$ & $\begin{array}{c}\operatorname{Tr}(\mathrm{J})<0 \\
\beta \mu<\phi_{\pi} W_{N T}\end{array}$ & (A) Estável \\
\hline & $\sigma_{T}+\sigma_{N T} l^{-2}<\gamma \phi_{\pi}$ & $\begin{array}{c}\operatorname{Tr}(\mathrm{J})>0 \\
\beta \mu>\phi_{\pi} W_{N T}\end{array}$ & (B) Instável \\
\hline & $\begin{array}{c}\operatorname{Det}(\mathrm{J})<0 \\
\sigma_{T}+\sigma_{N T} l^{-2}>\gamma \phi_{\pi}\end{array}$ & & (C) Instável \\
\hline \multirow{3}{*}{$\theta<0$} & $\operatorname{Det}(\mathrm{J})>0$ & $\begin{array}{c}\operatorname{Tr}(\mathrm{J})<0 \\
\beta \mu<\phi_{\pi} W_{N T}\end{array}$ & (D) Estável \\
\hline & $\sigma_{T}+\sigma_{N T} l^{-2}<\gamma \phi_{\pi}$ & $\begin{array}{c}\operatorname{Tr}(\mathrm{J})>0 \\
\beta \mu>\phi_{\pi} W_{N T}\end{array}$ & (E) Instável \\
\hline & $\begin{array}{c}\operatorname{Det}(\mathrm{J})<0 \\
\sigma_{T}+\sigma_{N T} l^{-2}<\gamma \phi_{\pi}\end{array}$ & & (F) Instável \\
\hline
\end{tabular}

Para cada sinal de $\theta$, temos uma situação de estabilidade e duas de instabilidade, dependendo do sinal de $\sigma_{T}+\sigma_{N T} l^{-2}-\gamma \phi_{\pi}$ e no sinal do traço $\left(\beta \mu-\phi_{\pi} W_{N T}\right)$. Como vimos na seção 2.2.1, a condição de estabilidade Keynesiana é uma condição suficiente para que $\theta$ seja positivo. Para melhor compreender estes resultados é interessante olhar primeiramente para os casos de instabilidade.

Porque o mark-up no setor não-comercializável é exógeno e constante, o preço e o salário nominal evoluem da mesma maneira $\left(\widehat{P}_{N T}=\widehat{W}_{N T}\right)$. O caso em que $\theta$ é positivo representa a situação em que o aumento no salário do setor de bens não-comercializáveis aumenta a participação relativa do produto (ou emprego) deste mesmo setor na economia. A instabilidade, neste caso, está relacionada com a presença de duas forças operando no mesmo sentido: o aumento no salário do setor NT cria uma pressão de custos e, ao mesmo tempo, uma pressão de demanda ( $\theta$ positivo), fazendo com que os preços cresçam de maneira explosiva.

Como explorado brevemente no Capítulo 1.4 desta dissertação, esta instabilidade pode ser relacionada com o fenômeno de inflação de serviços no Brasil. Relembrando o trabalho de Carvalho e Giovannetti (2016), existem dois prováveis canais que atuam mais fortemente em setores cuja produtividade média é menor: um canal de pressão de custos e um de pressão de demanda. Baumol e Bowden (1965) também argumentam que custos e preços dos setores com ganhos de produtividade relativamente baixos - como é característico do setor de serviços - tendem a crescer proporcionalmente mais do que aqueles de setores com ganhos de produtividade maiores. Para que se alcance uma situação estável, nesse caso, é necessário, então, ter um fraco poder de barganha dos trabalhadores 
para evitar que os salários cresçam muito rapidamente, reduzindo a pressão nos custos. Além disso, um ajustamento lento no emprego, ou seja, um $\beta$ baixo, também ajuda a estabilizar a economia, uma vez que ajuda a condição (A), do sinal negativo do traço, a ser satisfeita, uma vez que a pressão pelo lado da demanda ocorrerá de maneira mais lenta.

Quando $\theta$ é negativo, por outro lado, a redução da desigualdade salarial aumenta a participação do setor de comercializáveis em relação ao setor de não-comercializáveis. A última situação de instabilidade (F) é exatamente o caso em que os trabalhadores tem fraco poder de barganha. Por conta disso, os capitalistas do setor de bens comercializáveis poderão aumentar o lucro desejado deles, representado pela redução do salário nominal deste setor, possivelmente reduzindo ainda mais a desigualdade salarial e criando um espiral no sentido de aumentar a participação do setor de comercializáveis na economia. Tal processo poderia eventualmente atingir alguma limitação, como a disponibilidade de mão-de-obra. Se o poder de barganha dos trabalhadores é forte o suficiente de maneira que eles podem evitar o baixo crescimento (ou até queda) dos salários no setor de bens comercializáveis, como os capitalistas desejariam, a pressão sobre a composição do emprego seria reduzida e, então, a economia poderia atingir uma trajetória estável. Novamente, neste caso, para que o traço seja negativo, é importante que o parâmetro $\beta$ seja pequeno, ou seja, que mudanças no emprego ocorram lentamente.

O que é importante de notar é que, dependendo do sinal de $\theta$, as implicações para a política econômica variam consideravelmente. Nas primeiras situações, em que $\theta$ é positivo, a estabilidade requer que o poder de barganha dos trabalhadores seja baixo. Quando $\theta$ é negativo, por outro lado, é preciso que os trabalhadores tenham um poder de barganha mais forte para estabilizar a economia. A conclusão comum às duas situações é que $\beta$ tem que ser baixo, ou seja, um mercado de trabalho mais rígido que faça com que contratações e demissões ocorram mais lentamente ajuda a economia a se estabilizar. Dito de outra maneira, uma maior formalização do trabalho que exija mais burocracias ao contratante tanto para demissões quanto para admissões, por exemplo, exerce uma força estabilizadora nesta economia. No primeiro caso, contudo, é provável que este parâmetro tenha que ser menor do que no segundo caso, uma vez que a estabilidade total requer que $\phi_{\pi}$ seja grande o suficiente para que o poder de barganha dos capitalistas supere o dos trabalhadores.

\subsection{Conclusão}

O objetivo deste capítulo foi contribuir para a literatura pós-keynesiana, estendendo o modelo kaleckiano ao incorporar duas outras dimensões da desigualdade: a heterogeneidade setorial e a desigualdade salarial. Essas heterogeneidades são essenciais para a compreensão da recente trajetória econômica brasileira e de outros países da América do Sul, pois esclarecem muitas relações internas da dinâmica econômica em países cuja 
estrutura produtiva é precária e altamente heterogênea. Além disso, alguns dos resultados da análise das relações entre a composição do emprego e a desigualdade salarial, como a inflação de serviços, só fazem sentido em um arcabouço multissetorial.

Por meio de exercícios de estática comparativa, demonstrou-se que a redução da desigualdade salarial, representada por um aumento nos salários mais baixos do setor não-comercializável, na nomenclatura do modelo aqui desenvolvido, altera a composição do produto (e emprego) na direção deste mesmo setor, se considerarmos que a condição de estabilidade Keynesiana é válida. Dentro do contexto da teoria econômica, poderíamos explicar que esse movimento de acordo com a lei de Engel, que argumenta que à medida que aumenta a renda de um indivíduo, aumenta a participação de serviços e bens manufaturados de alta tecnologia consumidos por ele, uma vez que esses bens possuem caracteristicamente alta elasticidade-renda. No nosso caso, o consumo de bens manufaturados é importado, uma vez que a estrutura produtiva nacional é incapaz de fornecê-los, de modo que quanto maior a propensão a importar sobre a renda, menor o efeito multiplicador da redução da desigualdade salarial. A propensão média a importar, por sua vez, responderá à redução da desigualdade salarial de forma ambígua, dependendo do impacto global sobre o produto total da economia e sobre o produto do setor comercializável. Se a diminuição da desigualdade salarial aumenta o produto total da economia, o efeito pode ser positivo ou negativo, dependendo do parâmetro $s_{\pi}$, ou seja, a propensão a poupar dos capitalistas devido ao efeito multiplicador -, e das magnitudes do aumento (ou diminuição) no produto dos dois setores (e, consequentemente, do produto total). Se o produto total responde negativamente ao aumento dos salários no setor não-comercializável, a propensão média a importar também responderá negativamente.

Levando em consideração as dinâmicas de ajustamento de preços e os conflitos sobre os salários nominais, diferentes condições de estabilidade aparecem, a depender da temporalidade dos ajustes de preços e quantidades. Em consequência, cada caso resulta em diferentes implicações para políticas públicas. Primeiramente, a condição Keynesiana de estabilidade é uma condição suficiente para que a redução da desigualdade salarial gere um aumento mais do que proporcional no produto do setor não-comercializável, em relação ao setor comercializável, mas o sistema pode ser globalmente estável ou instável. Chamamos a situação de instabilidade de "inflação de serviços", uma vez que está relacionada à trajetória explosiva dos preços (e salários) no setor de bens não-comercializáveis. A presença de duas forças operando no mesmo sentido, a pressão de custos e a pressão de demanda, explicam esta instabilidade. Para estabilizar o sistema nesta situação é preciso que o poder de barganha dos trabalhadores seja baixo para frear o crescimento dos salários, assim como uma baixa velocidade de ajuste do emprego auxilia a redução da pressão de demanda. A estabilização nesse caso poderia ser obtida por meio de políticas de repressão salarial e flexibilização do mercado de trabalho, por exemplo. 
O segundo caso analisado é o que $\theta$ é negativo, ou seja, em que a redução da desigualdade salarial aumenta a participação relativa do setor de bens comercializáveis na economia. Este caso representa a situação em que a instabilidade está relacionada a um espiral que leva a economia a salários do setor de comercializáveis cada vez mais baixos, ao mesmo tempo em que seu produto aumenta. Diferentemente do caso anterior, é preciso que os trabalhadores tenham forte poder de barganha para impedir a redução dos salários no setor comercializável e estabilizar a economia. A velocidade de ajuste do emprego, contudo, também precisa ser baixa para facilitar a estabilidade.

Apesar das várias simplificações do modelo, é possível associá-lo com o período de crescimento brasileiro entre 2003-2014, assim como suas limitações. Tal como no exercício de estática comparativa, a redução da disparidade salarial no Brasil foi acompanhada de um aumento mais do que proporcional no emprego e no produto dos setores que empregam mão de obra menos qualificada, principalmente devido às mudanças no padrão de consumo da sociedade advindas do processo redistributivo. O efeito sobre a balança comercial, simbolizado pela mudança na propensão média a poupar advinda de uma redução na desigualdade salarial no modelo, associa-se com o primeiro limite discutido na seção 1.4, da restrição externa. Ainda que a redução da desigualdade salarial possa ser expansionista no nível do produto, ela pode também gerar um efeito adverso na balança comercial, fazendo com fiquemos com um trade-off ao reduzir a desigualdade em um modelo de economia aberta. Além disso, a instabilidade relacionada à "inflação de serviços" é evitada com uma redução do poder de barganha dos trabalhadores, relacionando-se com o terceiro limite (a distribuição da renda no topo). O aumento de preços dos serviços faz com que a classe média exija políticas de restrição salarial e de aumento do desemprego, para evitar a redução de lucros, representando um desafio político ao processo de distribuição de renda. 



\section{Estudo econométrico da relação entre es- trutura produtiva e desigualdade no Brasil}

\subsection{Introdução}

Os capítulos anteriores exploraram a principal hipótese desta dissertação - a causação circular e cumulativa - em uma perspectiva empírico-descritiva e teórica. Cabe aqui, antes de prosseguir para a contribuição deste capítulo à literatura, relembrar esta hipótese. O Brasil, entre os anos de 2003-2014 passou por mudanças de indicadores econômicos referentes, principalmente, à sua taxa de crescimento, à estrutura produtiva e à distribuição de renda. As políticas redistributivas dos governos Lula - essencialmente o Programa Bolsa Família e a valorização do salário mínimo - teriam estimulado o consumo das populações de renda mais baixa, permitindo o acesso a produtos que antes não tinham espaço em sua cesta de consumo, tais como serviços (restaurantes, cabelereiro, manicure) e bens manufaturados (celulares, computadores, televisão). Estes produtos manufaturados, por sua vez, foram majoritariamente importados, resultando em um crescimento interno do produto e do emprego principalmente nos setores de serviços e construção civil assim como em outros setores de bens não-comercializáveis. Estes setores, por serem majoritariamente trabalho-intensivos e contratarem mão de obra pouco qualificada, para suprir o aumento da demanda, aumentariam os postos de trabalho, dando emprego justamente à população mais pobre, que veria sua renda crescendo mais ainda devido aos novos empregos e, assim, aumentariam o consumo, reiniciando o ciclo de causação circular cumulativa.

Assim como no modelo teórico desenvolvido no Capítulo 2, é impossível tratar da realidade brasileira - descrita no Capítulo 1 - como um todo, sem que sejam feitas recortes e simplificações. No nosso caso, trataremos neste exercício empírico especificamente da relação entre estrutura do produto (ou do emprego) e a desigualdade de renda (ou salarial). Mesmo delimitando a relação específica entre as variáveis que queremos captar, a elaboração do exercício não é trivial. Composição do produto, composição do emprego, desigualdade de renda e desigualdade salarial são conceitos amplos, o que nos deixa com a obrigação de especificar qual a definição deles adotada. A estrutura produtiva da economia e a desigualdade de renda são variáveis estruturais da economia e que não se alteram bruscamente em curtos intervalos de tempo.

Nesse sentido, nos deparamos com um desafio ao elaborar este exercício empírico: os dados para um período mais longo - de 1980 a 2014 - só estão disponíveis com um maior nível de agregação setorial, incompatível com a desagregação da seleção feita no capítulo 1.3. Temos, contudo, dados mais detalhados, com maior nível de desagregação, 
mas disponíveis para um período relativamente curto - entre 2004 e o início de 2019 - e referentes a variações no nível destas variáveis, disponíveis no CAGED. Estas dificuldades nos levam, então, a realizar dois exercícios empíricos distintos, explicados mais adiante neste capítulo.

Dito isso, podemos definir os conceitos, à luz dos dados a serem utilizados, de composição do emprego, composição do produto, desigualdade de renda e salarial, tratados ao longo deste capítulo. Num primeiro exercício, com os dados de periodicidade mais longa, a composição do produto relaciona-se com a seleção feita na seção 1.3, porém, pela falta de maior especificação nos setores, esta variável é definida pela razão entre o produto do setor de serviços e construção civil sobre o produto da indústria de transformação. A desigualdade é representada pelo índice de Gini $^{1}$ para a renda total.

Para o segundo exercício, as mudanças na composição do emprego serão medidas pela comparação entre o número absoluto de admitidos e desligados nos setores mais impactados pela causação circular e cumulativa, selecionados na seção 1.3, em relação ao saldo análogo nos demais setores da economia. A medida de desigualdade salarial é calculada pelo diferencial de salários entre entre os novos trabalhadores contratados, e é definida por uma razão, análoga à composição do emprego: o salário médio dos admitidos nos setores selecionados sobre o salário médio dos admitidos nos demais setores.

Uma vez que a variável de composição do emprego, neste exercício, é uma variável que traduz a variação no nível de emprego nos setores, utilizar os salários médios iniciais, que também representa uma variável de nível adicional de renda para estes novos contratados, nos pareceu mais adequado neste segundo exercício. Fazendo isso, estamos investigando o efeito imediato do aumento das contratações nos setores selecionados relativamente aos outros nos salários relativos oferecidos aos trabalhadores destes setores, assim como o sentido contrário - o impacto de salários maiores oferecidos aos trabalhadores dos setores selecionados em relação aos outros no aumento das contrações nestes setores selecionados, comparativamente aos restantes. Dito de outra maneira, estaremos medindo os efeitos de variações de curto prazo entre as duas variáveis.

Este capítulo está dividido, então, em mais quatro sessões, além desta introdução. A seção 3.2, a seguir, discorre brevemente sobre algumas questões metodológicas ao se tratar de econometria de séries temporais. As duas próximas sessões consistem nos dois exercícios econométricos realizados: a primeira (3.3) utiliza as séries mais longas referentes ao nível do produto e à desigualdade da renda total; e a segunda (3.4) analisa mais especificamente o período mais recente - 2004 a 2019 - com foco nas oscilações nos níveis das variáveis

1 O Índice de Gini é um instrumento para medir o grau de concentração de renda em determinado grupo. Ele aponta a diferença entre os rendimentos dos mais pobres e dos mais ricos e varia de zero a um. O valor zero representa a situação de igualdade, ou seja, todos têm a mesma renda enquanto o valor um está no extremo oposto, isto é, uma só pessoa detém toda a riqueza. 
e com maior desagregação setorial dos dados. Por fim, a seção 3.5 resume os principais resultados e conclui o capítulo.

\subsection{Metodologia}

Ao estudar séries temporais econômicas que co-evoluem ao longo do tempo normalmente nos deparamos com questões do tipo: qual delas está determinando a outra? Ou melhor, qual está causando qual? O conceito de causalidade em sistemas bivariados foi inicialmente introduzido por Granger (1969), onde se elabora a definição de "causalidade de Granger", tal como utilizada atualmente na literatura. Formalmente, dizemos que uma variável $X_{t}$ Granger-causa $Y_{t}$ se formos mais capazes de prever $Y_{t}$ usando todas as informações disponíveis do que se o fizéssemos sem as informações presentes em $X_{t}$. Uma variável $Y_{t}$ é, então, considerada endógena quando é causada (no sentido de Granger) por alguma outra. Para estudar a relação entre duas séries temporais que possuem uma causalidade - no sentido de Granger - mútua, ou seja, entre duas variáveis endógenas, existem dois métodos elementares: o de vetores auto regressivos (VAR) e o vetor de correção de erros (VEC). Estes dois métodos diferem principalmente devido a existência ou não de cointegração entre as variáveis, conceito que desenvolveremos a seguir.

O método VAR foi inicialmente desenvolvido por Sims (1980) e é recomendado para descrever a relação dinâmica entre duas ou mais variáveis estacionárias ao longo do tempo. Assim sendo, o primeiro passo ao lidar com séries de tempo é analisar a estacionaridade das séries em questão. Se uma série é integrada de ordem d - nomenclatura I(d) - é suficiente diferencia-la d vezes de modo que ela se torna estacionária e, assim, utilizamos esta série diferenciada na estimação do VAR. Entretanto, o método de diferenciação das séries pode não ser o mais adequado para tratar variáveis não-estacionárias em um contexto multivariado, uma vez que se torna possível que alguma combinação linear das séries integradas seja estacionária, de modo que as variáveis são ditas cointegradas.

Como formalmente definido por Engle e Granger (1987), os componentes de um vetor $x_{t}=\left(x_{1 t}, x_{2 t}, \ldots, x_{n t}\right)^{\prime}$ são ditos cointegrados se todos os componentes do vetor $x_{t}$ são integrados de ordem $d$ e existe um vetor de coeficientes $\beta=\left(\beta_{1}, \beta_{2}, \ldots, \beta_{n}\right)$ de modo que

$$
\beta^{\prime} x_{t}=\beta_{1} x_{1 t}+\beta_{2} x_{2 t}+\ldots+\beta_{n} x_{n t}
$$

é integrado de ordem $(d-b)$, em que $d \geq b>0$ e $\beta$ é dito vetor de cointegração.

A cointegração significa que, ainda que outros mecanismos causem mudanças permanentes nos elementos individuais de $x_{t}$, existe alguma relação de equilíbrio de longoprazo amarrando componentes individuais das séries, representado pela combinação linear 
$\beta^{\prime} x_{t}$. O vetor de cointegração $\beta$, contudo, não é único: se $\beta$ é um vetor de cointegração, então, para todo escalar $a$ real não nulo, $a \beta$ também será. Uma normalização arbitrária de igualar o primeiro elemento de $\beta$ a um é usualmente feita para solucionar tal problema.

O vetor de correção de erros (VEC) é, então, uma adaptação do método VAR para quando as séries são estacionárias em sua primeira diferença e uma relação de cointegração pode ser estabelecida entre elas. Apesar de o VAR em diferenças não ser consistente em séries cointegradas, sua versão em nível pode ser, resultando em um vetor de correção de erros. Suponhamos duas variáveis $Y_{t}$ e $X_{t}, \mathrm{I}(1)$ e cointegradas. Normalizando o coeficiente referente a $Y_{t}$ como 1, temos que o vetor de correção de erros pode ser escrito como:

$$
e_{t}=Y_{t}-\alpha_{0}-\alpha_{1} X_{t}
$$

e é estacionário - I(0) -, pela definição de cointegração. Os desvios desta relação de equilíbrio entre $Y_{t}$ e $X_{t}$ são, então, representados exatamente pelo vetor de correção de erros $e_{t}$. Estimado este vetor " $\widehat{e}_{t}$ ", podemos inseri-lo na equação do VAR em diferenças usual, na qual os coeficientes relacionados às variáveis diferenciadas são entendidos como efeitos de curto prazo, enquanto o vetor de correção de erros simboliza a relação de longo prazo entre elas.

Seguindo este procedimento, dois exercícios foram realizados para estudar a relação entre a estrutura produtiva e a distribuição de renda, explicados nas sessões que seguem.

\subsection{A relação entre a composição do produto e a desi- gualdade de renda no Brasil no período 1980-2014}

Como mencionado na introdução deste capítulo, a composição do produto (e do emprego) e a desigualdade são variáveis de cunho estrutural da economia, nas quais as mudanças demoram algum tempo para se consolidarem. Pela falta de dados mais detalhados por um maior período de tempo, optamos por realizar, primeiramente, um experimento com uma série mais longa, ainda que isto signifique perder detalhamentos e especificidades setoriais dos dados. Para tal, utilizamos a série de PIB trimestral para os setores de serviços, indústria da construção e da transformação e o índice de Gini trimestral, de 1980 a 2014, construídos a partir de dados do IBGE, Ipeadata e da PNAD.

Para a estrutura produtiva, fizemos uma aproximação do indicador construído no Capítulo 1.3, referente ao produto dos setores que participaram mais significativamente deste processo de causação circular e cumulativa: construímos uma série trimestral do PIB do setor de serviços somado ao da construção civil sobre o PIB da indústria de transformação. Para construir tal indicador, contudo, nos deparamos com alguns problemas 


\subsection{A relação entre a composição do produto e a desigualdade de renda no Brasil no}

periodo 1980-2014

nas séries devido a quebras metodológicas nas pesquisas. O IBGE disponibiliza dados do Sistema de Contas Nacionais Trimestrais, referência 2000 a preços de 1995, a partir do primeiro trimestre de 1996. Para os anos anteriores, o Ipeadata construiu um índice para o PIB trimestral até 1980, em que o ano de 1995 é igualado a $100^{2}$. Este índice, contudo, não está disponível para a indústria de transformação, somente para as demais indústrias (construção, extração mineral e vegetal, eletricidade e gás, água, esgoto e limpeza urbana e indústria total) e para o setor de serviços. Foi preciso, então, calcular o crescimento deste índice para a indústria de transformação e, em seguida, trimestralizar as séries do PIB dos serviços, construção e indústria de transformação a partir do crescimento dos seus respectivos índices. Os cálculos utilizados estão reportados no Apêndice D

Figura 6 - Evolução das séries de PIB anual da indústria total e da indústria de transformações

\section{Fonte: IBGE}

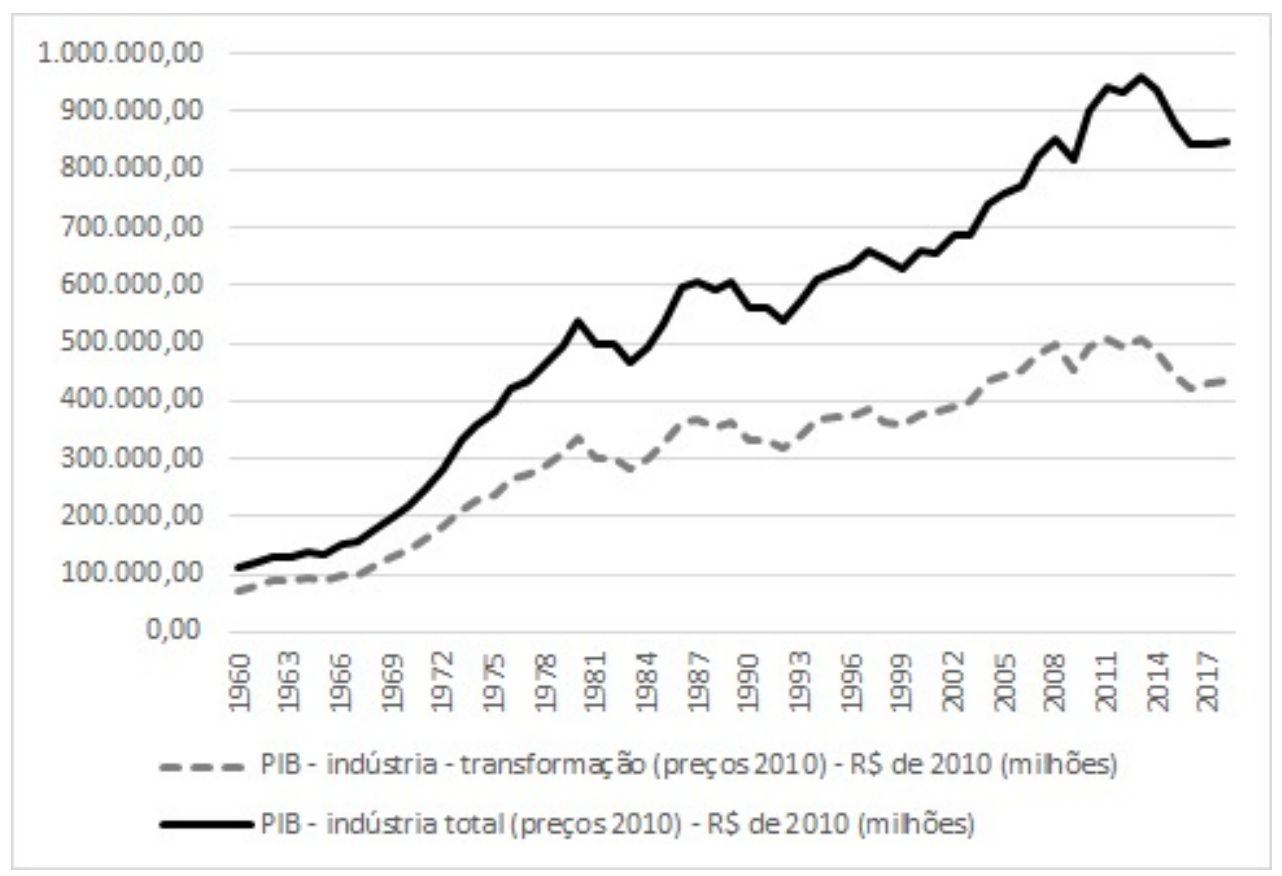

2 Para 1980-1990, as séries foram obtidas do "Indicadores do IBGE: Produto Interno Bruto. Neste período série encadeada pela taxa de variação real trimestral dos índices de base fixa média $1980=100$. Até 1994, a soma dos valores adicionados nos três grandes setores (agropecuária, indústria e serviços) supera o total do PIB a preços básicos, que inclui também um setor fictício com PIB negativo (pois não tem produção, só custos intermediários) denominado 'dummy financeiro' ou 'imputação de serviços de intermediação financeira'. Esse setor fictício, com séries disponíveis no Ipeadata, corresponde a custos financeiros indiretamente medidos pelo IBGE e que podem ter incidido sobre qualquer um dos setores. No Ipeadata, as séries em \% do PIB mantêm os percentuais tal como publicados pelo IBGE e, por isso, os três grandes setores somam mais de 100\% do PIB até 1994." (http://www.ipeadata.gov.br). No nosso caso, utilizar a série sem o ajuste do dummy financeiro - a série disponível no Ipeadata - ou a série com o ajuste elaborada por Morceiro (2019) não faz diferença, uma vez que o ajuste sugerido pelo autor distribui o dummy financeiro entre os setores de maneira proporcional ao seu tamanho. Como calculamos a razão de um setor sobre o outro, este ajuste do dummy financeiro acaba não sendo relevante para a evolução relativa dos setores. Para os anos de 1991-1994, os dados foram obtidos no Sistema de Contas Nacionais Trimestrais Referência 2000 (banco Sidra). A série foi descontinuada pela fonte desde 2015, devido a mudanças metodológicas. 
Além deste cálculo, realizamos outro método de trimestralização das séries para a indústria de transformação para certificar qual o melhor ajustamento. Na Figura 6 plotamos as séries anuais do PIB real da indústria total e da indústria de transformação e percebemos que, por mais que a distância entre elas aumente ao longo do tempo, as variações entre os anos parecem seguir um mesmo movimento, ou seja, os vales e picos das séries acontecem no mesmo período e em magnitude muito parecida. Por este motivo, optamos por trimestralizar a série da indústria de transformação utilizando o índice trimestral para a indústria total, a partir do método Denton (1971).

O método Denton consiste em encontrar uma série interpolada $x$ relacionando uma série de indicadores de frequência mais alta $z$ a uma série de referência de frequência mais baixa $y$, a partir da minimização da função de diferença proporcional:

$$
F=\sum_{t=1}^{T}\left(\frac{x(t)}{z(t)}-\frac{x(t-1)}{z(t-1)}\right)^{2}
$$

Sujeito a restrição:

$$
\sum_{t=b_{k}}^{c_{k}} x(t)=y_{k}
$$

com o benchmark y em cada período $\mathrm{k}$, em que $b_{k}$ e $c_{k}$ são o início e final dos períodos.

Figura 7 - Série de indústria de transformação trimestralizadas pelos dois métodos descritos

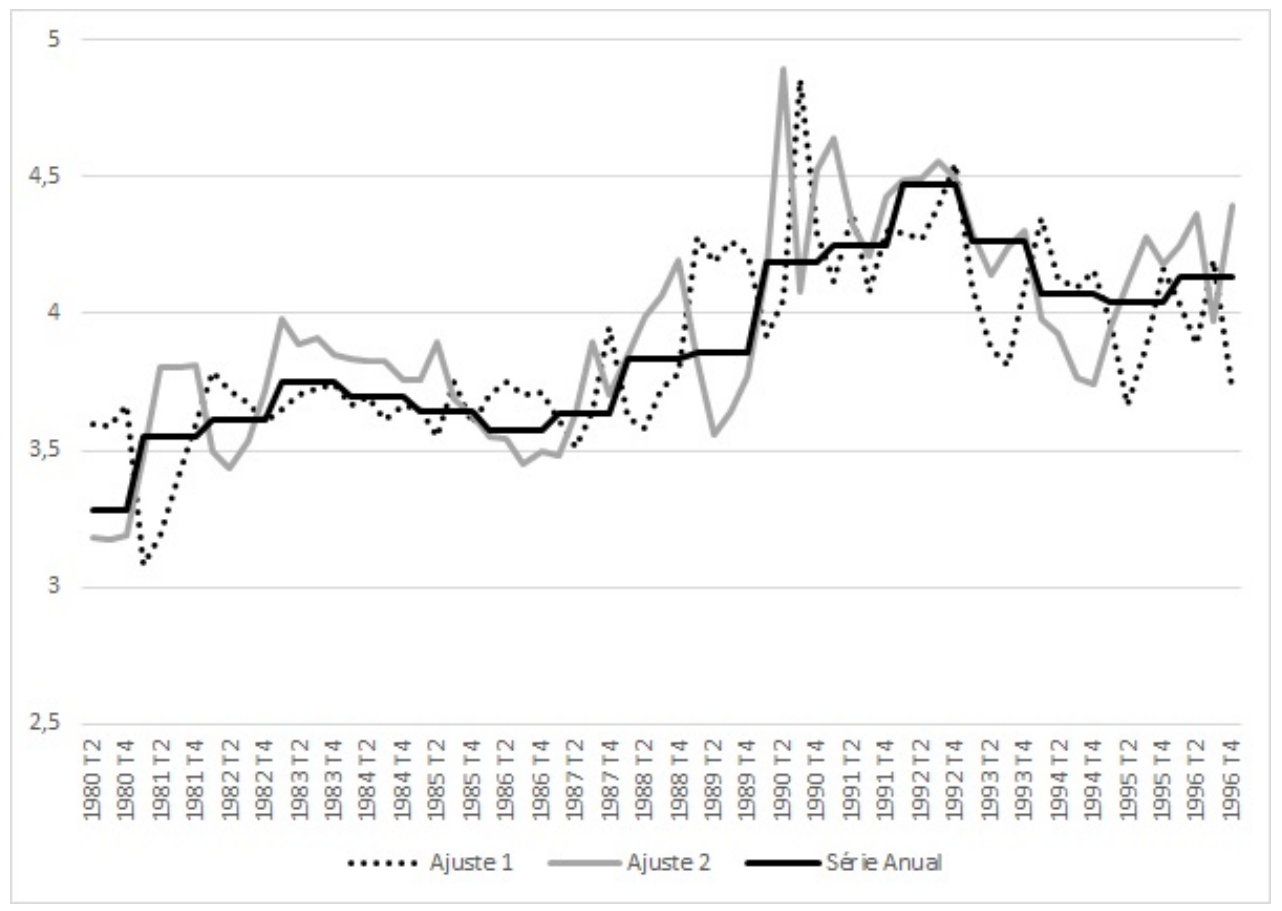


A Figura 7 mostra o resultado das séries trimestralizadas pelos dois métodos descritos acima, em que Ajuste 1 é a série trimestralizada pela taxa de crescimento do índice do PIB; e Ajuste 2 é a série trimestralizada pelo método Denton (1971). A série "anual" repete o valor do ano para todos os 4 trimestres. Notemos que os dois métodos resultaram em séries com sentidos opostos em alguns trimestres (como em 1981T1, 1982T2 e basicamente todo o período entre 1994T1 e 1996T4) e que, apenas pela análise do gráfico, é difícil chegar a alguma conclusão sobre qual série melhor se ajusta aos dados anuais. Para definir qual série será utilizada optamos, então, por calcular a soma dos erros ao quadrado ${ }^{3}$ e escolher a série que possuir o menor valor desta soma. Feito isso, concluímos que a série trimestralizada pelo método Denton (1971) é a que melhor se ajusta.

Por fim, construímos o indicador desejado, da razão do PIB do setor de serviços e construção civil sobre o PIB da indústria de transformação. Devido a estes ajustes realizados para os trimestres entre 1980 e 1995 o indicador apresentou uma quebra estrutural, que foi encadeada a partir de uma lógica de médias móveis:

$$
\text { série_concatenada } a_{t}=\text { série_trimestralizada } \frac{\sum_{i=1}^{4} \text { série_trimestral }_{t+i}}{\sum_{i=1}^{4} \text { série_trimestralizada }_{t+i}}
$$

em que $t \in[1980 T 2 ; 1995 T 4]$. O gráfico das séries originais e da série concatenada está reportado na Figura 8.

Para a distribuição da renda trimestralizamos o índice de Gini pelo método CubicMatch Last ${ }^{4}$, disponível no software Eviews. Tivemos um total de 139 observações entre o segundo trimestre de 1980 e o terceiro de 2014.

A Figura 9 mostra a evolução das séries ao longo do tempo, em que se nota uma mudança tendencial delas a partir do final de 2002, início de 2003. Entre 1980 e 2002, a série do Gini e da razão entre a indústria e o setor de serviços parecia evoluir conjuntamente, em uma relação positiva. A partir de 2003, contudo, as séries admitem uma tendência oposta, indicando que possivelmente a relação negativa entre elas - simbolizando uma relação entre a redução da desigualdade e o aumento mais do que proporcional do setor de serviços e construção quando comparado com a indústria de transformação - tenha se iniciado, ou ao menos se atenuado, a partir daí.

3 Para isso calculamos a seguinte soma: $S=\sum_{t=1}^{T}\left(\text { série_ajustada }_{i ; t}-\text { série_anual }_{t}\right)^{2}$, em que $i=1,2$ representa os ajustes e $t \in[1982 T 2 ; 1996 T 4]$.

4 Este método insere o valor da observação da série de baixa frequência no último período dos dados de alta frequência e executa uma interpolação de "spline cúbica" nos valores ausentes. Por exemplo, no valor referente a 2009Q4 será dado o valor anual de 2009, e 2010Q4 receberá o valor anual de 2010 e, em seguida, a interpolação cúbica irá preencher os valores de 2010Q1, 2010Q2, 2010Q3. A escolha deste método se deu devido a falta de opção de outra série de distribuição de renda ou próxima a isso de periodicidade trimestral para aplicar o método Denton (1971). 
Figura 8 - Série do PIB do setor de serviços e construção civil sobre o PIB do setor de indústria da transformação concatenada

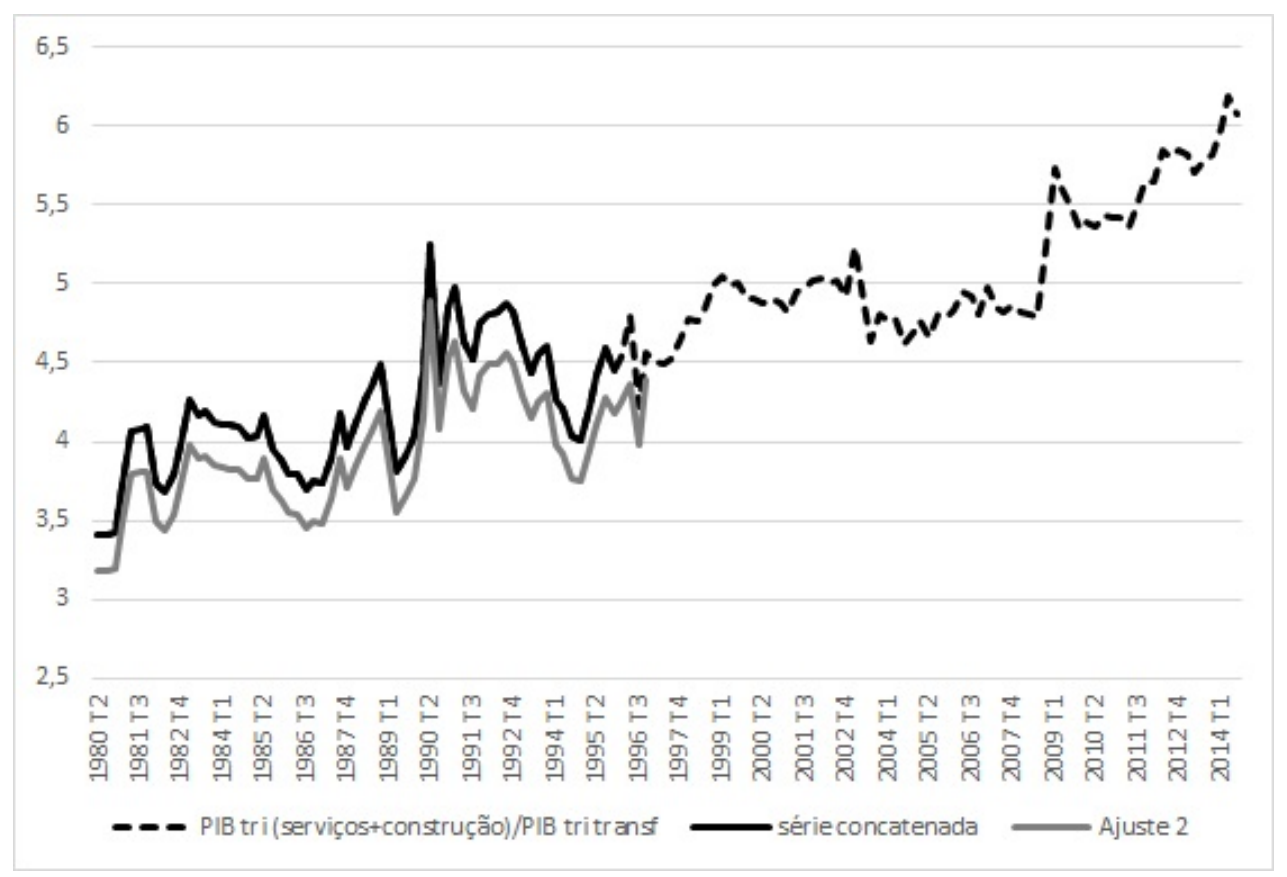

Figura 9 - Evolução das séries do primeiro exercício econométrico

Fonte: PIB serviços / PIB indústria: IBGE; Índice de Gini: PNAD

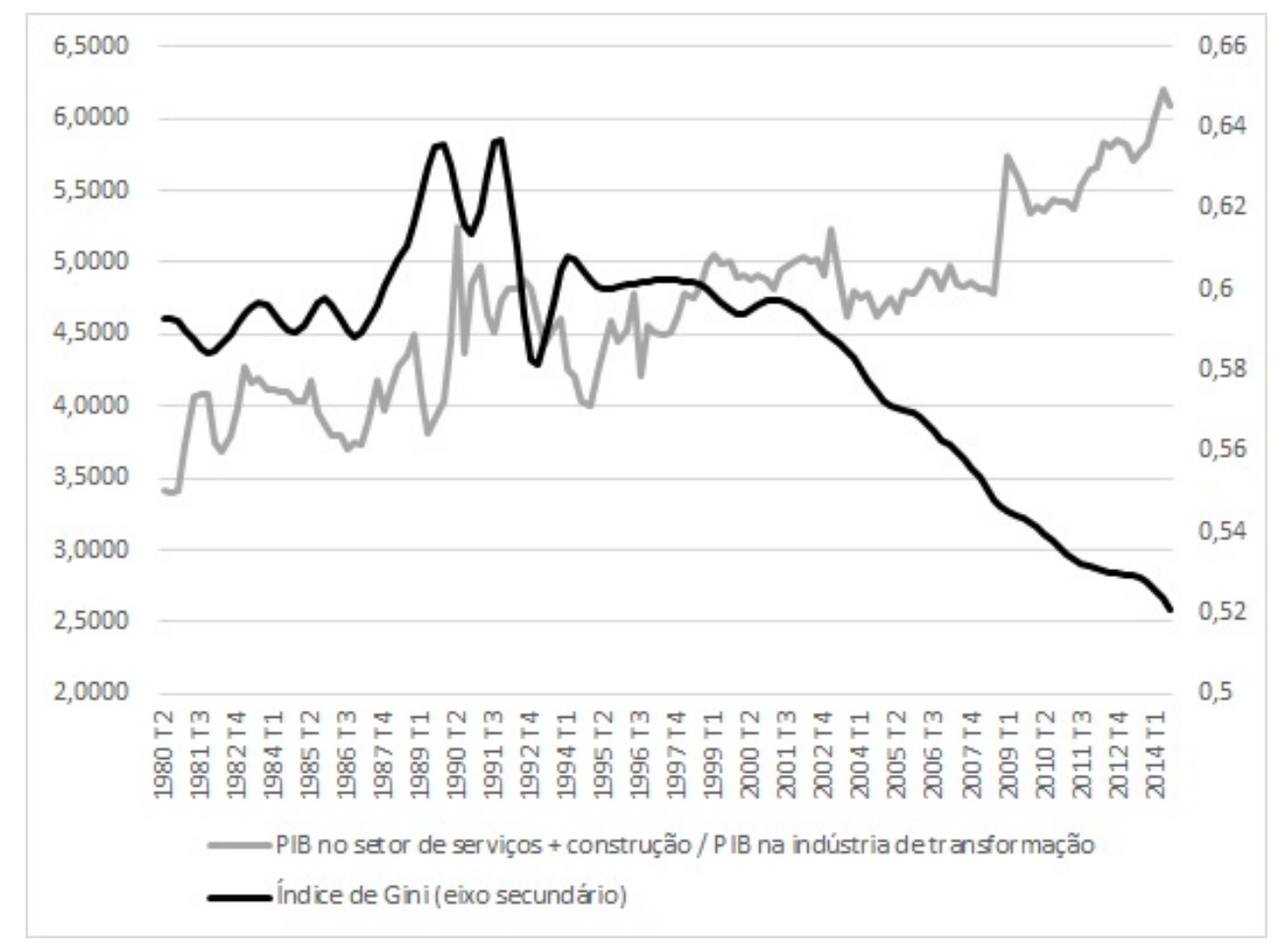

O primeiro passo da estimação, seguindo a metodologia descrita na seção 3.2 , foi realizar os testes de raiz unitária, cujos resultados se encontram na Tabela 11. Vale relembrar aqui as hipóteses nulas dos testes: para o ADF e PP, a hipótese nula é de que a série possui raiz unitária, enquanto para o KPSS a hipótese nula é de que a série é 
estacionária. O índice de Gini possui raiz unitária, indubitavelmente, enquanto a razão do PIB dos serviços e da indústria mostrou três situações contrárias em relação à maioria, a um nível de significância de 5\%, nos testes ADF, PP e KPSS quando incluímos a constante e a tendência. Contudo, consideramos o resultado da maioria dos testes, ou seja, de que está série é integrada de ordem 1.

Tabela 11 - Teste de Raíz unitária: primeiro exercício

\begin{tabular}{ccccccccc}
\multirow{2}{*}{ Variável } & \multicolumn{8}{c}{ P-valor } \\
\cline { 2 - 9 } & no c,t & $\mathrm{c}$ & $\mathrm{c}, \mathrm{t}$ & no c,t & $\mathrm{c}$ & $\mathrm{c}, \mathrm{t}$ & $\mathrm{c}$ & $\mathrm{c}, \mathrm{t}$ \\
\hline razao_setores & 0.955 & 0.616 & 0.005 & 0.999 & 0.574 & 0.006 & $<1 \%$ & $>\mathbf{1 0 \%}$ \\
gini & 0.116 & 0.999 & 0.924 & 0.191 & 0.983 & 0.894 & $<1 \% \mathrm{p}>1 \%$ & $<1 \%$
\end{tabular}

Feito isso, realizamos um teste de causalidade de Granger com 8 defasagens, que foi o número indicado pelos critérios de informação num VAR com as duas variáveis em nível, para confirmar a causalidade mútua entre elas. A Tabela 12 mostra o resultado deste teste, que confirma a causalidade mútua entre as variáveis a um nível de $5 \%$ de significância.

Tabela 12 - Teste de Causalidade de Granger: primeiro exercício

Amostra: 1980Q2 - 2014Q3

Lags: 8

\begin{tabular}{llll}
\hline Hipótese nula: & Obs & Estatística F & Prob. \\
\hline RAZAO_SETORES não Granger-causa GINI & 130 & 3.411 & 0.0015 \\
GINI não Granger-causa RAZAO_SETORES & & 2.251 & 0.0287
\end{tabular}

Em seguida, realizamos o teste de cointegração e o teste do traço apontou para a existência de um vetor de cointegração. Estimamos, então, um VEC com sete defasagens. A ordenação de Cholesky seguiu a hipótese de que a distribuição de renda é mais exógena do que a composição do produto. Os testes dos resíduos estão reportados no Apêndice E.

\subsubsection{Resultados}

O resultado dos coeficientes e seus respectivos níveis de significância estão reportados na Tabela 13. O coeficiente da equação de cointegração é negativo e significativo a 5\% tanto para a equação do índice de Gini quanto para a de razão entre o PIB do setor de serviços e construção civil sobre a indústria de transformação, como desejado neste tipo de modelo. Dentro da equação de cointegração o coeficiente referente à razão do PIB do setor de serviços e construção sobre o PIB da indústria de transformação foi significativo a $1 \%$ e teve sinal positivo. Como o aumento do índice de Gini representa um aumento da desigualdade, o sinal positivo está de acordo com a nossa hipótese, pois simboliza a relação positiva entre a redução de desigualdade de renda e a mudança na composição do produto 
em direção aos serviços e construção, isto é, uma queda no índice de Gini está relacionado ao aumento relativo do setor de serviços e construção. Para melhor entender este resultado, é importante relembrar a equação do vetor de correção de erros: $e_{t}=Y_{t}-\alpha_{0}-\alpha_{1} X_{t}$. Note que existe um sinal de menos na frente do coeficiente de $X_{t}$, que no nosso caso representa a composição do produto enquanto o $Y_{t}$ representa o índice de Gini, ou seja, para que elas sejam negativamente relacionadas o coeficiente deve ser positivo.

Figura 10 - Função resposta-impulso do primeiro exercício

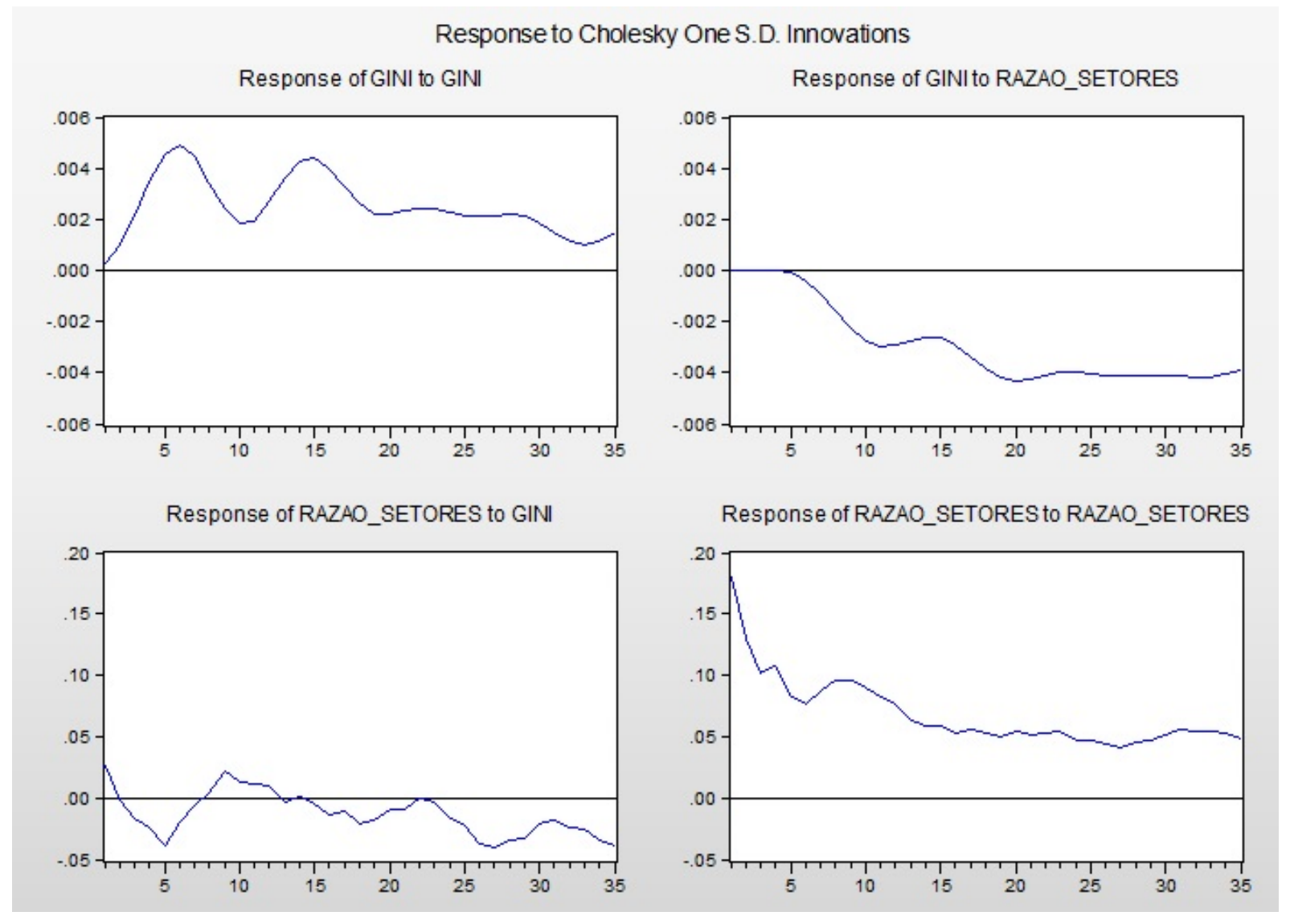

Quanto aos efeitos de curto prazo, percebemos que o índice de Gini apresenta uma dependência maior em relação aos seus valores defasados - todos foram significativos a $5 \%$ - e o coeficiente referente a razão dos setores defasado em 1 defasagem foi positivo e significativo a $5 \%$, enquanto os referentes a este indicador de composição do produto defasado em 4 e 7 defasagens foram negativos e significativos a 10\%. A alternância de sinais dos coeficientes do índice de Gini nesta primeira equação pode simbolizar as flutuações desta variável em resposta a ela mesma, também observado na impulso-resposta. Para a equação da razão do PIB de serviços e construção sobre o PIB da indústria de transformação, os coeficientes referentes ao Gini foram negativos em sua maioria e significativos somente com 1 e 2 defasagens, a $5 \%$ e 10\%, respectivamente, enquanto a própria variável da razão do PIB do setor de serviços sobre o de indústria defasada foi significante apenas com 1 defasagem, a 10\%. Apesar da baixa significância de alguns coeficientes, a função resposta ao impulso 
3.3. A relação entre a composição do produto e a desigualdade de renda no Brasil no período 1980-2014

deste modelo, reportada na Figura 10, nos dá mais alguns indicativos de confirmação da hipótese de causação circular e cumulativa. 
Tabela 13 - Resultado das estimações: primeiro exercício

\begin{tabular}{|c|c|c|}
\hline \multicolumn{3}{|l|}{ Equação de cointegração: } \\
\hline \multirow{4}{*}{$\begin{array}{l}G I N I_{-1} \\
R A Z A O \_S E T O R E S_{-1}\end{array}$} & \\
\hline & \multicolumn{2}{|l|}{1.00} \\
\hline & \multicolumn{2}{|l|}{$0.059 * * *$} \\
\hline & \multicolumn{2}{|l|}{$(4.207)$} \\
\hline $\mathrm{C}$ & \multicolumn{2}{|l|}{-0.864} \\
\hline coeficientes & $\Delta G I N I$ & $\triangle R A Z A O \_S E T O R E S$ \\
\hline \multirow[t]{2}{*}{ EqCoint $_{1}$} & $-0.004^{* * *}$ & $-1.530^{* *}$ \\
\hline & $(-3.18585)$ & $(-1.976)$ \\
\hline \multirow{2}{*}{$\Delta G I N I_{-1}$} & $2.517^{* * *}$ & $-67.79^{*}$ \\
\hline & $(40.005)$ & $(-1.713)$ \\
\hline \multirow[t]{2}{*}{$\Delta G I N I_{-2}$} & $-2.417^{* * *}$ & 117.88 \\
\hline & $(-16.807)$ & $(1.304)$ \\
\hline \multirow[t]{2}{*}{$\Delta G I N I_{-3}$} & $0.918^{* * *}$ & -75.51 \\
\hline & $(5.643)$ & $(-0.738)$ \\
\hline \multirow[t]{2}{*}{$\Delta G I N I_{-4}$} & $-0.878^{* * *}$ & -1.187 \\
\hline & $(-5.483)$ & $(-0.012)$ \\
\hline \multirow[t]{2}{*}{$\Delta G I N I_{-5}$} & $2.107^{* * *}$ & 57.03 \\
\hline & $(13.104)$ & $(0.564)$ \\
\hline \multirow[t]{2}{*}{$\Delta G I N I_{-6}$} & $-2.002^{* * *}$ & -66.92 \\
\hline & $(-14.402)$ & $(-0.766)$ \\
\hline \multirow[t]{2}{*}{$\Delta G I N I_{-7}$} & $0.711^{* * *}$ & 45.75 \\
\hline & $(11.677)$ & $(1.196)$ \\
\hline \multirow{2}{*}{$\triangle R A Z A O \_S E T O R E S_{-1}$} & $0.0003^{* *}$ & $-0.190^{*}$ \\
\hline & $(1.993)$ & $(-1.910)$ \\
\hline \multirow[t]{2}{*}{$\triangle R A Z A O \_S E T O R E S_{-2}$} & 0.0002 & -0.139 \\
\hline & $(0.828)$ & $(-1.345)$ \\
\hline \multirow[t]{2}{*}{$\triangle R A Z A O \_S E T O R E S_{-3}$} & 0.0002 & 0.0104 \\
\hline & $(1.262)$ & $(0.101)$ \\
\hline \multirow[t]{2}{*}{$\triangle R A Z A O \_S E T O R E S_{-4}$} & $-0.0003^{*}$ & -0.099 \\
\hline & $(-1.729)$ & $(-1.008)$ \\
\hline \multirow[t]{2}{*}{$\triangle R A Z A O \_S E T O R E S_{-5}$} & -0.0001 & -0.072 \\
\hline & $(-0.846)$ & $(-0.751)$ \\
\hline \multirow[t]{2}{*}{$\triangle R A Z A O \_S E T O R E S_{-6}$} & $7.45 \mathrm{E}-05$ & -0.024 \\
\hline & $(0.498)$ & $(-0.259)$ \\
\hline \multirow[t]{2}{*}{$\triangle R A Z A O \_S E T O R E S_{-7}$} & $-0.0002^{*}$ & 0.0525 \\
\hline & $(-1.646)$ & $(0.571)$ \\
\hline \multirow[t]{2}{*}{$C$} & $-2.60 \mathrm{E}-05$ & 0.029 \\
\hline & $(-0.873)$ & $(1.570)$ \\
\hline$R^{2}$ & 0.994 & 0.218 \\
\hline Estatística F & 0.994 & 0.115 \\
\hline
\end{tabular}

* simboliza $10 \%$ de significância ** simboliza $5 \%$ de significância *** simboliza $1 \%$ de significância Estatísticas t em ( ) 
$\mathrm{Na}$ função impulso-resposta fica clara a relação entre desigualdade salarial e estrutura produtiva: a resposta do Gini a um choque na razão (Serviços + Construção)/(Indústria da Transformação) é de um efeito contemporâneo nulo, seguido de um decaimento gradual, se estabilizando a um patamar muito inferior do que o inicial após aproximadamente 20 períodos do choque. A resposta da composição setorial a um aumento na desigualdade (choque positivo no índice de Gini), por sua vez, tem uma resposta um pouco contra-intuitiva: o efeito contemporâneo é de baixa da razão, porém seguido de uma alta, ficando próximo ao zero por aproximadamente 10 períodos, mas voltando a decair após cerca de 23 períodos.

Figura 11 - Evolução dos componentes internos do setor de serviços (\%)

\section{Fonte: IBGE}

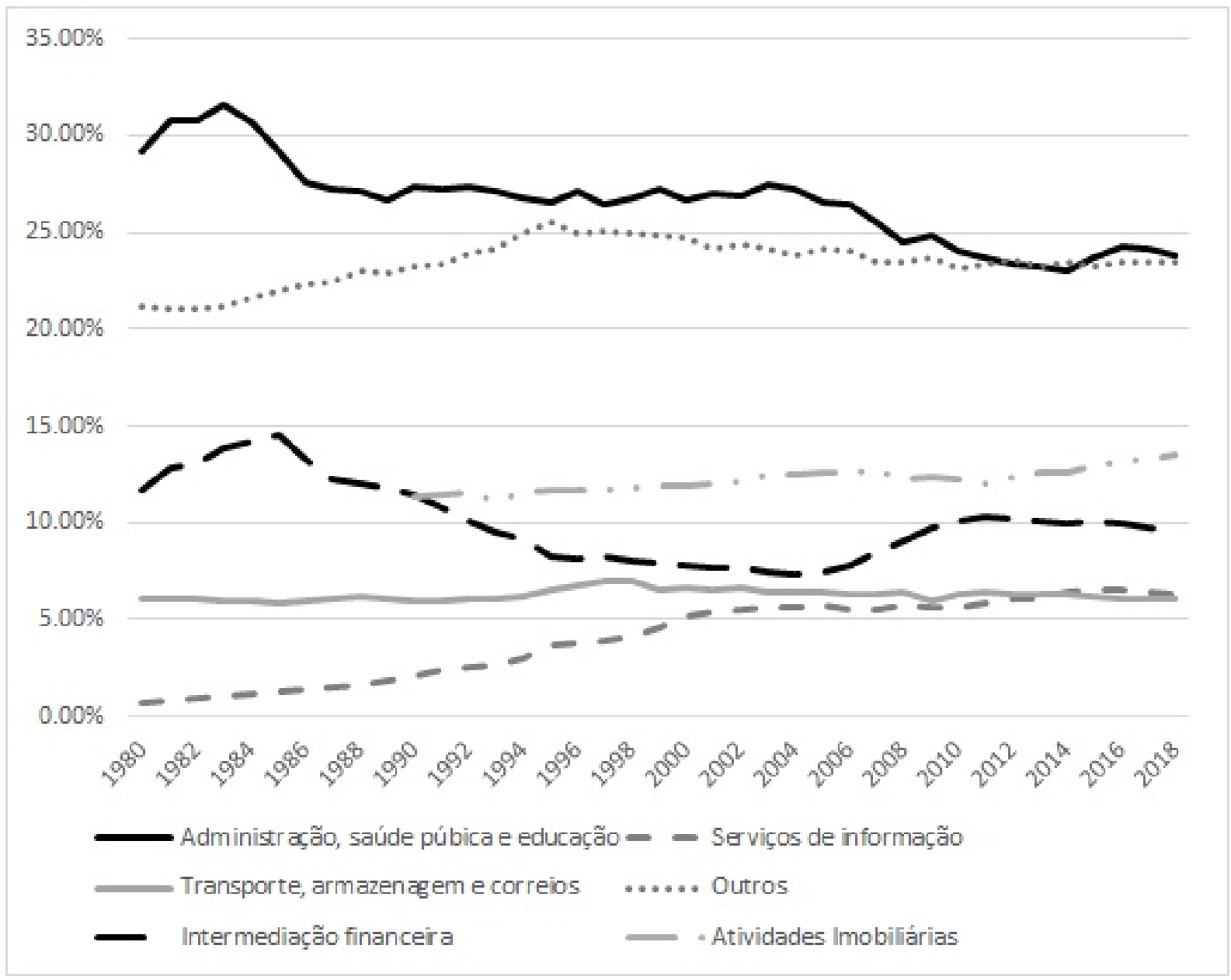

Apesar de encontrados os efeitos esperados neste primeiro exercício, com dados para um período mais longo, nos deparamos com a dificuldade já reportada da falta de especificidade dos dados, tanto setoriais quando de desigualdade, já que o índice de Gini para a renda representa a desigualdade da renda total e não a desigualdade salarial, que parece ter sido a mais afetada no processo de causação circular e cumulativa. Além disso, o setor de serviços é incluído na estimação sem que sejam feitas distinções entre 
subsetores, que possuem características muito distintas entre eles. Na Figura 11, plotamos a participação anual de cada subsetor dentro do setor de serviços entre 1980 e $2018^{5}$ a preços de 2010, disponível no SCN do IBGE, e percebemos que ocorrem modificações na sua estrutura ao longo destes anos. Os serviços de intermediação financeira, informação, atividades imobiliárias, administração pública, saúde e educação são serviços que possuem salários mais elevados e, muitas vezes, empregam mão de obra qualificada, variam bastante quanto à sua participação no total de serviços, o que poderia significar que a inclusão deles neste exercício poderia retirar o foco da hipótese específica que queremos analisar. Além disso, os serviços selecionados na seção 1.3, são todos parte da divisão do SCN de "outros serviços", impedindo também um maior detalhamento dentro desta subcategoria.

A fim de solucionar os problemas de especificidade setoriais e da desigualdade salarial, optamos por realizar um segundo exercício para os anos de 2004 a 2019, que representam exatamente o período em que o índice de Gini e a composição do produto, tal como aqui calculada, parecem assumir tendências opostas (Figura 9), além de apresentarem uma desagregação setorial compatível com a seleção do capítulo 1.3. Este segundo exercício é descrito a seguir.

\subsection{A relação entre variações na composição do emprego e na desigualdade salarial no Brasil entre 2003 e 2019}

Para investigar mais especificamente o período recente brasileiro, dos anos 2004 até $2019^{6}$, com um maior detalhamento setorial dos dados, utilizamos dados do Cadastro Geral de Empregados e Desempregados (CAGED). O CAGED um nível muito maior de desagregação setorial, nos permitindo utilizar exatamente aqueles selecionados no Capítulo 1, seção 1.3. Os setores selecionados são vestuário, calçados e têxteis; construção civil; móveis e produtos de diversas indústrias; serviços de manutenção e reparo; serviços prestados a famílias e associações; serviços domésticos; e serviços de alojamento e alimentação, que correspondem a 30.3\% do emprego, na média, entre 2004 e 2015, e por $13.7 \%$ do PIB, na média, durante o mesmo período, segundo dados do Sistema de Contas Nacionais do IBGE.

Para as estimações construímos dois indicadores para mudanças na composição do emprego e desigualdade salarial, com periodicidade mensal, entre janeiro de 2004 a março de 2019, resultando num total de 183 observações. As séries foram dessazonalizadas pelo método X-12-ARIMA. Antes de explicar a construção dos indicadores, é preciso fazer uma consideração a respeito dos empregos informais, uma vez que o CAGED possui dados referentes apenas aos empregados formais. O mecanismo de causação circular e cumulativa

\footnotetext{
5 A série para serviços imobiliários só está disponível a partir de 1990.

6 A série se inicia em 2004 devido à disponibilidade dos dados.
} 
descrito no Capítulo 1.3 desta dissertação, o qual pretendemos avaliar empiricamente neste exercício, realça a importância do aumento no emprego em setores de salários mais baixos e que empregam trabalhadores de menor qualificação. Estes setores são, por sua vez, os que possuem maiores índices de informalidade no Brasil. Apesar de o avanço no aumento na formalização do trabalho - entre 2003-2011 o emprego formal no Brasil passou de 51.6\% para $61.6 \%$-, a informalidade ainda é um problema no mercado de trabalho brasileiro. Maurizio (2014) mostra que a probabilidade da formalização do trabalho é maior no setor público e em grandes empresas, enquanto os setores de comércio, construção e serviços doméstico - que são majoritariamente os setores que selecionamos - representam a menor incidência de formalização. Não levar em conta estes trabalhadores informais, contudo, cria uma análise subestimada deste processo: o efeito da causação circular e cumulativa poderia ser ainda maior se também levássemos em consideração os empregos informais criados - o que faz com que nosso trabalho de identificação deste efeito, aqui, seja mais difícil.

O primeiro indicador a ser usado representa as mudanças na composição do emprego ao longo dos meses, para o qual usamos a diferença entre o saldo mensal de admitidos menos dispensados dos setores selecionados, subtraído deste mesmo saldo nos demais setores da economia. A equação (3.4), abaixo, apresenta o indicador construído, em que $\Delta_{i}=$ Admitidos $_{i}-$ Desligados $_{i}$, com $i=$ setores_selecionados, outros_setores.

$$
\text { dif_saldo }=\Delta_{\text {setores_selecionados }}-\Delta_{\text {outros_setores }}
$$

O segundo indicador construído pretende, por sua vez, medir a desigualdade salarial entre os trabalhadores admitidos nos setores em cada mês e consiste no logaritmo da razão entre o salário médio dos setores selecionados e o salário médio dos demais setores da economia - chamamos de "l_razao_sal". Assim, quando este indicador aumenta, significa que os trabalhadores que estão sendo contratados nestes setores estão ganhando mais relativamente aos trabalhadores dos outros setores. Como os trabalhadores dos setores selecionados têm um salário médio menor que o resto da economia, o aumento dessa variável, em conjunto com o aumento nas contratações, significa que a desigualdade salarial está se reduzindo.

As séries a serem utilizadas são as mesmas reportadas no Capítulo 1, na Figura 3, porém sem considerar as médias móveis de 12 meses (Figura 12).

É possível perceber a presença de vários vales e picos mais acentuados nas séries, principalmente na série da diferença do saldo de emprego, o que nos fez incluir nas estimações duas variáveis dummies: uma de agosto de 2008 a fevereiro de 2009, referente à crise de 2008, e uma para os meses de dezembro que, apesar do ajuste sazonal, ainda apresentam uma variação destoante dos demais meses. 
Figura 12 - Evolução das séries de desigualdade salarial entre admitidos e mudanças na composição do emprego a partir dos setores selecionados: dados mensais Fonte: CAGED

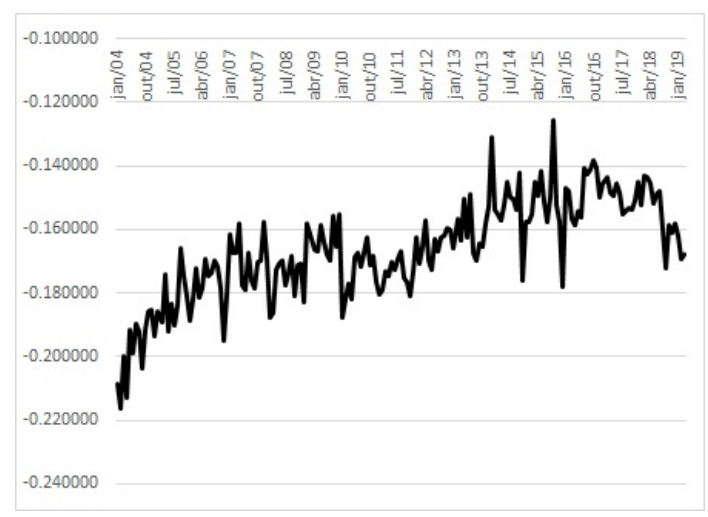

(a) Logaritmo da razão do salário médio dos trabalhadores admiidos nos setores selecionados sobre os demais setores

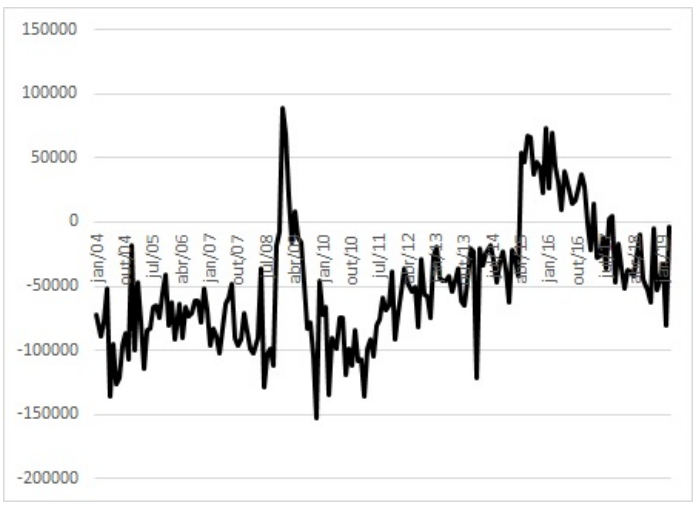

(b) Diferença no saldo de contratações nos setores selecionados no dos demais

Seguindo o procedimento descrito na seção 3.2, realizamos testes de raíz unitária nas séries e concluímos que ambas são estacionárias. Os resultados baseiam-se nos testes de Augmented Dickey-Fuller (ADF), com os critérios de Akaike para escolher as defasagens, Phillips-Perron (PP) e Kwiatkowski, Phillips, Schmidt e Shin (KPSS) ${ }^{7}$, e estão reportados na Tabela 14. A hipótese nula dos testes ADF e PP é de que a variável é estacionária, enquanto para a KPSS a hipótese nula é de que a variável possui raiz unitária. Para a primeira variável, "l_razao_sal", os testes ADF e PP sem constante e tendência indicavam a presença de raiz unitária, contudo, como tanto a constante quanto a tendência foram significantes, concluímos sobre a estacionariedade da variável baseado no resultado dos testes que incluem estes controles ("c" e "t").

Tabela 14 - Teste de Raíz unitária: segundo exercício

\begin{tabular}{ccccccccc}
\multirow{2}{*}{ Variável } & \multicolumn{7}{c}{ P-valor } \\
\cline { 2 - 9 } & no c,t & $\mathrm{c}$ & $\mathrm{c}, \mathrm{t}$ & no c,t & $\mathrm{c}$ & $\mathrm{c}, \mathrm{t}$ & $\mathrm{c}$ & $\mathrm{c}, \mathrm{t}$ \\
\hline l_razao_sal & 0.231 & 0.060 & 0.000 & 0.293 & 0.0003 & 0.000 & $<1 \%$ & $10 \%>\mathrm{p}>5 \%$ \\
dif_saldo & 0.023 & 0.025 & 0.014 & 0.004 & 0.0003 & 0.000 & $<1 \%$ & $>10 \%$
\end{tabular}

Antes de começar o processo das estimações, fizemos o teste de causalidade de Granger, para verificar que as duas variáveis são, de fato, endógenas. O teste de causalidade de Granger com 4 defasagens, que foi o sugerido pela maioria dos critérios de informação FPE: Final prediction error; AIC: Akaike information criterion; SC: Schwarz information criterion; HQ: Hannan-Quinn information criterion - apontou para uma causalidade mútua entre as variáveis, a um nível de $10 \%$ de significância. Apesar de a causalidade no sentido 
da desigualdade salarial entre os admitidos para a diferença nos saldos de contratação não ter sido significante a 5\%, prosseguimos o exercício considerando que ambas são endógenas.

Tabela 15 - Teste de Causalidade de Granger: segundo exercício

Amostra: 2004M1 - 2019M3

Lags: 4

\begin{tabular}{llll}
\hline Hipótese nula: & Obs & Estatística F & Prob. \\
\hline L_RAZAO_SAL não Granger-causa DIF_SALDO & 179 & 1.988 & 0.0985 \\
DIF_SALDO não Granger-causa L_RAZAO_SAL & & 3.910 & 0.0046
\end{tabular}

Feito o teste de causalidade de Granger e confirmando a endogeneidade e a estacionariedade das duas variáveis em questão, procedemos para a estimação do VAR com 4 defasagens. Os resultados são apresentados a seguir.

\subsubsection{Resultados}

Os resultados dos coeficientes estimados estão reportados na Tabela 16, enquanto a função resposta-impulso na Figura 13 e a acumulada na Figura 14. A ordenação de Cholesky seguiu o que foi imposto no primeiro exercício deste capítulo: a desigualdade salarial é mais exógena do que as variações no saldo de contratação entre os setores. Os testes dos resíduos estão reportados no Apêndice E.

O sinal positivo de todos os coeficientes signiticativos a, pelo menos, 10\%, nos dá indícios de uma relação positiva entre as variáveis. Na equação de desigualdade salarial entre os admitidos, apenas os coeficientes referentes a esta mesma variável defasada em 1 defasagem e em 4 defasagens e a diferença no saldo de emprego entre os setores, defasado em 4 defasagens, foram significativos a 5\%. A significância do coeficiente de diferença no saldo de emprego defasada em 4 defasagens na equação de desigualdade salarial entre os admitidos pode simbolizar uma demora maior para que o aumento mais do que proporcional nas contratações nos setores selecionados em relação aos demais tenha algum impacto no salário médio relativo de admissão nestes setores.

Na equação da diferença no saldo do emprego, o coeficiente referente à desigualdade salarial entre os admitidos defasada em 1 defasagem foi significativo a 10\%, e os coeficientes da diferença de saldo de emprego defasados em 1 e 2 defasagens foram significativos a $1 \%$. As dummies se mostraram significantes (a $1 \%$ para a crise de 2008 e a $5 \%$ para os meses de dezembro) para explicar somente a trajetória da diferença de saldo entre o emprego nos setores selecionados e os demais, o que pode ser um indicativo de que esta variável é mais sensível aos ciclos econômicos e à sazonalidade.

Na função impulso resposta (Figura 13), nota-se que ambas as variáveis em questão respondem positivamente ao choque na outra. Um choque na diferença do saldo entre 
Tabela 16 - Resultado das estimações: segundo exercício

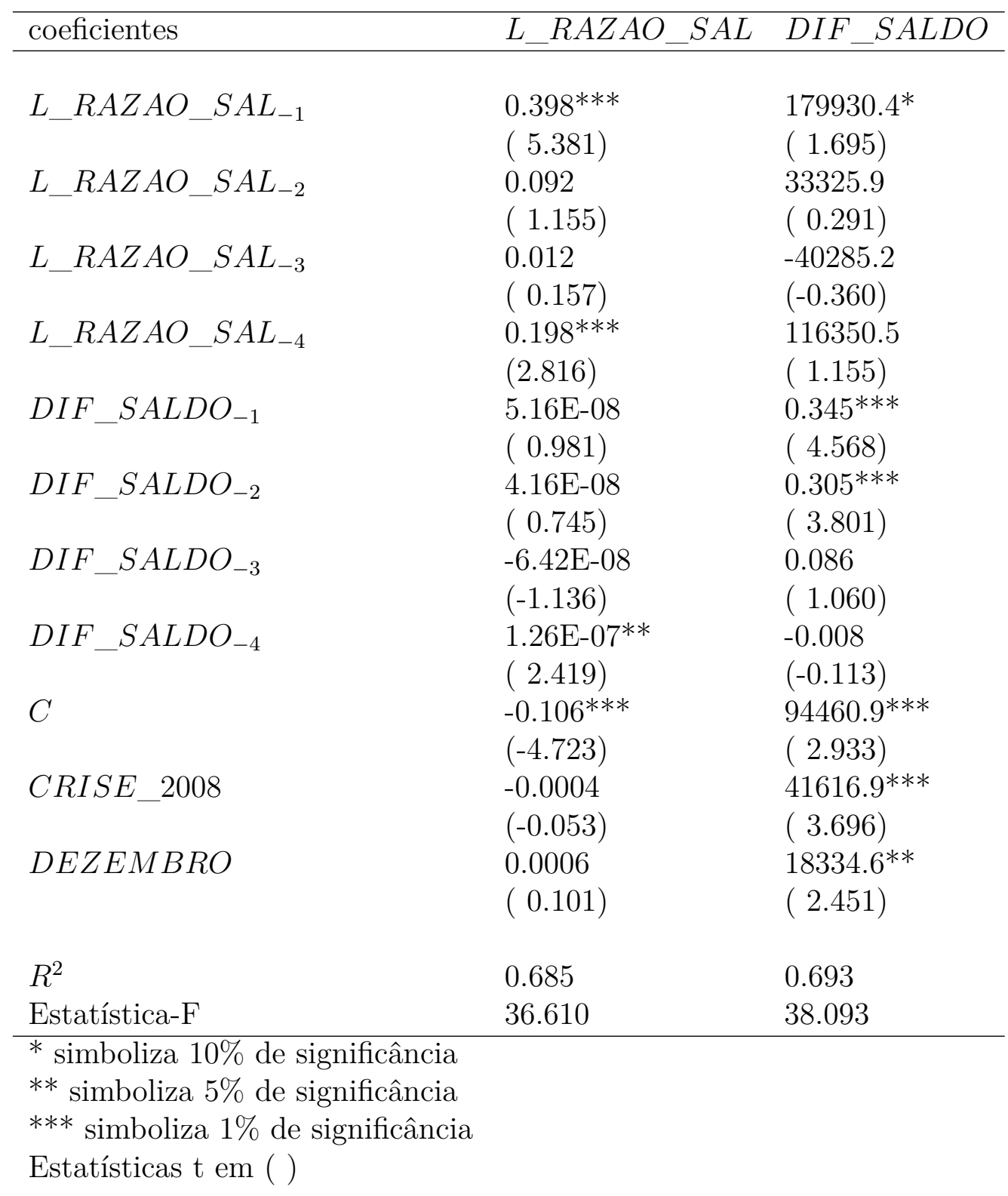

admitidos e desligados dos setores selecionados em relação aos demais gera uma redução na desigualdade salarial (aumento do indicador de " $L \_R A Z A O \_S A L$ ") significante a $5 \%$ após 5 períodos, efeito no qual decai lentamente, mas continuando significativo por aproximadamente mais 20 períodos. No outro sentido, um choque no salário relativo dos admitidos nos setores selecionados em comparação com os demais também impacta positivamente a diferença no saldo de emprego entre os setores, que passa a ser significativo a $5 \%$ a partir do quinto período, se mantento significativo por mais de 15 períodos.

Analisando os resultados para a função impulso-resposta acumulada (Figura 14), é possível confirmar a relação mútua e positiva entre as variáveis em questão. Um aumento mais do que proporcional no salário médio das contratações nos setores selecionados, isto é, um choque positivo em $L \_R A Z A O \_S A L$ é acompanhado por um aumento permanente 
Figura 13 - Função impulso-resposta: segundo exercício

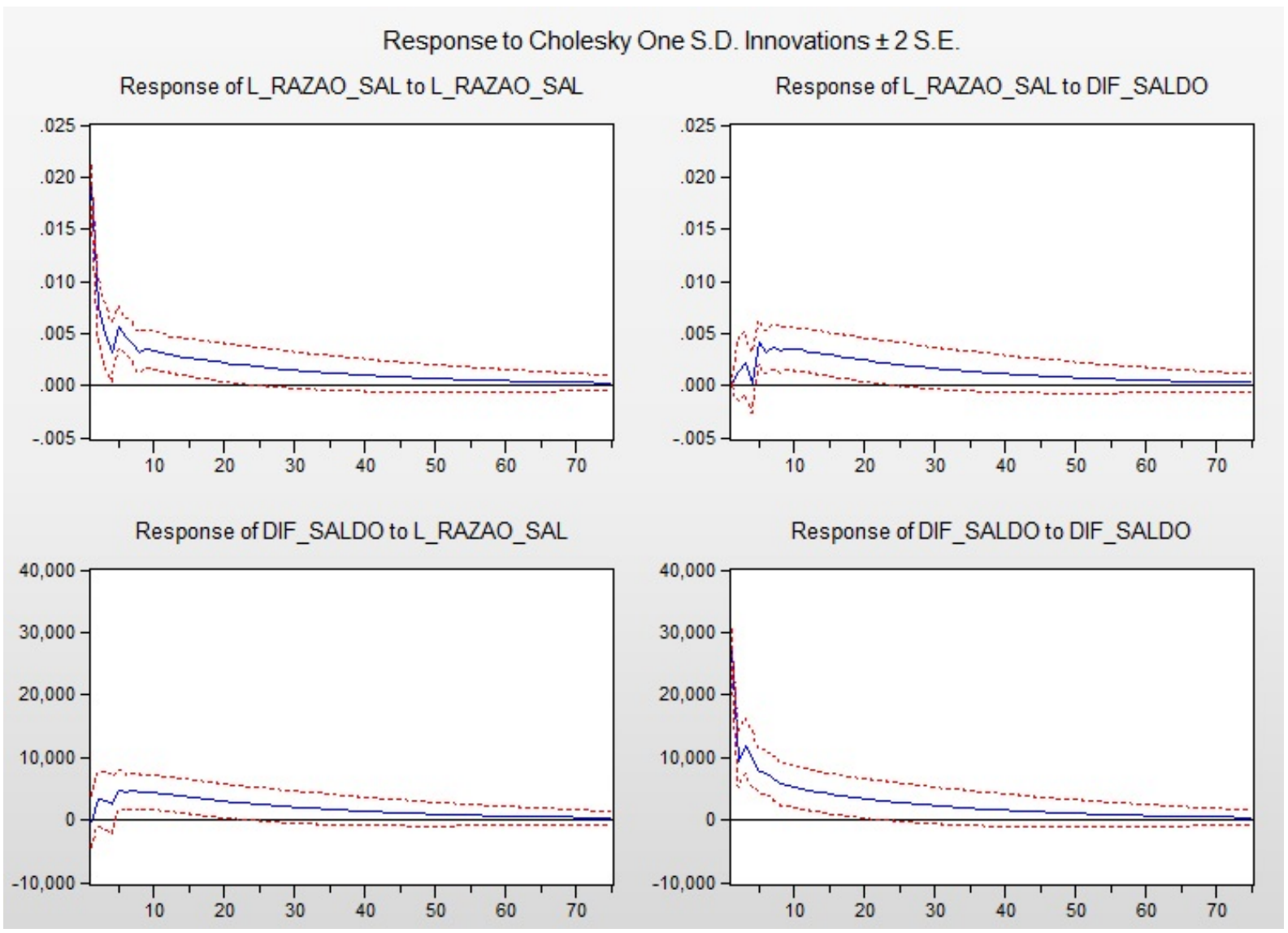

na diferença do saldo de emprego destes setores em relação aos outros. Este é um resultado importante por ilustrar exatamente o efeito da redução da desigualdade salarial representada por um aumento no salário médio inicial dos setores selecionados em relação aos demais - no aumento do nível de emprego nos setores de mais baixa qualificação. O aumento no emprego nos setores de menor produtividade e trabalho-intensivos, como resposta do aumento no salário inicial em setores de mais baixa qualificação, que emprega a população mais pobre, pode simbolizar justamente o efeito do aumento da demanda por estes setores, oriundo do aumento da renda destes novos empregados. O efeito na outra direção, de mudanças no saldo de contratações dos setores selecionados em relação aos demais na desigualdade salarial dos admitidos, também obteve a direção esperada e significante a $5 \%$ de aumento permanente no salário inicial dos trabalhadores contratados nos setores selecionados setores em resposta a um aumento no saldo de emprego nestes em relação aos demais. Este segundo efeito pode simbolizar o imapcto que uma maior demanda por força de trabalho nos setores selecionados pode gerar no poder de barganha dos trabalhadores que estão sendo contratados, já que o mercado de trabalho nestes setores estaria mais aquecido, valorizando-os.

Embora alguns dos coeficientes não tenha sido significativos a 5\%, as funções 
Figura 14 - Função impulso-resposta acumulada: segundo exercício

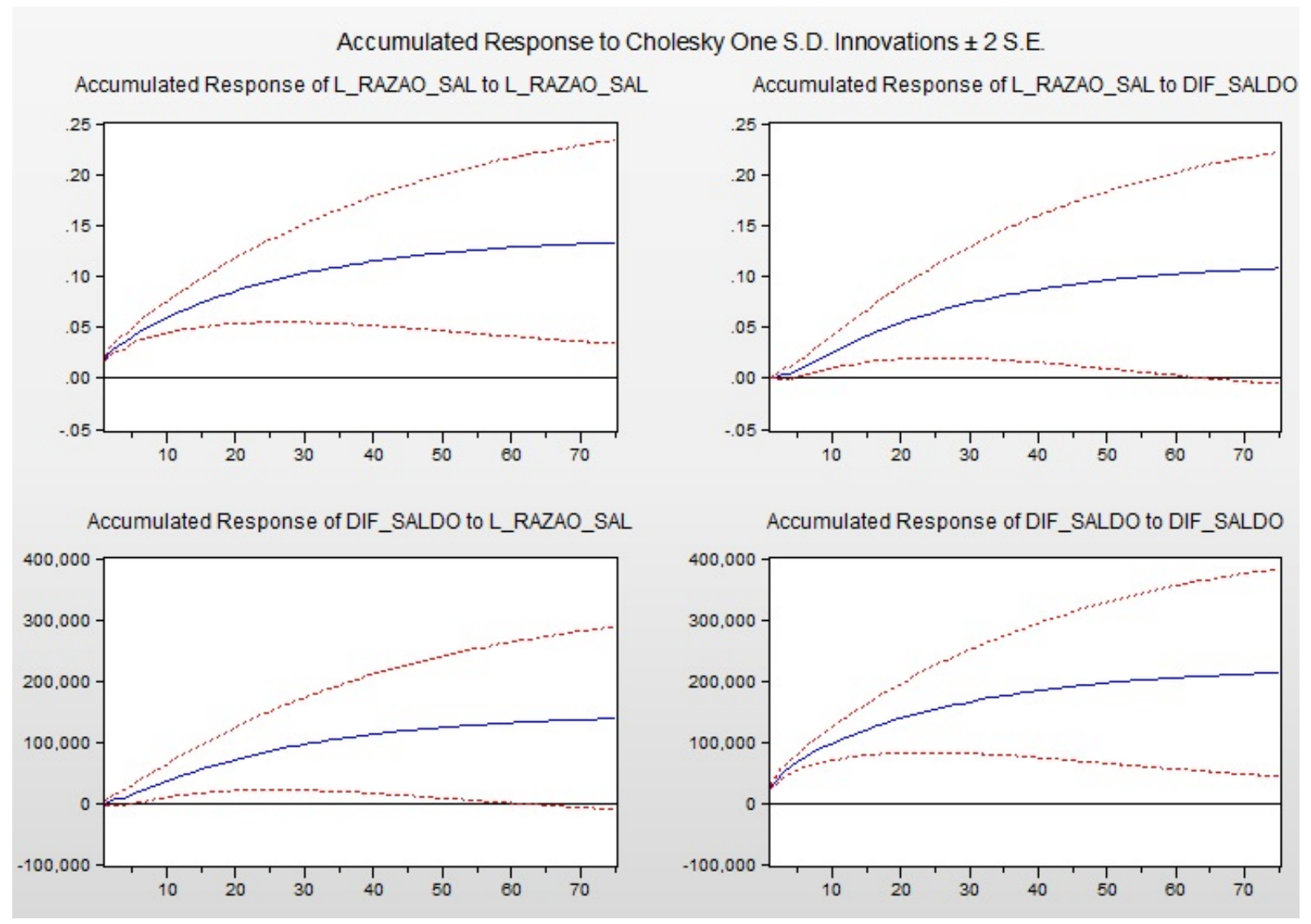

impulso-resposta confirmam a hipótese de que variações na composição do emprego e mudanças na desigualdade salarial estão mutuamente e positivamente correlacionadas.

\subsection{Conclusão}

O presente capítulo pretende contribuir para a literatura empírica ao realizar os primeiros testes econométricos relacionados à hipótese do processo de causação circular e cumulativa, tal como formalizado por Rugitsky (2017) e explorada nesta dissertação. A relação entre a estrutura de emprego (ou do produto) e a desigualdade, contudo, é extremamente complexa, o que torna a tarefa de traduzi-la em um exercício empírico muito difícil. Apesar das várias simplificações de mecanismos e dos indicadores utilizados e da baixa significância de vários dos coeficientes estimados, foi possível identificar que estas variáveis estão mutuamente correlacionadas. Os dois diferentes exercícios, quando analisados de maneira conjunta, nos trazem insights sobre a possível assimetria temporal entre mudanças na composição do emprego (ou do produto) e na desigualdade dentro do mecanismo de causação circular e cumulativa, no sentido de que a distribuição da renda parece ser mais rígida, mudando mais lentamente em resposta a mudanças no emprego e no produto, do que no caso contrário. Desse modo, a hipótese de Rugitsky (2017) parece 
ser confirmada, ainda que o efeito sobre a composição do emprego seja mais rápido do que sobre a desigualdade.

O primeiro exercício é entendido como um exercício de mais longo prazo - 1980 a 2014 -, em que utilizamos dados mais agregados referentes ao tamanho do setor de serviços e construção civil em relação ao da indústria de transformação e a desigualdade de renda medida pelo índice de Gini. Os resultados mostram que estas variáveis possuem uma relação de Granger-causalidade, que se reflete numa cointegração, ou seja, numa relação estrutural de longo-prazo. Um choque na composição do produto reduz a desigualdade de renda, mesmo com a agregação de todos os setores de serviços em um único indicador, ignorando as heterogeneidades internas deste setor. No outro sentido da relação, da desigualdade de renda para a razão do produto dos setores se serviços e construção civil e o produto da indústria de transformação, também foi possível evidenciar uma resposta negativa do segundo ao primeiro, significando que, de fato, as mudanças na distribuição de renda afetam o produto dos setores da economia.

Inspirados pela mudança tendencial dos indicadores utilizados neste primeiro exercício a partir de 2003, junto com a tentativa de utilizar dados com maior especificidade setorial, realizamos um segundo exercício entendido como algo de mais "curto prazo", não só pela periodicidade menor - 2004 a 2019 - mas também pelo fato de os dados simbolizarem variações no nível de emprego e a desigualdade salarial no momento de admissão dos trabalhadores. Ao estimar um VAR, mais uma vez encontramos o resultado de uma relação mútua entre estas variáveis. As funções impulso-resposta e impulso-resposta acumulada deixam claro esta relação para o período analisado, uma vez que as reações são significantes a $5 \%$ nos dois sentidos dos choques, dando robustez aos resultados do primeiro exercício.

Por fim, é importante ressaltar que vários outros canais relevantes para explicar a trajetória econômica brasileira não são levados em consideração nesta análise, tais como a dinâmica dos setores intermediários da economia, a dinâmica dos preços, as mudanças econômicas internacionais, as considerações políticas, e etc. O primeiro deles é o papel dos produtos intermediários, que são eliminados da análise no momento de seleção dos setores, já no capítulo 1.3, e que muito provavelmente influenciam a dinâmica dos setores nos quais eles fornecem insumos. A dinâmica dos preços da economia foi brevemente explorada no 1.4, quando discutimos o fenômeno de "inflação de serviços", entendido como um limitador deste processo. O aumento do rendimento com base da distribuição aumenta o consumo de bens e serviços de baixa tecnologia - já que os de alta tecnologia são importados, como já discutido nesta dissertação, na seção 1.3 -, o que cria uma pressão inflacionária nestes setores pelo lado da demanda. Além disso, a valorização do salário mínimo e a formalização do mercado de trabalho criam pressões nos custos desses mesmos setores intensivos em mão-de-obra, uma vez que, como argumentado por Baumol e Bowden (1965), custos e 
preços de setores sujetos a menores ganhos de produtividade, característicos dos serviços, tendem a crescer mais rapidamente do que aqueles com altos ganhos de produtividade. Além disso, a dinâmica tanto da demanda externa pelos produtos produzidos internamente como do câmbio afeta internamente a economia tanto pelo lado da demanda quanto pelo lado da oferta, ao mudarem os custos dos produtos importados, podendo gerar inflação em alguns setores, ao mesmo tempo que cria uma certa vantagem via preços em setores exportadores.

A incorporação de algumas dessas variáveis tornaria a análise mais precisa e poderia fornecer insights sobre algumas das limitações enfrentadas pela economia, e ficam como sugestões para próximos trabalhos. Estas poderiam ser dificuldades inerentes a este processo de distribuição e ao processo de mudança da composição produtiva, como discutimos no Capítulo 1.4, ou, em alguns casos, resultam de choques exógenos (por exemplo, mudanças políticas e internacionais). Além disso, mesmo após a rápida recuperação econômica em 2008, a crise brasileira interna instaurada após 2014 oferece desafios adicionais à análise desses mecanismos. 


\section{Conclusão}

A presente dissertação tem como principal contribuição a retomada da centralidade do papel da estrutura produtiva no debate sobre as causas e efeitos da desigualdade de renda, sob uma perspectiva empírica e teórica e à luz do período recente de crescimento econômico brasileiro. Analisar a relação entre a distribuição da renda e a estrutura produtiva nos auxilia no estudo dos efeitos de políticas públicas para a dinâmica da economia.

O primeiro capítulo investiga dois períodos de de expansão da economia brasileira em que a desigualdade e a composição do produto e do emprego podem estar relacionadas: os anos 1960-1973 e os anos 2003-2014. Assim como argumentado por Tavares e Serra (1972), o o aumento da desigualdade a partir de meados dos anos 1960 contou com um efeito significativo das políticas de restrição do salário mínimo e de repressão de atividades sindicais, característico do governo militar, iniciado em 1964, mas também respondeu às alterações na estrutura produtiva que marcaram o processo de industrialização do período, com uma dinâmica interna de interação com a estrutura produtiva de modo a reforçar o aumento da desigualdade. Para além de observar o efeito de mudanças na composição setorial da economia sobre as desigualdades de rendimento, Wells (1974) destaca a importância de se analisar os determinantes do alto diferencial de salários entre o setor moderno e o setor tradicional ao se estudar o processo de desenvolvimento econômico.

It therefore seems to be the case that, at least according to these data, the shift of employment to more modern sectors, which characterized the process of economic growth in Brazil, was responsible to some extent for increasing differentiation. However, even though it is true that intersectoral differences in average earnings and changes in employment structure were responsible for an increasing proportion of inequality, this does not explain anything other than in a purely statistical sense; what we really need to know is why it is that more 'modern' sectors pay higher earnings than 'traditional' sectors and why it is that the dispersion of earnings is greater in the former than in the latter (WELLS, 1974, p. 20).

Nesse sentido, os anos 2000 parecem ter sido marcados pelo mesmo dilema entre modernizar e distribuir, ainda que com a dinâmica reversa: desta vez, houve redução das desigualdades salariais à custa de uma regressão da estrutura produtiva, com perda de peso dos setores industriais e aumento da participação de setores não comercializáveis de baixa produtividade. Assim, em um mecanismo de causação circular e cumulativa, o 
crescimento de setores intensivos em mão de obra menos qualificada reforçava os ganhos salariais maiores na base da pirâmide e vice-versa.

As políticas redistributivas dos governos Lula - essencialmente o Programa Bolsa Família e a valorização do salário mínimo -, por aumentarem a renda da população mais pobre, teriam estimulado o consumo, visto que essas pessoas possuem uma propensão a consumir maior do que a da população mais rica, permitindo o acesso a produtos que antes não estavam disponíveis para elas, tais como serviços (restaurantes, cabelereiro, manicure) e bens manufaturados (celulares, computadores, televisão). Tais produtos manufaturados, por sua vez, foram majoritariamente importados, resultando num crescimento interno do produto e do emprego no setor de serviços e construção civil, principalmente, assim como em outros setores de bens não-comercializáveis. Estes setores, por serem majoritariamente trabalho-intensivos e contratarem mão de obra pouco qualificada, para suprir o aumento da demanda, criaram postos de trabalho, dando emprego justamente à população mais pobre, que viu sua renda crescer mais ainda devido aos novos empregos e, assim, expandiram o consumo, reiniciando o ciclo de causação circular cumulativa.

A seção 1.3 olhou para a evolução do emprego e do consumo das famílias que recebem até 3 salários mínimos, e para o nível da produtividade e de salário médio dos setores da economia entre os anos de 2003 e 2008, no intuito de selecionar quais os setores teriam sido os mais afetados neste processo. Foram selecionados 7 setores (vestuário, calçados e têxteis; construção civil; móveis e produtos de diversas indústrias, serviços de manutenção e reparo, serviços prestados a famílias e associações; serviços domésticos; e serviços de alojamento e alimentação), que correspondem a 30.3\% do emprego, na média, entre 2004 e 2015, e por $13.7 \%$ do PIB, na média, durante o mesmo período. Os dados do CAGED para admissões e demissões por setor e de salário médio entre os admitidos por setor confirmam o movimento de crescimento no emprego e de valorização no salário dos setores selecionados em relação aos demais. O aumento mais do que proporcional do salário de admissão dos setores selecionados, em relação aos demais, significa que os trabalhadores que estão sendo contratados nestes setores estão ganhando mais relativamente aos trabalhadores dos outros setores. Como os trabalhadores dos setores selecionados tem um salário médio menor que o resto da economia, o aumento dessa variável, em conjunto com o aumento nas contratações, significa que a desigualdade salarial realmente reduziu por esse efeito.

O capítulo 1 se encerra apontando os limitadores que este processo de crescimento e de causação circular e cumulativa enfrentaram no Brasil. O primeiro limitador está diretamente relacionado à precariedade da estrutura produtiva brasileira, isto é, à dependência externa para a produção e consumo de bens mais sofisticados, que exige a importação de tecnologias ainda não produzidas internamente, e que é potencializada neste período, principalmente por conta da taxa de câmbio sobrevalorizada. O segundo limitador está 
relacionado com a própria dinâmica interna da economia: a pressão via demanda e via custo nos setores trabalho-intensivos e não-comercializáveis geram um aumento substancial de preços - criando um fenômeno de "inflação de serviços". Por fim, o último limitador diz respeito à maneira como a distribuição de renda foi feita, com a manutenção da alta parcela da renda apropriada pelo topo da distribuição e uma redução da desigualdade na base, restringindo o escopo para a continuação de tal processo distributivo. Além disso, a perda de participação dos trabalhadores do meio da pirâmide, que pode ser compreendida como o outro lado da moeda da própria inflação de serviços, pode ter acirrado conflitos distributivos sobre a renda e criado limitadores políticos para a continuidade do processo em questão.

O segundo capítulo da dissertação se propôs a investigar este processo de causação circular e cumulativa em um modelo liderado pela demanda agregada do tipo Kaleckiano. Para tal, criamos um modelo de economia aberta com dois setores, um comercializável e outro não-comercializável, em que há desigualdade salarial entre eles. A análise de exercícios de estática comparativa já nos permitiu perceber relações importantes. Demonstrou-se que a redução da desigualdade salarial, representada por um aumento nos salários mais baixos do setor não-comercializável altera a composição do produto (e emprego) na direção deste mesmo setor, se considerarmos que a condição de estabilidade Keynesiana é válida. Além disso, a propensão média a importar responde à redução da desigualdade salarial de forma ambígua, dependendo do impacto global sobre o produto total da economia e sobre o produto do setor comercializável. A ambiguidade sugere um trade-off entre distribuição de renda e equilíbrio da balança comercial. Se a diminuição da desigualdade salarial aumenta o produto total da economia, o efeito pode ser positivo ou negativo, dependendo da propensão a poupar - devido ao efeito multiplicador-, e das magnitudes do aumento (ou diminuição) no produto dos dois setores (e, consequentemente, do produto total). Se o produto total responde negativamente ao aumento dos salários do setor não-comercializável, a propensão média a importar também responderá negativamente.

Levando em consideração as dinâmicas de ajustamento de preços e os conflitos sobre os salários nominais, diferentes condições de estabilidade aparecem, a depender da temporalidade dos ajustes de preços e quantidades. Em consequência, cada caso resulta em diferentes implicações para políticas públicas. Primeiramente, a condição Keynesiana de estabilidade é uma condição suficiente para que a redução na desigualdade salarial seja acompanhada de um aumento mais do que proporcional no setor de bens não-comercializáveis que, conjuntamente com as dinâmicas de evolução da composição do emprego e da desigualdade salarial ao longo do tempo, pode resultar num sistema globalmente estável ou instável.

Chamamos a situação de instabilidade de "inflação de serviços", uma vez que está relacionada à trajetória explosiva dos preços (e salários) no setor de bens não- 
comercializáveis. A presença de duas forças operando no mesmo sentido, a pressão de custos e a pressão de demanda, explicam esta instabilidade e são características de uma situação do tipo "inflação de serviços". Para estabilizar o sistema nesta situação é preciso que o poder de barganha dos trabalhadores seja baixo para frear o crescimento dos salários, assim como uma baixa velocidade de ajuste do emprego auxilia a redução da pressão de demanda.

O segundo caso analisado é quando a condição de estabilidade Keynesiana não é válida, ou seja, em que a redução da desigualdade salarial aumenta a participação relativa do setor de bens comercializáveis na economia. Este caso representa a situação em que a instabilidade está relacionada a um espiral que leva a economia a salários do setor de comercializáveis cada vez mais baixos, ao mesmo tempo em que seu produto aumenta. Diferentemente do caso anterior, é preciso que os trabalhadores tenham forte poder de barganha para impedir a redução dos salários no setor comercializável e estabilizar a economia. A velocidade de ajuste do emprego, contudo, também precisa ser baixa para facilitar a estabilidade. A conclusão comum às duas situações é que um mercado de trabalho mais rígido que faça com que contratações e demissões ocorram mais lentamente ajuda a economia a se estabilizar. Dito de outra maneira, uma maior formalização do trabalho que exija mais burocracias ao contratante tanto para demissões quanto para admissões, por exemplo, exerce uma força estabilizadora nesta economia.

Por fim, e capítulo 3 apresentou uma análise econométrica da hipótese de causação circular e cumulativa em dois exercícios empíricos distintos. O primeiro consistiu em estimar um VEC para a relação a composição do produto e a desigualdade de renda entre 1980 e 2014. A composição do produto foi medida pela razão entre o PIB dos setores de serviços e construção civil e o PIB na indústria de transformação. Já a desigualdade foi medida pelo índice de Gini. Os resultados mostram que estas variáveis possuem uma relação de Granger-causalidade que se reflete em uma cointegração. Os resultados mostram que um aumento na participação dos serviços e da construção civil reduz a desigualdade de renda. No outro sentido, um choque na desigualdade de renda também parece reduzir a razão do produto dos setores de serviços e construção civil em relação ao produto da indústria de transformação.

O segundo exercício consiste na estimação de um VAR para a relação entre composição do emprego e desigualdade salarial entre os meses de janeiro de 2004 a março de 2019. A partir de dados do Cadastro Geral de Empregados e Desempregados (CAGED), construímos os indicadores de mudanças na composição do emprego e na desigualdade salarial baseados na seleção de setores de baixa produtividade e salário e com pouco conteúdo importado marcados por um crescimento do consumo e do emprego ao longo do período. Mais uma vez, as funções impulso-resposta deixam clara a existência de um processo de causação circular e cumulativa em que a queda nos diferenciais de salário e o 
aumento do peso de tais setores no emprego se reforçam mutuamente.

A falta de dados melhores para os anos 60 e 70 nos impede que exercício similar seja realizado para avaliar a interação entre a composição do produto e a desigualdade durante o período do chamado "milagre econômico brasileiro". Contudo, o resgate do debate da época sobre as causas do aumento da desigualdade e, em especial, da contribuição de Tavares e Serra (1972), elucidaram canais de interação entre a distribuição de renda e a estrutura produtiva que se revelaram úteis para a compreensão do período recente. A verificação empírica do processo de causação circular e cumulativa que já havia sido formalizado por Rugitsky (2017) lançou luz sobre os desafios para o desenho de um modelo de desenvolvimento econômico que combine crescimento e distribuição. Tais desafios se mostraram ainda maiores à luz da recente crise política e econômica brasileira. Para caminharmos em direção a uma sociedade mais igualitária e com maiores níveis educacionais, é necessário desenvolver setores que incorporem esses trabalhadores, o que por sua vez depende do dinamismo da demanda interna e externa por estes produtos. Nesse sentido, o processo de desenvolvimento deve ser analisado sob uma perspectiva dinâmica em que a redução da desigualdade acompanha a demanda por trabalhadores mais qualificados.

A experiência brasileira também traz lições para a literatura téorica kaleckiana: a incorporação da heterogeneidade estrutural e outras dimensões de desigualdade de renda é fundamental para a compreensão de formas sustentáveis de se alcançar uma distribuição mais equitativa da renda junto ao processo de crescimento econômico dos países. 



\section{Referências}

BAUMOL, W. J.; BOWDEN, W. G. On the performing arts: The anatomy of their economic problems. The American economic review, JSTOR, v. 55, n. 1/2, p. 495-502, 1965. Citado 3 vezes nas páginas 56, 76 e 101.

BHADURI, A. On the dynamics of profit-led and wage-led growth. Cambridge Journal of Economics, v. 32, n. 1, p. 147-160, 2008. Disponível em: <http://dx.doi.org/10.1093/cje/bem012>. Citado na página 75.

BIELSCHOWSKY, R. Estratégia de desenvolvimento e as três frentes de expansão no Brasil: um desenho conceitual. [S.1.], 2012. Citado 2 vezes nas páginas 31 e 63.

BLECKER, R. Open economy models of distribution and growth. 01 2011. Citado 3 vezes nas páginas 67,72 e 74 .

BRENCK, C.; CARVALHO, L. Limites para o crescimento com mudança estrutural no brasil no século xxi. In: CEPAL (Ed.). Alternativas para o desenvolvimentto brasileiro: novos horizontes para a mudança estrutural com igualdade. Brasília: [s.n.], 2019. Citado 2 vezes nas páginas 31 e 57.

BRUNO, O. Long-run positions and short-run dynamics in a classical growth model. Metroeconomica, Wiley Online Library, v. 50, n. 1, p. 119-137, 1999. Citado na página 75.

CARVALHO, L. Valsa brasileira: do boom ao caos econômico. [S.l.]: Editora Todavia SA, 2018. Citado 3 vezes nas páginas 31, 43 e 54.

CARVAlHO, L.; GIOVANNETTI, L. F. Distribuição de renda, mudança estrutural e inflação de serviços no brasil. XLIII Encontro Nacional de Economia. ANPEC-Associação Nacional dos Centros de Pósgraduação em Economia, 2016. Disponível em: <https://www.anpec.org.br/encontro/2015/submissao/files_I/i6216b6356aa9ce39d4bdf966e3021f511.pdf >. Citado 3 vezes nas páginas 54, 56 e 76.

CARVALHO, L.; REZAI, A. Personal income inequality and aggregate demand. Cambridge Journal of Economics, v. 40, n. 2, p. 491-505, 2016. Disponível em: <http://dx.doi.org/10.1093/cje/beu085>. Citado 2 vezes nas páginas 25 e 61.

CARVALHO, L. Barbosa de; RUGITSKY, F. Growth and distribution in Brazil the 21st century: revisiting the wage-led versus profit-led debate. [S.l.], 2015. Disponível em: $<$ https://EconPapers.repec.org/RePEc:spa:wpaper:2015wpecon25>. Citado 5 vezes nas páginas 26, 29, 31, 43 e 46.

CARVALHO, S. S. de et al. O Consumo das Famílias no Brasil entre 2000 e 2013: uma análise estrutural a partir de dados do Sistema de Contas Nacionais e da Pesquisa de Orçamentos Familiares. [S.1.], 2016. Citado na página 45.

CLARK, C. The morphology of economic growth. The Conditions of Economic Progress (Macmillan, London), p. 337-373, 1940. Citado na página 55. 
CORRÊA, V. P.; SIMIONI, M. Desenvolvimento e igualdade. [S.l.]: Instituto de Pesquisa Econômica Aplicada (Ipea), 2010. Citado na página 52.

DENTON, F. T. Adjustment of monthly or quarterly series to annual totals: an approach based on quadratic minimization. Journal of the American Statistical Association, Taylor \& Francis, v. 66, n. 333, p. 99-102, 1971. Citado 2 vezes nas páginas 86 e 87.

DUTT, A. K. Growth, distribution and uneven development. [S.l.]: CUP Archive, 1990. Citado 2 vezes nas páginas 25 e 61.

DUTT, A. K. Profit-rate equalization in the kalecki-steindl model and the "overdetermination" problem. The Manchester School, Wiley Online Library, v. 65, n. 4, p. 443-451, 1997. Citado 2 vezes nas páginas 25 e 61.

ENGLE, R. F.; GRANGER, C. W. Co-integration and error correction: representation, estimation, and testing. Econometrica: journal of the Econometric Society, JSTOR, p. 251-276, 1987. Citado na página 83.

FUJITA, S. Mark-up pricing, sectoral dynamics, and the traverse process in a two-sector kaleckian economy. Kyoto University Graduate School of Economics Discussion Paper Series, E-15-005, 2015. Citado 2 vezes nas páginas 25 e 61.

GIOVANNETTI, L. F. L. Inflação de serviços no Brasil: pressão de demanda ou de custos? Dissertação (Mestrado) - Mestrado Profissional -Fundação Getúlio Vargas, SP, 2013. Citado 2 vezes nas páginas 26 e 30.

GOBETTI, S. W.; ORAIR, R. O. et al. Tributação e distribuição da renda no Brasil: novas evidências a partir das declarações tributárias das pessoas físicas. [S.l.], 2015. Citado na página 30.

GRANGER, C. W. Investigating causal relations by econometric models and cross-spectral methods. Econometrica: Journal of the Econometric Society, JSTOR, p. 424-438, 1969. Citado na página 83.

HOFFMANN, R. Distribuição de renda e crescimento econômico. Estudos Avançados, scielo, v. 15, p. 67 - 76, 04 2001. ISSN 0103-4014. Disponível em: <http://www.scielo.br/scielo.php?script=sci_arttextpid=S0103-40142001000100007nrm=iso $>$. Citado na página 33.

HOFFMANN, R. Desigualdade da renda e das despesas per capita no brasil, em 2002-2003 e 2008-2009, e avaliação do grau de progressividade ou regressividade de parcelas da renda familiar. Economia e Sociedade, scielo, v. 19, p. 647 - 661, 12 2010. ISSN 0104-0618. Disponível em: <http://www.scielo.br/scielo.php?script=sci_arttextpid=S0104$06182010000300010 \mathrm{nrm}=$ iso $>$. Citado na página 45.

HOFFMANN, R.; OLIVEIRA, R. The evolution of income distribution in brazil in the agricultural and the non-agricultural sectors. World Journal of Agricultural Research, v. 2, n. 5, p. 192-204, 2014. Citado na página 44.

KALECKI, M. A theory of profits. The Economic Journal, JSTOR, v. 52, n. 206/207, p. 258-267, 1942. Citado na página 25. 
KOMATSU, B. K.; FILHO, N. A. M. Salário mínimo e desigualdade salarial: um estudo com densidades contrafactuais nas regiões metropolitanas brasileiras. Instituto de Pesquisa Econômica Aplicada (Ipea), 2015. Citado 2 vezes nas páginas 43 e 44.

KUZNETS, S. Economic growth and income inequality. The American economic review, JSTOR, v. 45, n. 1, p. 1-28, 1955. Citado na página 33.

LANGONI, C. G. Distribuição da renda e desenvolvimento econômico do brasil. Estudos Econômicos (São Paulo), v. 2, n. 5, p. 5-88, 1972. Citado 5 vezes nas páginas 34, 38, 41, 42 e 59.

LAVOIE, M. Post-Keynesian economics: new foundations. [S.1.]: Edward Elgar Publishing, 2014. Citado na página 68.

LOUREIRO, P. The Ebb and Flow of the Pink Tide: reformist development strategies in Brazil and Argentina. Tese (Doutorado) - Department of Economics, SOAS, University of London, 2018. Citado 3 vezes nas páginas 45, 46 e 52.

MARTINS, G. K.; RUGITSKY, F. The commodities boom and the profit squeeze: output and profit cycles in Brazil (1996-2016). [S.1.], 2018. Citado na página 58.

MAURIZIO, R. Labour formalization and declining inequality in argentina and brazil in 2000s: a dynamic approach. ILO Research Paper, n. 9, 2014. Citado na página 95.

MAURIZIO, R.; VAZQUEZ, G. Distribution effects of the minimum wage in four latin american countries: Argentina, brazil, chile and uruguay. International Labour Review, Wiley Online Library, v. 155, n. 1, p. 97-131, 2016. Citado na página 44.

MEDEIROS, C. A. d. Inserçãoo externa, crescimento e padrões de consumo na economia brasileira. Instituto de Pesquisa Econômica Aplicada (Ipea), 2015. Citado 5 vezes nas páginas 43, 44, 45, 47 e 48.

MEDEIROS, M.; CASTRO, F. Á. de. A composição da renda no topo da distribuição: evolução no brasil entre 2006 e 2012, a partir de informações do imposto de renda. Economia e Sociedade, v. 27, n. 2, 2018. Citado na página 30.

MEDEIROS, M.; SOUZA, P. H. Ferreira de; CASTRO, F. Avila de. O topo da distribuiçãoo de renda no brasil: primeiras estimativas com dados tributários e comparaçãoo com pesquisas domiciliares (2006-2012). Dados-Revista de Ciências Sociais, Universidade do Estado do Rio de Janeiro, v. 58, n. 1, 2015. Citado 2 vezes nas páginas 30 e 57.

MORCEIRO, P. C. Influência Metodológica na Desindustrialização Brasileira e Correções na Composição Setorial do PIB. [S.1.], 2019. Citado na página 85.

MORGAN, M. Extreme and persistent inequality: New evidence for brazil combining national accounts, surveys and fiscal data, 2001-2015. World Inequality Database (WID. org) Working Paper Series, v. 12, p. 1-50, 2017. Citado na página 57.

NASSIF, A.; FEIJO, C.; ARAÚJO, E. Structural change and economic development: is brazil catching up or falling behind? Cambridge Journal of Economics, Oxford University Press UK, v. 39, n. 5, p. 1307-1332, 2014. Citado 2 vezes nas páginas 52 e 54. 
NISHI, H. A dynamic analysis of demand and productivity growth in a two-sector kaleckian model. 2018. Citado 2 vezes nas páginas 25 e 61.

PARK, M.-S. Accumulation, capacity utilisation and distribution. Contributions to Political Economy, Oxford University Press, v. 16, n. 1, p. 87-101, 1997. Citado 2 vezes nas páginas 25 e 61 .

PIKETTY, T. Capital in the twenty-first century. [S.l.]: Harvard University Press, 2014. Citado na página 26.

ROWTHORN, R. E. Conflict, inflation and money. Cambridge Journal of Economics, JSTOR, v. 1, n. 3, p. 215-239, 1977. Citado na página 74.

RUGITSKY, F. Milagre, miragem, antimilagre: A economia política dos governos lula e as raízes da crise atual. Rev. Fevereiro, v. 9, 2016. Citado na página 31.

RUGITSKY, F. The rise and fall of the Brazilian economy (2004-2015): the economic antimiracle. [S.1.], 2017. Citado 8 vezes nas páginas 26, 45, 47, 48, 60, 62, 100 e 107.

SANTOS, C. H. M. d. et al. A natureza da inflação de serviços no brasil: 1999-2014. Instituto de Pesquisa Econômica Aplicada (Ipea), 2016. Citado na página 55.

SANTOS, C. H. M. d. et al. Por que a elasticidade-câmbio das importações é baixa no brasil? evidências a partir das desagregações das importações por categorias de uso. Instituto de Pesquisa Econômica Aplicada (Ipea), 2015. Citado 3 vezes nas páginas 46, 52 e 65.

SERRANO, F.; SUMMA, R. Aggregate demand and the slowdown of brazilian economic growth in 2011-2014. Nova Economia, SciELO Brasil, v. 25, n. SPE, p. 803-833, 2015. Citado na página 31.

SIMS, C. A. Macroeconomics and reality. Econometrica: journal of the Econometric Society, JSTOR, p. 1-48, 1980. Citado na página 83.

SOARES, S. et al. Programas de tranferência condicionada de renda no brasil, chile e méxico: impactos sobre a desigualdade. Instituto de Pesquisa Econômica Aplicada (Ipea), 2007. Citado na página 44.

SOUTO, A. M. Distribuição pessoal da renda e elasticidade renda da demanda por importações no Brasil: evidências a partir de regressões quantílicas para o período 2002-2009. Dissertação (Mestrado) — Universidade de São Paulo, 2015. Citado 2 vezes nas páginas 30 e 71 .

SOUZA, P. H. G. F. d. A desigualdade vista do topo: a concentração de renda entre os ricos no brasil, 1926-2013. 2016. Citado 2 vezes nas páginas 32 e 34.

TAVARES, M. d. C.; SERRA, J. Além da estagnação. Da substituição de importações ao capitalismo financeiro, Zahar Rio de Janeiro, p. 153-207, 1972. Citado 11 vezes nas páginas 25, 26, 30, 32, 35, 36, 42, 47, 59, 103 e 107.

TAYLOR, L. Demand composition, income distribution, and growth. In: Joan Robinson and Modern Economic Theory. [S.l.]: Springer, 1989. p. 623-637. Citado 2 vezes nas páginas 61 e 63. 
TAYLOR, L.; BACHA, E. L. The unequalizing spiral: A first growth model for belindia. The Quarterly Journal of Economics, JSTOR, p. 197-218, 1976. Citado 2 vezes nas páginas 61 e 62 .

THIRLWALL, A. The balance of payments constraint as an explanation of international growth rate differences. BNL Quarterly Review, v. 32, n. 128, p. 45-53, 1979. Disponível em: <https://EconPapers.repec.org/RePEc:psl:bnlaqr:1979:01>. Citado na página 53.

THIRLWALL, A. P. Reflections on the concept of balance-of-payments-constrained growth. Journal of Post Keynesian Economics, Taylor \& Francis, v. 19, n. 3, p. 377-385, 1997. Citado na página 53.

VELOSO, F. A.; VILLELA, A.; GIAMBIAGI, F. Determinantes do"milagre"econômico brasileiro (1968-1973): uma análise empírica. Revista Brasileira de Economia, SciELO Brasil, v. 62, n. 2, p. 221-246, 2008. Citado na página 32.

WEINTRAUB, S. approach to the theory of income distribution. Chilton Co., 1958. Citado na página 74 .

WELLS, J. Distribution of earnings, growth and the structure of demand in brazil during the 1960's. World Development, Elsevier, v. 2, n. 1, p. 9-24, 1974. Citado 6 vezes nas páginas 25, 30, 32, 39, 59 e 103. 

Apêndices 



\section{APÊNDICE A - Tabela de Tradução da POF para o SCN}

Para realizar a tradução entre a classificação das Pesquisas de Orçamentos Familiares (POF) e o Sistema de Contas Nacionais (SCN), nos beneficiamos do dicionário para os microdados da POF, disponível no site do IBGE. Como a descrição dos dados do POF tem uma agregação muito diferente daquela dos dados de produção, optamos por unir alguns dos setores do SCN em grupos maiores, o que nos ajudou a adequar melhor as categorias de consumo a eles. Isso pode ser encontrado na Tabela 17.

Tabela 17 - Setores do SCN unificados

\begin{tabular}{|c|c|}
\hline $\begin{array}{c}\text { Agricultura } \\
\text { Pecuária e Pesca } \\
\text { Alimentos e bebidas }\end{array}$ & Alimentação \\
\hline $\begin{array}{c}\text { Serviços prestados a famílias e associações } \\
\text { Serviços domésticos }\end{array}$ & Outros serviços \\
\hline $\begin{array}{c}\text { Produtos de celulose e papel } \\
\text { Discos, jornais, revistas }\end{array}$ & $\begin{array}{c}\text { Discos, jornais, revistas } \\
\text { e outros produtos de papel }\end{array}$ \\
\hline $\begin{array}{c}\text { Têxteis } \\
\text { Roupas e acessórios } \\
\text { Artefatos de couro e sapato }\end{array}$ & $\begin{array}{c}\text { Vestuário, calçados e têxteis } \\
\text { Produtos de madeira - exceto móveis } \\
\text { Borracha e Plástico }\end{array}$ \\
$\begin{array}{c}\text { Produtos de madeira, borracha e plástico - } \\
\text { exceto móveis }\end{array}$ \\
\hline
\end{tabular}




\begin{tabular}{|c|c|}
\hline POF & SCN \\
\hline \multicolumn{2}{|l|}{1 Despesas totais } \\
\hline \multicolumn{2}{|l|}{2 Despesas correntes } \\
\hline \multicolumn{2}{|l|}{ 2.1 Gasto com consumo } \\
\hline \multirow[t]{3}{*}{ 2.1.1 Alimentação } & Agricultura \\
\hline & Pecuária e pesca \\
\hline & Alimentos e bebidas \\
\hline \multicolumn{2}{|l|}{ 2.1.2 Moradia } \\
\hline 2.1.2.1 Aluguéis & Construção \\
\hline 2.1.2.2 Serviços e taxas & Serviços de alimentação e acomodação \\
\hline 2.1.2.2.1 Energia elétrica & $\begin{array}{l}\text { Geração de eletricidade e distribuição de gás } \\
\text { e água e limpeza urbana }\end{array}$ \\
\hline 2.1.2.2.2 Telefone & Serviços de informação \\
\hline 2.1.2.2.3 Celulares & $\begin{array}{l}\text { Máquinas de escritório e } \\
\text { equipamentos eletrônicos }\end{array}$ \\
\hline 2.1.2.2.4 Gás & $\begin{array}{l}\text { Geração de eletricidade e distribuição de gás } \\
\text { e água e limpeza urbana }\end{array}$ \\
\hline 2.1.2.2.5 Água e esgoto & $\begin{array}{l}\text { Geração de eletricidade e distribuição de gás } \\
\text { e água e limpeza urbana }\end{array}$ \\
\hline 2.1.2.2.6 Outros & Serviços de alimentação e acomodação \\
\hline 2.1.2.3 Menutenção da casa & Serviços de alimentação e acomodação \\
\hline 2.1.2.4 Produtos de limpeza & Higiene, limpeza pessoal e perfumaria \\
\hline 2.1.2.5 Móveis e objetos para a casa & Móveis e produtos de diversas indústrias \\
\hline 2.1.2.6 Eletrodomésticos & Equipamentos eletrônicos \\
\hline 2.1.2.7 Reparo de objetos domésticos & Serviços de manutenção e reparação \\
\hline \multicolumn{2}{|l|}{ 2.1.3 Vestuário } \\
\hline 2.1.3.1 Roupas masculinas & Vestuário, calçado e têxteis \\
\hline 2.1.3.2 Roupas femininas & Vestuário, calçado e têxteis \\
\hline 2.1.3.3 Roupas infantis & Vestuário, calçado e têxteis \\
\hline 2.1.3.4 Sapatos & Vestuário, calçado e têxteis \\
\hline 2.1.3.5 Joalharia e bijutaria & Vestuário, calçado e têxteis \\
\hline 2.1.3.6 Têxteis & Têxteis \\
\hline \multicolumn{2}{|l|}{ 2.1.4 Transporte } \\
\hline 2.1.4.1 Trasporte urbano & Transporte, armazenagem e correio \\
\hline 2.1.4.2 Gasolina - veículo próprio & Refino de petróleo e coque \\
\hline 2.1.4.3 Álcool - veículo próprio & Álcool \\
\hline 2.1.4.4 Manutenção - veículo próprio & Serviços de manutenção e reparação \\
\hline 2.1.4.5 Aquisição de veículos & Automóveis, caminhões e ônibus \\
\hline 2.1.4.6 Viagens & Serviços de alimentação e acomodação \\
\hline 2.1.4.7 Outros & Transporte, armazenagem e correio \\
\hline \multicolumn{2}{|l|}{ 2.1.5 Higiene e cuidados pessoais } \\
\hline 2.1.5.1 Perfume & Higiene, limpeza pessoal e perfumaria \\
\hline 2.1.5.2 Produtos de cabelo & Higiene, limpeza pessoal e perfumaria \\
\hline 2.1.5.3 Sabonete & Higiene, limpeza pessoal e perfumaria \\
\hline 2.1.5.4 Ferramentas e produtos para uso pessoal & Higiene, limpeza pessoal e perfumaria \\
\hline \multicolumn{2}{|l|}{ 2.1.6 Saúde assistance } \\
\hline 2.1.6.1 Medicina & Produtos farmacêuticos \\
\hline 2.1.6.2 Seguro saúde & $\begin{array}{l}\text { Seguro intermediário financeiro e pensão } \\
\text { complementar e serviços relacionados }\end{array}$ \\
\hline
\end{tabular}




\begin{tabular}{|c|c|}
\hline \multicolumn{2}{|l|}{ Continuação } \\
\hline POF & SCN \\
\hline 2.1.6.4 Consultas médicas & Saúde \\
\hline 2.1.6.5 Tratamento ambulatorial & Saúde \\
\hline 2.1.6.6 Serviços de cirurgia & Saúde \\
\hline 2.1.6.7 Hospitalização & Saúde \\
\hline 2.1.6.8 Exames & Saúde \\
\hline 2.1.6.9 Equipamentos de tratamento & Saúde \\
\hline 2.1.6.10 Outros & Saúde \\
\hline \multicolumn{2}{|l|}{ 2.1.7 Educação } \\
\hline 2.1.7.1 Cursos regulares & Educação \\
\hline 2.1.7.2 Cursos de graduação e pós-graduação & Educação \\
\hline 2.1.7.3 Outros cursos & Educação \\
\hline 2.1.7.4 Livros e revistas acadêmicas & Produtos de celulose e papel \\
\hline 2.1.7.5 Artigos escolares & Produtos de celulose e papel \\
\hline 2.1.7.6 Outros & Educação \\
\hline \multicolumn{2}{|l|}{ 2.1.8. Recreação e cultura } \\
\hline 2.1.8.1 Jogos e brinquedos & $\begin{array}{l}\text { Produtos de madeira, borracha e plástico - } \\
\text { exceto móveis }\end{array}$ \\
\hline 2.1.8.2 Celulares e acessórios & $\begin{array}{l}\text { Máquinas de escritório e } \\
\text { equipamentos eletrônicos }\end{array}$ \\
\hline 2.1.8.3 Livros, jornais e revistas & Jornais revistas discos \\
\hline 2.1.8.4 Entretenimento e esportes & Serviços prestados a famílias e associações \\
\hline 2.1.8.5 Outros & Serviços prestados a famílias e associações \\
\hline 2.1.9 Fumo & Produtos do fumo \\
\hline \multicolumn{2}{|l|}{ 2.1.10 Serviços pessoais } \\
\hline 2.1.10.1 Cabelereiro & Serviços prestados a famílias e associações \\
\hline 2.1.10.2 Manicure e pedicure & Serviços prestados a famílias e associações \\
\hline 2.1.10.3 Reparação de itens pessoais & Serviços prestados a famílias e associações \\
\hline 2.1.10.4 Outros & Serviços prestados a famílias e associações \\
\hline \multicolumn{2}{|l|}{ 2.1.11 Despesas diversas } \\
\hline 2.1.11.1 Jogos e apostas & Serviços prestados a famílias e associações \\
\hline 2.1.11.2 Comunicação & Serviços de informação \\
\hline 2.1.11.3 Festas e cerimônias & Serviços prestados a famílias e associações \\
\hline 2.1.11.4 Serviços profissionais & Serviços prestados a famílias e associações \\
\hline 2.1.11.5 Propriedades para uso ocasional & Serviços de alimentação e acomodação \\
\hline 2.1.11.6 Outros & Serviços prestados a famílias e associações \\
\hline \multicolumn{2}{|l|}{2.2 Outras despesas correntes } \\
\hline \multicolumn{2}{|l|}{2.2 .1 Imposto } \\
\hline 2.2.2 Contribuição trabalhista & $\begin{array}{l}\text { Seguro intermediário financeiro e pensão } \\
\text { complementar e serviços relacionados }\end{array}$ \\
\hline 2.2.3 Serviços bancários & $\begin{array}{l}\text { Seguro intermediário financeiro e pensão } \\
\text { complementar e serviços relacionados }\end{array}$ \\
\hline 2.2.4 Pensões, subsídios e doações & $\begin{array}{l}\text { Seguro intermediário financeiro e pensão } \\
\text { complementar e serviços relacionados }\end{array}$ \\
\hline 2.2.5 Aposentadoria privada & $\begin{array}{l}\text { Seguro intermediário financeiro e pensão } \\
\text { complementar e serviços relacionados }\end{array}$ \\
\hline 2.1.6.3 Tratamento odontológico e consultas & $\begin{array}{l}\text { Seguro intermediário financeiro e pensão } \\
\text { complementar e serviços relacionados }\end{array}$ \\
\hline
\end{tabular}




\begin{tabular}{|l|l|}
\hline \multicolumn{1}{|c|}{ Continuação } \\
\hline \multicolumn{1}{|c|}{ POF } \\
\hline 2.2.6 Outros \\
\hline 2.3 Aumento de ativos & Construção \\
\hline 2.3.1 Imóveis (aquisição) & Serviços de manutenção e reparação \\
\hline 2.3.2 Imóveis (reforma) & \\
\hline 2.3.3 Outros investimentos & $\begin{array}{l}\text { Seguro intermediário financeiro e pensão } \\
\text { complementar e serviços relacionados }\end{array}$ \\
\hline 2.4 Diminuição do passivo & \\
\hline 2.4.1 Empréstimo e caderneta & \\
\hline 2.4.2 Renderização de propriedade &
\end{tabular}




\section{APÊNDICE B - Setores excluídos}

A Tabela 18 abaixo apresenta os setores que foram excluídos da análise e o motivo para tal: se são bens intermediários e/ou não consumidos diretamente pelas famílias ou se tiveram um coeficiente de importação acima da média.

Tabela 18 - Setores excluídos

Óleo e gás natural

Químicos

Produtos químicos e preparações diversas

Pesticidas

Máquinas de escritório e equipamentos eletrônicos

Refino de petróleo e coque

Fabricação de resinas e elastômeros

Comércio

Outros produtos de mineração e extração

Minério de ferro

Fabricação de aço e seus derivados

Metalurgia de metais não ferrosos

Cimento e outros produtos minerais não metálicos

Administração pública e segurança social

Serviços administrativos

Tintas, vernizes e esmaltes

Peças e acessórios para veículos motorizados

Outros equipamentos de transporte

Produtos metálicos - máquinas e equipamentos exclusivos

Máquinas e equipamentos, incluindo manutenção e reparos

Importação

Importação

Importação

Importação

Importação

Importação

Importação

Não consumido diretamente

Não consumido diretamente

Não consumido diretamente

Não consumido diretamente

Não consumido diretamente

Não consumido diretamente

Não consumido diretamente

Não consumido diretamente

Não consumido diretamente

Não consumido diretamente

Não consumido diretamente

Não consumido diretamente

Não consumido diretamente 



\section{APÊNDICE C - Critérios de seleção dos setores}

A Tabela 19 representa os critérios para seleção dos setores utilizados na análise empírico-descritiva do capítulo 1 e, em seguida, no segundo exercício econométrico do capítulo 3. A cor verde simboliza que o setor atendeu ao critério em cada coluna crescimento positivo do consumo das famílias de até 3 salários mínimos, crescimento positivo do emprego, produtividade em 2003 abaixo da média e salário médio em 2003 abaixo da média. Os selecionados foram, então, aqueles que cumpriram os quatro requesitos. 
Tabela 19 - Critérios para a seleção de setores

Fonte: Crescimento do consumo: POF 2002-03 e 2008-09; Emprego, produtividade e salário médio: $\mathrm{SCN}$

\begin{tabular}{|c|c|c|c|c|}
\hline Classificação adaptada & $\begin{array}{l}\text { Cresc consumo } \\
\text { ate } 3 \mathrm{SM}\end{array}$ & Cresc emprego & \begin{tabular}{|l|} 
VA/emprego \\
valor 2003 \\
\end{tabular} & $\begin{array}{l}\text { Salário } \\
\text { médio em } \\
2003\end{array}$ \\
\hline Alimentação & $7 \%$ & $-0.05 \%$ & 0.0071 & 329.19 \\
\hline Produtos do fumo & $-11 \%$ & $16.54 \%$ & 0.0511 & $2,272.90$ \\
\hline Vestuário, calçados e têxteis & $17 \%$ & $16.85 \%$ & 0.0090 & 501.82 \\
\hline $\begin{array}{l}\text { Produtos de madeira, borracha e } \\
\text { plástico - exclusive móveis }\end{array}$ & $41 \%$ & $16.49 \%$ & 0.0195 & 933.65 \\
\hline $\begin{array}{c}\text { Discos, jornais, revistas e outros } \\
\text { produtos de papel }\end{array}$ & $17 \%$ & $24.48 \%$ & 0.0467 & $1,433.94$ \\
\hline Álcool & $31 \%$ & $75.61 \%$ & 0.0846 & 628.77 \\
\hline Produtos farmacêuticos & $96 \%$ & $13.03 \%$ & 0.1266 & $2,966.98$ \\
\hline Perfumaria higiene e limpeza & $64 \%$ & $9.93 \%$ & 0.0146 & 899.19 \\
\hline Eletrodomésticos e material elétrico & $135 \%$ & $53.50 \%$ & 0.0292 & $2,063.80$ \\
\hline $\begin{array}{c}\text { Automóveis camionetas caminhões e } \\
\text { ônibus }\end{array}$ & $87 \%$ & $36.21 \%$ & 0.1110 & $3,545.05$ \\
\hline $\begin{array}{l}\text { Móveis e produtos das indústrias } \\
\text { diversas } \\
\end{array}$ & $42 \%$ & $16.67 \%$ & 0.0164 & 451.64 \\
\hline $\begin{array}{l}\text { Produção e distribuição de eletricidade } \\
\text { gás água esgoto e limpeza urbana }\end{array}$ & $43 \%$ & $19.81 \%$ & 0.0873 & $1,340.88$ \\
\hline Construção civil & $101 \%$ & $20.89 \%$ & 0.0120 & 319.59 \\
\hline Transporte armazenagem e correio & $30 \%$ & $20.26 \%$ & 0.0138 & 634.60 \\
\hline Serviços de informação & $11 \%$ & $31.82 \%$ & 0.0709 & $1,878.84$ \\
\hline $\begin{array}{c}\text { Intermediação financeira seguros e } \\
\text { previdência complementar e serviços } \\
\text { relacionados }\end{array}$ & $63 \%$ & $3.07 \%$ & 0.1124 & $3,662.02$ \\
\hline Atividades imobiliárias e aluguéis & $33 \%$ & $8.74 \%$ & 0.4762 & 366.89 \\
\hline Serviços de manutenção e reparação & $37 \%$ & $17.55 \%$ & 0.0138 & 307.49 \\
\hline Serviços de alojamento e alimentação & $24 \%$ & $4.75 \%$ & 0.0058 & 252.49 \\
\hline Educação mercantil & $76 \%$ & $39.44 \%$ & 0.0180 & $1,180.64$ \\
\hline Saúde mercantil & $61 \%$ & $22.60 \%$ & 0.0196 & 734.05 \\
\hline Outros serviços & $42 \%$ & $22.35 \%$ & 0.0114 & 325.16 \\
\hline Total & $31 \%$ & $12.4 \%$ & 0.0182 & 633.89 \\
\hline
\end{tabular}




\section{APÊNDICE D - Trimestralização das séries do PIB de serviços, construção e indústria da transformação}

Para obtermos o PIB trimestral do setor de serviços, construção, e indústria da transformação desde 1980, foi preciso realizar alguns ajustes nas séries. Primeiramente, para os setores de serviços e de construção civil, para os quais temos as séries de PIB anual e as séries do índice de volume construído pelo Ipeadata, fizemos um ajuste, dividindo a série anual do ano seguinte pelo crescimento no quarto trimestre do ano anterior. Para o quarto trimestre de 1996, por exemplo, a série ajustada é:

$$
\text { série }{ }_{1996 T 4}=\frac{\text { série }_{\text {ano } 1997}}{1+\Delta \% N I_{1996 T 4}}
$$

em que NI é o número índice construído pelo Ipeadata e $\Delta \%$ é a sua variação percentual. Feito isso, para os outros três trimestres do mesmo ano, dividimos o valor seguinte pelo crescimento no trimestre, ou seja, os outros três trimestre de 1996 são iguais a:

$$
\text { série } 1996 T i=\frac{\text { série }_{1996 T(i+1)}}{1+\Delta \% N I_{1996 T i}}
$$

em que $i=1,2,3$. Assim, obtivemos os valores de PIB trimestral de serviços e construção até o segundo trimestre de 1980, já que ao calcular a taxa de crescimento do número índice perdemos o valor do primeiro trimestre de 1980.

Para a indústria da transformação, por sua vez, foi preciso primeiramente construir a série de crescimento deste setor, uma vez que não existia a série de número índice construído pelo Ipeatada. Para construir essa série, assumimos que a parcela do PIB das subdivisões da indústria no PIB da industrial total é constante ao longo de um mesmo ano, de modo que a seguinte igualdade nos permite calcular o crescimento da indústria de transformação:

$\Delta \%$ ind $_{\text {total }}$ ano $t ;$ tri $i=s \_$ext $_{\text {ano } t} \Delta \%$ ext $_{\text {ano } t ; \text { tri } i}+s \_$energ ano $t_{t} \Delta \%$ energ $_{\text {ano } t ; \text { tri } i}+$

$$
+s \_ \text {const }{ }_{\text {ano } t} \Delta \% \text { const }_{\text {ano } t ; \text { tri } i}+s \_ \text {transfano } t \Delta \% \text { transf } f_{\text {ano } t ; \text { tri } i}
$$


em que $t \in[1980 ; 1996], i=1,2,3,4$, ind total é o total da indústria e $s \_x=$

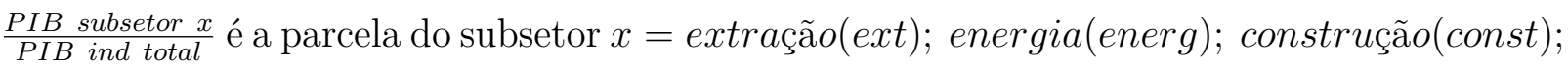
transformação(transf) no PIB da indústria total. Pelos dados do IBGE, dispomos do PIB anual real (a preços de 2010) de todos os setores e subsetores desde 1947, de forma que a parcela de cada subsetor na indústria total é facilmente obtida. Pelos índices construídos pelo Ipeadata de PIB trimestral real, temos o crescimento da indústria total e dos subsetores de extração, energia e construção, de modo que nos resta como resíduo da igaldade acima o crescimento da indústria de transformação. Obtido o crescimento da indústria de transformação, realizamos o mesmo ajuste das equações (D.1) e (D.2) na série de indústria de transformação. 


\section{APÊNDICE E - Testes nos resíduos}

\section{E.1 Primeiro exercício: "A relação entre a composição do produto e a desigualdade de renda no Brasil no período 1980-2014"}

No primeiro exercício, os resíduos apresentaram autocorrelação com 3,4 e 6 lags, a um nível de $5 \%$ de significância, no modelo estimado com 7 lags, já que os critérios de informação para o VAR em nível indicaram 8 lags. Ao incluir variáveis exógenas - dummies para o final dos anos 90 e a crise de 2008 - os resultados da correlação dos resíduos não mudaram, o que nos fez optar por não utilizar tais controles na estimação final.

Tabela 20 - Teste LM de correlação serial dos resíduos (VEC)

Hipótese nula: não existe correlação serial para o lag h

Amostra: 1980Q1 2014Q3

Observações incluídas: 131

$\begin{array}{lll}\text { Lags } & \text { Estat-LM } & \text { Prob. } \\ 1 & & \\ 2 & 8.372897 & 0.0788 \\ 3 & 6.511363 & 0.1641 \\ 4 & 13.00770 & 0.0112 \\ 5 & 58.47968 & 0.0000 \\ 6 & 8.604671 & 0.0718 \\ 7 & 11.84751 & 0.0185 \\ 8 & 8.666332 & 0.0700 \\ & 8.662851 & 0.0701\end{array}$

Probabilidades obtidas em uma chi-quadrada com 4 gl.

Uma vez estimado o VEC, é preciso analisar a estabilidade de suas raízes. O modelo de vetor de correção de erros impõe que uma das raízes seja igual a 1. Para a estabilidade, então, devemos ter as demais raízes dentro do cícrulo unitário, o que foi alcançado no VEC estimado.

O teste de normalidade dos resíduos rejeitou a hipótese de que os resíduos possuem distribuição Normal. 
Tabela 21 - Raízes do primeiro exercício

\begin{tabular}{ll}
\hline $\begin{array}{l}\text { Variáveis Endógenas: GINI RAZAO_SETORES } \\
\text { Lags: } 7\end{array}$ \\
\hline Raíz & Módulo \\
& \\
1.000000 & 1.000000 \\
$0.666096-0.712134 \mathrm{i}$ & 0.975099 \\
$0.666096+0.712134 \mathrm{i}$ & 0.975099 \\
$-0.677264-0.695260 \mathrm{i}$ & 0.970604 \\
$-0.677264+0.695260 \mathrm{i}$ & 0.970604 \\
$0.788571-0.528412 \mathrm{i}$ & 0.949243 \\
$0.788571+0.528412 \mathrm{i}$ & 0.949243 \\
$0.932347-0.099561 \mathrm{i}$ & 0.937648 \\
$0.932347+0.099561 \mathrm{i}$ & 0.937648 \\
$-0.214901-0.694793 \mathrm{i}$ & 0.727269 \\
$-0.214901+0.694793 \mathrm{i}$ & 0.727269 \\
$-0.608257-0.310169 \mathrm{i}$ & 0.682774 \\
$-0.608257+0.310169 \mathrm{i}$ & 0.682774 \\
$0.427206-0.523665 \mathrm{i}$ & 0.675818 \\
$0.427206+0.523665 \mathrm{i}$ & 0.675818 \\
0.604708 & 0.604708
\end{tabular}

VEC satisfaz as condições de estabilidade

Tabela 22 - Teste de normalidade dos resíduos: primeiro exercício

RESID 1 RESID 2

\begin{tabular}{lll}
\hline Média & 0.000000 & $-1.08 \mathrm{E}-17$ \\
Mediana & $-1.39 \mathrm{E}-05$ & -0.008138 \\
Desv. Pad. & 0.000273 & 0.171604 \\
Assimetria & 0.295833 & 0.117966 \\
Curtosi & 5.220552 & 5.682642 \\
& & \\
\hline Jarque-Bera & 28.60497 & 39.28293 \\
Probabilidade & 0.000001 & 0.000000
\end{tabular}

\section{E.2 Segundo exercício: "A relação entre variações na composição do emprego e na desigualdade salarial no Brasil entre 2003 e 2019"}

Os resíduos não apresentaram autocorrelação a 5\% de significância no modelo estimado com 4 lags, que foram os mais indicados pelos critérios de informação (Tabela 
23).

Tabela 23 - Teste LM de correlação serial dos resíduos (VAR)

Hipótese nula: não existe correlação serial para o lag h

Amostra: 2004M01 2019M03

Observações incluídas: 179

$\begin{array}{lcc}\text { Lags } & \text { Estat-LM } & \text { Prob. } \\ 1 & & \\ 2 & 3.849856 & 0.4267 \\ 3 & 3.487180 & 0.4798 \\ 4 & 4.805263 & 0.3079 \\ 5 & 7.979998 & 0.0923 \\ 6 & 3.351023 & 0.5009 \\ 7 & 1.466161 & 0.8326 \\ 8 & 1.203349 & 0.8775 \\ 9 & 7.260902 & 0.1227 \\ 10 & 2.778133 & 0.5956 \\ 11 & 1.611028 & 0.8068 \\ 12 & 3.913063 & 0.4179 \\ & 3.542674 & 0.4714\end{array}$

Probabilidades obtidas em uma chi-quadrada com 4 gl.

Uma vez estimado o VAR, é preciso analisar a estabilidade de suas raízes. No nosso caso, ele é estável, já que não apresentou nenhuma raíz fora do círculo unitário.

Tabela 24 - Raízes do segundo exercício

\begin{tabular}{ll}
\hline Variáveis Endógenas: L_RAZAO_SAL DIF_SALDO & \\
Variáveis exógenas: C CRISE_2008 DEZEMBRO & \\
Lags: 4 & Módulo \\
\hline & \\
Raíz & \\
0.961785 & 0.961785 \\
-0.663567 & 0.663567 \\
$0.099418-0.635298 \mathrm{i}$ & 0.643030 \\
$0.099418+0.635298 \mathrm{i}$ & 0.643030 \\
0.633941 & 0.633941 \\
$-0.369080-0.377878 \mathrm{i}$ & 0.528216 \\
$-0.369080+0.377878 \mathrm{i}$ & 0.528216 \\
0.349991 & 0.349991 \\
\end{tabular}

Não há raízes fora do círculo unitário

VAR satisfaz as condições de estabilidade 
Tabela 25 - Teste de normalidade dos resíduos: segundo exercício

RESID 1 RESID 2

\begin{tabular}{lll}
\hline Média & $1.76 \mathrm{E}-16$ & $-2.24 \mathrm{E}-12$ \\
Mediana & 0.001543 & 1660.754 \\
Desv. Pad. & 0.018605 & 26706.14 \\
Assimetria & -0.244145 & -0.241094 \\
Curtosi & 4.391069 & 4.157436 \\
& & \\
\hline Jarque-Bera & 16.21068 & 11.72571 \\
Probabilidade & 0.000302 & 0.002843
\end{tabular}

Por fim, o teste de normalidade dos resíduos rejeitou a hipótese de que os resíduos possuem distribuição Normal. 